University of Rhode Island

DigitalCommons@URI

Open Access Master's Theses

2018

\title{
COMPARISON OF AMERICAN, GERMAN AND JAPANESE CAR DEALERSHIP APPROACHES FOR SALES AND SERVICE
}

Lukas Schoske

University of Rhode Island, lukas_schoske@my.uri.edu

Follow this and additional works at: https://digitalcommons.uri.edu/theses

\section{Recommended Citation}

Schoske, Lukas, "COMPARISON OF AMERICAN, GERMAN AND JAPANESE CAR DEALERSHIP APPROACHES FOR SALES AND SERVICE" (2018). Open Access Master's Theses. Paper 1330. https://digitalcommons.uri.edu/theses/1330

This Thesis is brought to you for free and open access by DigitalCommons@URI. It has been accepted for inclusion in Open Access Master's Theses by an authorized administrator of DigitalCommons@URI. For more information, please contact digitalcommons-group@uri.edu. 
COMPARISON OF AMERICAN, GERMAN AND JAPANESE

CAR DEALERSHIP APPROACHES FOR SALES AND SERVICE

BY

LUKAS SCHOSKE

A THESIS SUBMITTED IN PARTIAL FULFILLMENT OF THE

REQUIREMENTS FOR THE DEGREE OF

MASTER OF SCIENCE

IN

MECHANICAL ENGINEERING

UNIVERSITY OF RHODE ISLAND

2018 


\section{MASTER SCIENCE THESIS}

OF

\section{LUKAS SCHOSKE}

\section{APPROVED:}

Thesis Committee:

Major Professor $\quad$ Valerie Maier-Speredelozzi
David Taggart
Sigrid Berka
Nasser H. Zawia
DEAN OF THE GRADUATE SCHOOL

UNIVERSITY OF RHODE ISLAND 


\begin{abstract}
Based on previous literature, it is known that American, German and Japanese car dealerships use their own strategy to fulfill customer demand and face the different challenges from mass customization. Furthermore, after-sales-service is becoming increasingly important for car dealerships in order to create a positive differentiator or even a unique characteristic in competition between different companies. Therefore, this study aims to gain a deeper understanding of the different order fulfilment and aftersales strategies that are used by US car dealerships representing auto makers from Japan, Germany and the US. In order to be able to conduct this research and to achieve the goals, a self-made questionnaire containing 17 questions is developed. The objective is to schedule interviews with managers or top managers of the dealership to give semistructured interviews with them. After collecting all interviews, the results are compared with ten different hypotheses and sub-hypotheses by using multiple two-paired t-tests. After running all the tests, it can be found that Japanese, German and US car dealership activities have become more similar and German and US car dealerships have been successfully closed the gap to their competitors from Japan.
\end{abstract}

For example, Japanese luxury car dealerships have a higher delivery time than GE luxury car dealerships and a comparable one to US luxury car dealerships. Furthermore, American, German and Japanese standard car dealerships sell the same percentage of cars from their inventory by now. However, Japanese makers still have a slight advantage over their German and American rivals in terms of electric vehicles but this is likely to change as German car dealerships are changing their strategy, personnel's mindset and products. 


\section{ACKNOWLEDGEMENTS}

First of all I would like to express my sincere thanks to my major advisor Dr. Valerie Maier-Speredelozzi. Her motivating and ambitious way of teaching and sharing her expertise in this field of research made the thesis an effective and enjoyable experience. Furthermore, I want to thank her in supporting my various interviews.

Thank you to my committee members Professor David Taggart, Professor Sigrid Berka and the Chair of Defense Professor Norbert Mundorf for reviewing and evaluating my thesis and sharing their knowledge.

In addition to that, I would like to thank everybody involved in the cooperation between the University of Rhode Island and the Technische Universität Braunschweig, Germany. This accounts for Prof. Dr.-Ing. Ulrike Krewer and Patrick Schön in particular, as they serve as my German committee. I want to thank Nina Schneider and Dr. Ute Kopka from the International Office of the Technische Universität Braunschweig that I received the opportunity to make this academic and social experience of living in the United States and studying at the University of Rhode Island.

Last but not least, I am thankful for the great support of my parents Carola Schoske and Rainer Schoske, my brother Marvin Schoske and all my beloved ones. Without their unlimited assistance, this experience would not have been possible. 


\section{TABLE OF CONTENTS}

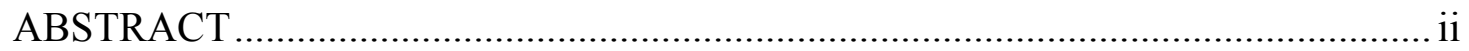

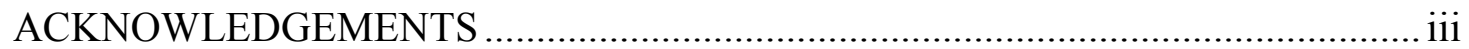

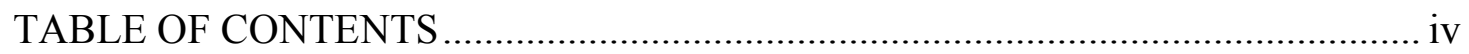

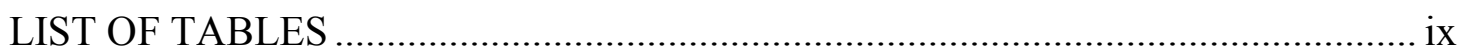

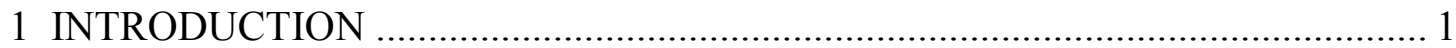

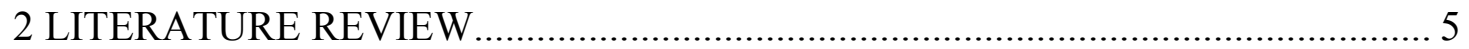

3 METHODOLOGY

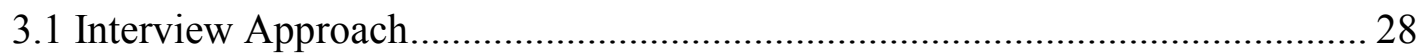

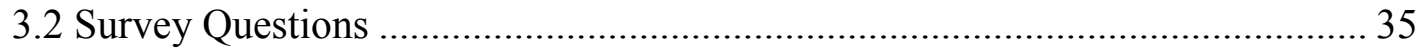

3.3 IRB Approved Procedures \& Analysis Methods ................................................. 42

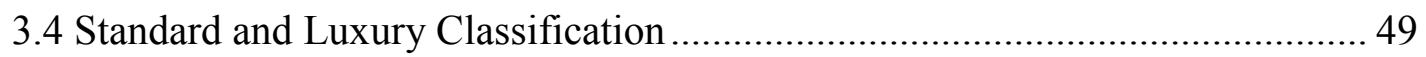

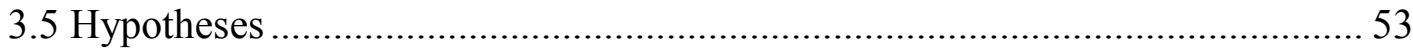

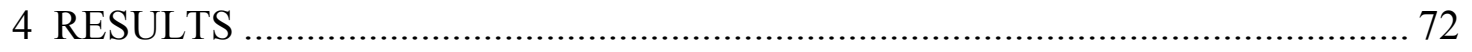

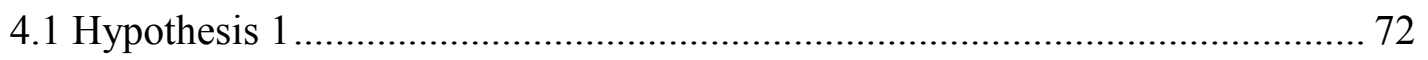

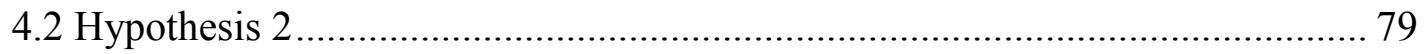

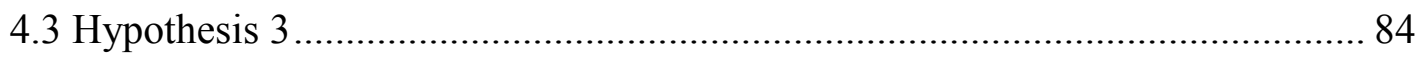

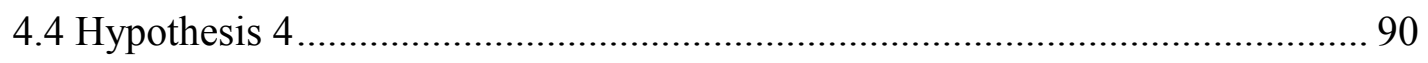


4.5 Hypothesis 5 ........

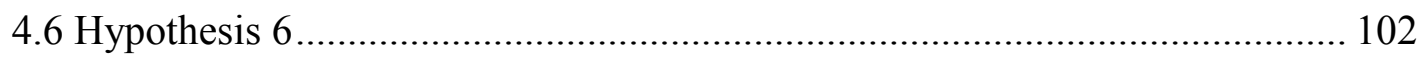

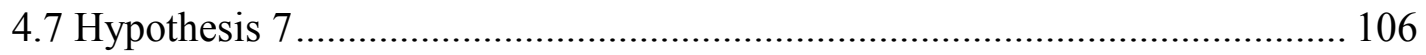

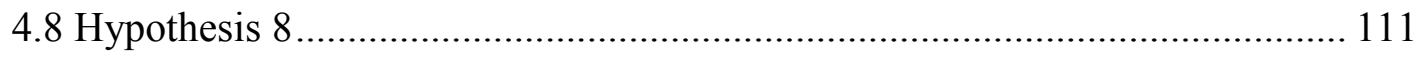

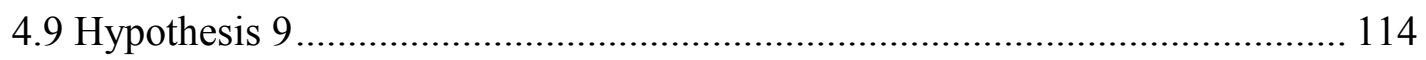

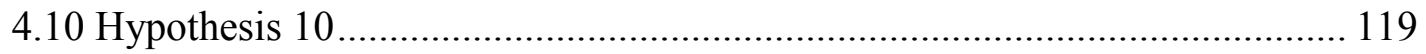

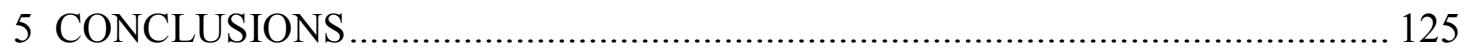

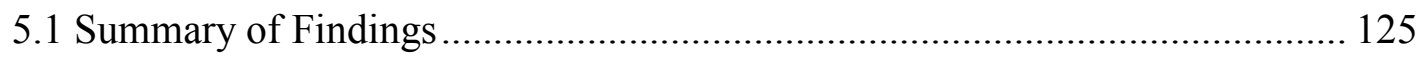

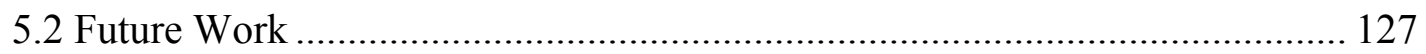

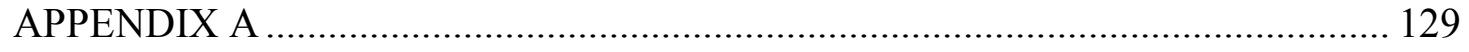

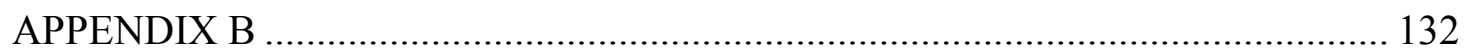

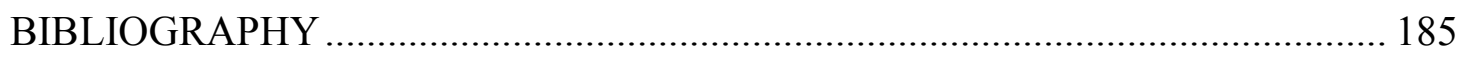




\section{LIST OF FIGURES}

Figure 1: Market share on US auto market by nation in 2017 .................................. 3

Figure 2: Percentage of an automotive company's turnover at different company's

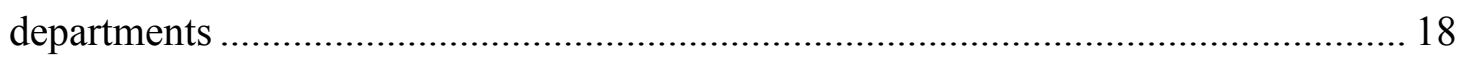

Figure 3: Percentage of an automotive company's profit at different company's

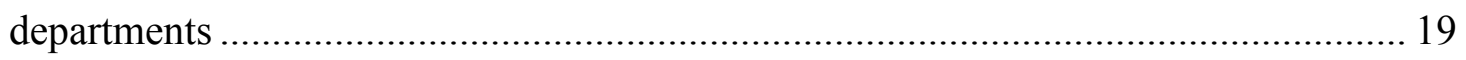

Figure 4: In 2025, what area of operations will be most profitable? ........................ 23

Figure 5: US market share of most important car makers from the US, Japan and

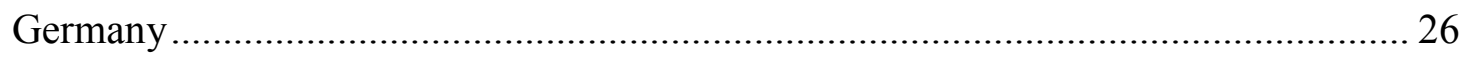

Figure 6: Major tasks for an interview using a questionnaire ................................ 34

Figure 7: The Modern Dice Roller is used to randomly select 8 Japanese and American

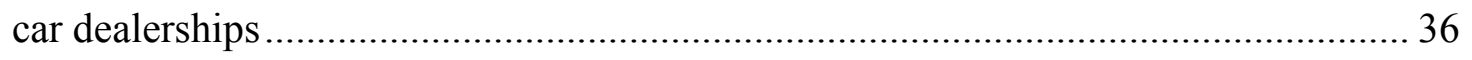

Figure 8: First route calculated by google maps to seven different car dealerships .... 44

Figure 9: Extended spreadsheet using colors to show status of dealerships ............... 45

Figure 10: Minitab screenshot of the data tables and the selection of the 2-sample t test

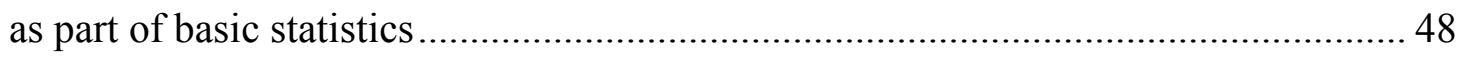

Figure 11: The two pairs of data for the 2-sample t-test are selected. ...................... 48

Figure 12: Output window of Minitab after running a two-sample t-test ................... 49

Figure 13: Number of models offered by car manufacturers, every maker ............... 74 
Figure 14: Number of models offered by car manufacturers, standard 75

Figure 15: Number of models offered by car manufacturers, luxury 75

Figure 16: Minitab output two-sample t-test comparison models JP and models GE. 76

Figure 17: Test section of the Minitab output window 77

Figure 18: Time to get car after placing order at the auto maker (mean time), all makers 81

Figure 19: Time to get car after placing order at the auto maker (mean time), standard 81

Figure 20: Time to get car after placing order at the auto maker (mean time), luxury 82

Figure 21: Number of models over cars sold from inventory 85

Figure 22: Number of models over cars sold from inventory, standard 88

Figure 23: Number of models over cars sold from inventory, luxury 88

Figure 24: MSRP in $\$$ of the different makers 91

Figure 25: Number of different models from standard makers over MSRP [\$] 94

Figure 26: Number of different models from luxury makers over MSRP [\$] 94

Figure 27: "Bumper-to-bumper"-coverage, standard makers 111

Figure 28: "Bumper-to-bumper"-coverage, luxury makers 112

Figure 29: Powertrain and transmission coverage, luxury 113

Figure 30: Powertrain and transmission coverage, standard. 113 
Figure 31: Grouping and their percentual distribution...................................... 118

Figure 32: How convinced are car dealerships about e-mobility? .......................... 121 


\section{LIST OF TABLES}

Table 1: Manufacturing conditions in five German and five Japanese car makers in 2012

Table 2: Advantages and disadvantages of structured interviews 30

Table 3: Advantages and disadvantages of unstructured interviews 31

Table 4: Advantages and disadvantages of semi-structured interviews..... 32

Table 5: List of automakers that are part of the study and their classification in "normal" and "luxury" 50

Table 6: Classification of standard and luxury car makers 53

Table 7: All hypotheses and sub-hypothesis summarized 71

Table 8: Number of different models at JP, GE and US car makers. 73

Table 9: JP makers offer more models than US or GE, summary 78

Table 10: Delivery time in weeks at JP, GE and US makers

Table 11: JP delivery time is lower than US or GE, summary 83

Table 12: Vehicles sold from inventory in $\%$ at different makers 84

Table 13: GE have lower percentage of cars sold from the inventory than JP or US, summary 89

Table 14: MSRP of different makers 92

Table 15: JP MSRP is the lowest, summary 95 
Table 16: Dealer options at Japanese car dealerships 98

Table 17: Dealer options at German car dealerships

Table 18: Dealer options at American car dealerships 100

Table 19: GE makers have most extended dealer options, summary 101

Table 20: Car sales per dealership 104

Table 21: Average dealer inventory at different makers, luxury and standard makers distinguished 104

Table 22: Average inventory turns at different makers, luxury and standard makers distinguished 105

Table 23: Training of personnel at Japanese car dealerships 107

Table 24: Training of personnel at German car dealerships 108

Table 25: Training of personnel at American car dealerships 108

Table 26: JP follow different approach in personnel training, summary 109

Table 27: Most important words and number of times it was mentioned in the interviews 116

Table 28: Description of the three groups

Table 29: Number of sub-hypotheses that were found significant 124 


\section{CHAPTER 1}

\section{INTRODUCTION}

It is commonly stated in literature and among economic and engineering historians that the automotive business will have major changes within the next years. Especially technology-driven trends such as shared mobility, self-driving and electrified vehicles will have a tremendous impact on the today's business of many automotive suppliers and manufacturers (McKinsey \& Company, 2016). In order to be able to successfully participate in these changes, car manufacturers have to ensure that they are able to continuously attract their customers.

In recent years, automotive companies have become increasingly interested in providing mass customization as a crucial factor of attracting customers. As companies are continuously improving their product quality, it turns out that this is the only way to succeed in a globalized world against the many competitors. To be able to create further growth and to keep customer retention, car manufacturers have to bring together the advantages of mass production and the production of individual products. Therefore, mass customization allows the automotive manufacturers to deliver customized products at low costs, associated with mass production, in a short order lead-time (Investopedia, 2018). Lead time is defined as time between ordering a vehicle at the manufacturer and receiving it at the dealership (Spearman \& Hopp, 2001). Furthermore, researchers found out that mass customization does not only offer the potential to boost business for car makers but also creates new challenges which will be discussed in chapter 2 . 
Previous literature has found that different car makers follow different approaches and strategies in order to handle these challenges and successfully fulfill customer demand. Moreover, car manufacturers are using the tools of after sales service more and more, in order to create a positive differentiator or even a unique characteristic in competition between different companies (Malorny, 2018). Therefore, car manufacturers not only try to offer the best primary product, in this case a car, but also aim to offer excellent service to their customers. Consequently, the car manufacturer's performance in a market is heavily dependent on professional dealerships, as they are the customer's first place to go.

Especially in the United States, with its franchise dealership system, a close cooperation between the dealerships and the car manufacturers is very important. Furthermore, the US automotive market is a highly competitive and despite it being the only major car market in the world with weaker car sales in 2017 compared to 2016 , with its 17.13 million vehicles sold, the US still accounted for $22 \%$ of all car sales and was the second biggest car market after China (Bekker, 2018) (Reuters, 2018) (Statista, 2018). According to Figure 1, there were three nations responsible for the major car sales in the US by the end of 2017: US car makers with a market share of $45 \%$, Japanese makers with $39 \%$ and German car makers with a market share of $8 \%$ respectively (Wall Street Journal, 2018) (Cremer, 2018). Others were 8\%, mainly South Korea with 7\% and other European counties were 1\%.

Following the data in Figure 1, it can be seen that the Japanese car makers are very strong in the US car market. Based on this fact, a lot of researchers and car makers have focused on finding out the secret of Japanese car makers and tried to adapt 
Japanese methods in order to defend or even gain back their market share. However, these studies have usually analyzed and compared differences in the manufacturing process at automotive manufacturing plants and did not consider the different strategies of dealerships in the study.

Market share on US auto market by nation in 2017

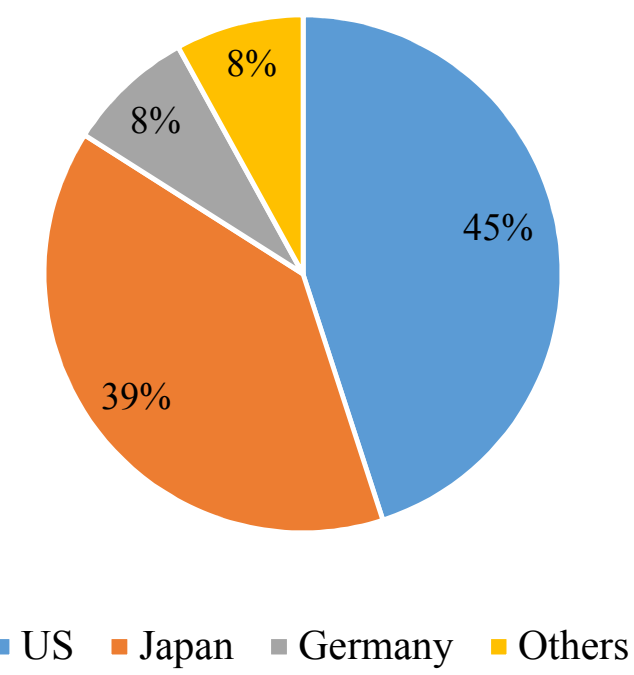

Figure 1: Market share on US auto market by nation in 2017 (Wall Street Journal, 2018)

Moreover, most research studies only examine car manufactures from a single country such as Japan or Germany (Hitomi, 1992) (Chappell, 2002). One well-known exception is the book "The machine that changed the world" by Womack, Jones and Roos that was published in 1990. This book was a major initiator for German and American car makers to adapt Japanese makers' methods and consider Japanese cars and an example of high-quality products that are produced in lean and fast manufacturing lines. Later, Staeblein and Aoki (2014) compared planning and scheduling methods of Japanese and German automakers but did not consider American makers. Nevertheless, the trend of after sales activities used by modern car makers has 
not been considered in (Womack, Jones, \& Roos, 1990) or (Staeblein \& Aoki, 2014). A holistic, cross-company comparison of the most important car makers in the US in terms of their sales and service strategy could not be found in literature.

This study aims to close the research gap, as it provides a general overview of the different order fulfilment and after sales strategies used by the most important automobile manufacturers in the US. To do so, similarities and differences between the various approaches that automotive manufacturers use will be analyzed. Furthermore, the research will contain a discussion about the advantages and disadvantages of the chosen strategies. The collected information will also be used to verify and update the data found in previous literature which will be presented in Chapter 2.

A cross-company comparison not only gives the reader of this study an overview of the worlds' most powerful and biggest car manufacturers but also provides crucial input for American and German makers to determine whether they still have optimization potential in order to close their gap to their Japanese competitors. Based on the results of the study, the Japanese car makers can also determine to what extent they still have a lead over their German and American competitors. 


\section{CHAPTER 2}

\section{REVIEW OF LITERATURE}

The following chapter examines the most important literature in the field of study and includes the current knowledge. In the past 30 years, a lot of research has been done in the field of order fulfilment strategy in the automotive industry.

A major milestone in automotive manufacturing research was the results of the first international automobile assembly plant study conducted by the MIT between 1985 and 1990 (Womack, Jones, \& Roos, 1990). The book that contains the results of this five year study ("The machine that changed the world") was the first piece of work in literature that cross-compared Japanese, US and European automotive makers and their fundamentally different business systems. On the one hand the mass production system, mainly applied by the US and European automakers and on the other hand the lean production system, applied by the Japanese makers. The study also examined their production philosophy and their ways of thinking about how humans should work together in order to create value and build cars.

The study of the differences between these auto nations became necessary, as American car makers saw their US market share shrinking. According to the data given in (Womack, Jones, \& Roos, 1990), the downswing of the American-owned firms had been consequently going on since the mid-1950s. In 1955, American makers nearly had a market share of $100 \%$ in the US. However, by that time mass production had become the state of the art technique for most automotive manufactures around the globe. With their compact and economic cars such as the Volkswagen Beetle or their very modern 
and sporty luxury cars such as Mercedes, European car makers increased their market share in the US from the early 1950s into the 1970s. The rise of the Japanese lean production system and the demand for low price, compact vehicles as a consequence of a significantly higher oil price after 1971 further eroded the market share of American auto makers in the US and prevented the further market share increase of European makers (Automotive News, 2018) (Womack, Jones, \& Roos, 1990). Moreover, Japanese car makers became known for their high quality in the 1980s and 1990s by building cars that were much more reliable than their competitors at that time (West, 2015).

Womack, Jones and Roos (1990) basically found out that the Japanese systems was much more efficient, faster and profitable than the US and European system and product quality was even better. In 1986, Toyota for example needed less than $50 \%$ of the time that GM needed to assemble a car had one third of the assembly defects as GM which cause expensive and time-consuming rework. A lot of attention was paid to the fact that luxury car assembly quality and productivity was much better at the Japanese system than the US or European system. Especially for the Europeans and in particular the German luxury brands such as BMW, Mercedes and Audi, these results were a disaster. Womack, Jones and Roos (1990) proved that Japanese makers were not only able to successfully establish their system in Japan but also were able to rebuild factories in North America that would achieve comparable results in productivity and quality as in Japan. In the end, they predicted that the lean system would triumph over mass production. Followed by this study, automotive companies from Europe and the US and 
many researchers around the world extended and applied the findings from the Womack, Jones and Roos study.

In 1992, Katsundo Hitomi took a closer look at the Japanese manufacturing and management system. The most important information in his paper are that Japanese manufacturing technologies usually come from the US, Germany and the UK and are usually largely modified and refined to make them more suitable for the use in their factories and to further optimize the quality, the costs and the productivity of the machines. Furthermore, the machines are constantly improved over time whereas US and European machines are usually bought and working without any changes for many years before they are replaced by a new generation of machines. Hitomi (1992) also mentioned Japanese inventions in production control such as Just-in-time, quality circles and total quality control as a key for Japanese success. However, the author also pointed out that the high living costs, poor housing conditions and the fact that employees usually never change their employer during their work life might create challenges for the lean production system in the future (Hitomi, 1992).

In 2005, Hitomi described historical trends and the present state of the US industry and manufacturing system. He found out that compared to his previous study about Japan, the manufacturing industry had lost influence on the total US GDP and the US labor market. In $1955,30 \%$ of the 57 million labor population in the US worked in manufacturing compared to $13 \%$ out of the 135 million labor population in 2001 . Furthermore, Hitomi stated that recent US economic growth has mostly been supported by the tertiary industry (service sector) compared to Japan. However, the author showed that contrary to common belief, efficiency in US manufacturing is comparable to 
Japan's and that profit on sales for US manufacturing was much bigger than in Japan in 2000 (Hitomi, 2005).

In order to not further lose market share to their Japanese competitors, German and US car makers quickly started establishing their own lean production systems but it took years for them to change their decades old mind-set of mass-production and investment of personnel. For example Volkswagen, today's world's biggest car maker, was in serious economic problems in 1993. In order to be able to gain back market share that was lost to Japanese makers around the globe, Ferdinand Piech, CEO at Volkswagen at that time significantly increased efforts and spendings in the establishment of lean production systems at his company (Schneider, 2016) (Volkswagen AG, 1993).

Another aspect that shaped the automotive industry for the last two decades is the idea of mass customization. Mass customization is used "to develop, produce, market, and deliver affordable goods and services with enough variety and customization [such] that nearly everyone finds exactly what [he/she wants]" (Pine, 1993). By following this approach, the companies are convinced that they are able to maximize the fit between product offerings and customer desires which makes it possible for them to keep or even increase their market share (Salvadora, Forzab, \& Rungtusanathama, 2008). Rungtusanatham and Salvador (2008) find out that redesigning the manufacturers' products, processes and supply chains are essential in order to install mass customization in their factories (Salvadora, Forzab, \& Rungtusanathama, 2008). 
In their paper, Holweg and Pil (2004) distinguish between two different approaches in mass customization (Holweg \& and Pil, 2004). The first mass customization principle is used by Japanese automotive manufacturers. By bundling individual accessory options into packages instead of offering single accessory options to the customer, the auto makers significantly decrease the amount of variants for their production system but also reduce the degree of customization to the customer. Furthermore, these packages are not assembled at the manufacturing line as the manufacturers only produce very similar and standardized vehicles in their factories based on their forecasting models. The customization is done outside the factory at dealerships and allows the maker to establish very simple and lean manufacturing lines. Holweg and Pil (2004) call this principle assembly-/distribution-based customization. The second mass customization principle is the design-based approach and mainly use by German car makers. Here, variety is achieved with different product platforms, from which different models are derived. Instead of having the complexity outside the manufacturing lines at their dealerships, German car makers had the complexity in their factories. The car makers would produce their components such as engines, transmissions and car bodies based on forecasting models but the actual assembly process would be based on customer demand. A good example for the design-based mass customization principle is to use product architecture, such as Volkswagen's “Modular Transverse Toolkit” (Takeishi A., 2001).

As an American maker, General Motors introduced their new vehicle delivery system in 1996, using the full potential of mass customization. The idea was to stock most of their cars in the most popular configurations at regional distribution centers. 
When a customer ordered one of these vehicles, the company was able to deliver the car within 24 hours to the dealership. For more uncommon configurations, the vehicles still had to be produced at the factory and it took several weeks to get them. With this concept, General Motors combined the so-called make-to-stock principle which means that the most important elements of the car were already produced and put together based on demand forecasts without any relation to a specific customer order, and the socalled make-to-order or build-to-order principle, as the last parts such as options were assembled to the car at the dealership based on an actual customer order (Spearman \& Hopp, 2001).

Later on, especially German car makers started to improve Toyota's lean production system and General Motor's new vehicle delivery system as they established their own system which was basically a full build to-order-system. This allowed them to offer a large variety of choices for their customers and still deliver highly customized vehicles in a relatively short amount of time to their customers (Chappell, 2002). Chappell (2002) described the changes that were done in several BMW manufacturing plants in order to install this build-to-order system. The author shows that the suppliers play a major role in BMW's new strategy. The most important information from that article is that the car manufacturer gradually redesigned its vehicles in order to reduce variations for production and simplify assembly processes. Furthermore, the company wants to be more flexible in their assembly order as BMW will construct and paint their bodies based on improved and tightened forecasting models before the production control department releases the actual order. Then, the pre-produced parts will be taken from the inventory and finally assembled. According to the author, the car manufacturer 
will be more accurate in terms of their delivery date and moreover, customers can still ask for changes in their order after it is placed (Chappell, 2002).

A paper published by Meyr in 2004 underlines the findings of Chappell (2002). The main purpose of Meyr's article is to discuss recent developments in supply chain planning in the German automotive industry. The author analyses the impact of a further increase of the build-to-order system in the German automotive industry on the planning system and the planning methods of the maker. Meyr (2004) concluded that a build-toorder system will have a huge impact on the planning processes of car makers which requires steady supplier involvement in the automotive planning and scheduling processes (Meyr, 2004).

However, literature also analyzed the disadvantages of mass customization. Salvadora et al. (2008) found out that mass customization ends up increasing the product variety of the company which requires more complex manufacturing processes and managerial experience. Manufacturing lines have to be more flexible to deal with the increasing amount of variants and products (Salvadora, Forzab, \& Rungtusanathama, 2008). Moreover, the managerial practice and experience becomes more and more important and highly skilled and trained employees are crucial for a company. Based on these circumstances, it can also be assumed that the planning and scheduling process in a company's order fulfilment system gets more complex when mass customization is implemented. (Holweg \& and Pil, 2004) (Meyr, 2004) (Tomino, 2009) (Volling \& Spengler, 2011).

One of the most important articles for this study was published in 2014 and basically started the idea for this research. In 2014, Staeblein \& Aoki published an 
important paper, where they compared the planning and scheduling strategies at German and Japanese auto makers between 2007 and 2012. In order to be able to compare the two different auto nations with each other, the authors conducted 25 semi-structured interviews at different automakers in Japan and Germany and two case studies with an additional 17 interviews at automotive companies and 14 at suppliers and dealers. The case study simulated the entire order fulfilment process. In the end, they created a map of the different order fulfilment processes and planning and scheduling functions from which they drew their conclusions. In addition to the interviews, they defined five key indicators to compare the car manufacturer with each other. The five indicators were:

1. Production volume per model

2. Production volume per platform

3. Number of products per plant

4. Number of models per assembly line

5. Inventory turns $=\frac{\text { annual cost of goods sold in } \$}{\text { value of inventory in } \$}$

The inventory turns are defined as "annual cost of goods sold divided by the value of inventory" and are understood as an indicator of leanness (Schonberger, 2007). The goal is to achieve a high inventory turn, characterizing a lean and fast manufacturing system.

Table 1 summarizes the main results for the manufacturing conditions at German and Japanese car makers. It shows that there are significant differences between German and Japanese makers. German car makers tend to produce fewer different car models on one assembly line and in one manufacturing facility than Japanese car makers. 
Japanese car makers have development lean manufacturing lines that allow them to easily produce various models. Furthermore, Japanese car makers have a much smaller production volume per model and platform. Despite a significantly higher number of different models (27.0 for the Japanese compared to 9.6 for the German car makers), the Japanese makers achieve a faster inventory turn. According to the authors, the main reason is the remarkable difference of varieties.

Table 1: Manufacturing conditions in five German and five Japanese car makers in 2012 (Staeblein \& Aoki, 2014)

\begin{tabular}{|l|l|l|}
\hline Indicator & $\begin{array}{l}\text { German auto } \\
\text { makers }\end{array}$ & $\begin{array}{l}\text { Japanese auto } \\
\text { makers }\end{array}$ \\
\hline Production volume per model & 95,538 & 47,047 \\
\hline Production volume per platform & 205,222 & 120,408 \\
\hline Number of products per plant & 3.2 & 7.4 \\
\hline Number of models per assembly line & 1.6 & 3.8 \\
\hline Inventory turns & 4.5 & 7.7 \\
\hline
\end{tabular}

Staeblein \& Aoki (2014) also found out that German makers offer a much larger amount of customization and product varieties than Japanese makers in order to meet customer demand. The variety of German manufacturers in body-styles and powertrains compensates for the significantly higher number of models at Japanese makers. However, a much larger number of paint-trim combinations and factory-fitted options by German makers lead to a significantly higher number of variants in the end $\left(3.7 \times 10^{24}\right.$ possible configurations created inside the factory of German car makers versus 4,296 in Japanese). This is because German car makers follow the demand-oriented build-toorder principle, offering their customers a huge choice of extras and giving them the 
chance to build their own customized car. Consequently, German makers have larger complexity in their factories with higher levels of buffer stock between paint and final assembly compared to Japanese makers who follow the lean factory approach. Furthermore, Staeblein \& Aoki (2014) determine that dealerships play a more important role in the order fulfilment process of Japanese auto makers than in that of German auto makers as they are more connected. Japanese car manufacturers keep their manufacturing processes lean but outsource the product variety to their dealers by using late-configuration customization techniques. Therefore, finished cars are transported to so-called New Car Service Centers, where all the dealer options are assembled and then brought to the local dealership. Staeblein \& Aoki (2014) claimed that the so-called Keiretsu-dealer-system puts pressure on dealerships to sell forecasted demand with high discounts even though demand does not occur. Furthermore, they found out that the average delivery time for a German car is between 20 to 80 days, whereas for a Japanese car it is 14 to 28 days.

In the second part of the research, Staeblein \& Aoki (2014) found out that the design and the management of the planning and scheduling functions are not influenced as much as by country (German or Japanese) as was expected. German and Japanese car makers used similar planning and scheduling functions. In a more detailed analysis, the authors were able to find out that the auto makers from Japan and Germany used similar frequencies for their demand forecasting (12 times per year), their master production planning (12 times per year) or their car sequencing (daily). Furthermore, both auto makers have a comparable use of computer support for their planning and scheduling functions and start their planning and scheduling process with demand 
forecasting. However, differences in the planning and scheduling functions can be found in the use of different time-horizons, especially for MRP (Materials Requirements Planning) and Demand Forecasting (German car makers forecast their demand every 24 months, Japanese makers every three months). Furthermore, the MRP function in Germany is based on actual demand and is closely linked to the master production plan and serves as a fundamental information source for suppliers, whereas in Japan it is mainly based on forecasts. Japanese car makers use a three-month production plan that relates to monthly, weekly and daily production schedules, whereas the daily production schedule shows all of the specifications for each car and is the only plan that is linked to actual customer demand.

In recent years, researchers have become increasingly interested in the question of how existing manufacturing systems could be increased in order to make them more innovative and sustainable. In their paper, Parry and Roehrich (2013) discussed how the build to order principle can be used to follow the principles of lean production and furthermore, can be used as a sustainable approach to build cars in the pace of customer's demand. The key question the authors address is if it is possible to significantly reduce the time that a build to order process needs and on the same side reduce the ecological impact. The most important information in this engineering article is that the build to order principle can be used in order to fully sustainable achieve the three main sustainable goals of companies. They can reach their economics, environmental and societal goals by providing build to order cars that exactly fit the customers demand, reduce suppliers' inventory and cut overproduction and avoid unnecessary transportation. Furthermore, product development should increase their 
effort in design for manufacturing and include logistics in their planning. The authors propose to use more modularity instead of single parts which leads to a reduction of costs in logistics and development. Finally, Parry and Roehrich conclude that a build to order system in the automobile industry is an appropriate solution in order to minimize overcapacity and implement the full potential of lean production (Parry \& Roehrich, 2013).

For the last 10 years, automobile manufacturers have significantly increased their interest in the field of after-sales services in order to create a positive differentiator or even a unique characteristic in competition between different companies as the quality of the primary products adjusts each other (Malorny, 2018). In the United States (and also Canada), car dealership activities are regulated by so-called franchise state laws. According to these laws, automotive manufacturers are not allowed to sell their products directly to their customers and new cars can only be sold by franchised dealers. The owner of that dealership is the franchisee in this business concept and the manufacturer (who is the franchiser) licenses their know-how, business procedures and intellectual property to the franchisee. Furthermore, the auto maker gives the dealership the right to sell the branded products and services to the market. Therefore, the franchisee pays the franchiser a certain fee and agrees to comply with certain obligations. Usually several dealerships are owned by a dealership group (Bodisch, 2009) (Wieczorek, 2012).

In his article "An Introduction to Automotive Dealerships" Carter (2015) gives a general overview of the function and work of an automobile dealership in the US. According to that article, car dealerships have five different fields of work: The sales of 
new and used vehicles, fixed operations, parts, and finance and insurance. According to the author, used vehicle sales and fixed operations are becoming more and more important for the profit of a dealership. Furthermore, car dealerships use their store to sell extended warranty policies and finance packages to their customers. This business is especially interesting in a time of low interest rates and easy credit. One of the main conclusions of the article is that new vehicle sales are usually used as a business-opener in order to bring the customers to the dealership. Further business will follow after a customer bought his first car (spare parts, extended warranty policies, finance or tradein). Furthermore, the author thinks that the European dealership system, where manufacturers can indeed directly sell their new cars, will not influence the American system by a great extent as US law forbids car manufacturers from getting in contact with customers directly. These laws has been defended many times in the past (Carter, 2015).

In 2017, a study by Wyman found that the automotive business is making the greatest profits in the field of after sales and financial services. Wyman summed up the turnover and profit of all major automotive companies and assigned it to the departments of new vehicles, uses vehicles, after sales, financial services and mobility/connectivity. Figure 2 and 3 show the results. Therefore, a modern automotive company's major business is by selling new vehicles followed by selling used vehicles. The after-sales department only accounts for $10 \%$ of the profit. However, this looks very different if one takes a look at the profit distribution which figure 3 shows. According to Wyman (2017), the majority of today's automotive company's profit comes from the after-sales and the financial services department. Companies barely earn money by selling new or 
used vehicles as profit margins are continuously shrinking. This underlines the importance of a well working after sales business of modern automotive companies, executed by their dealerships (Wyman, 2017).

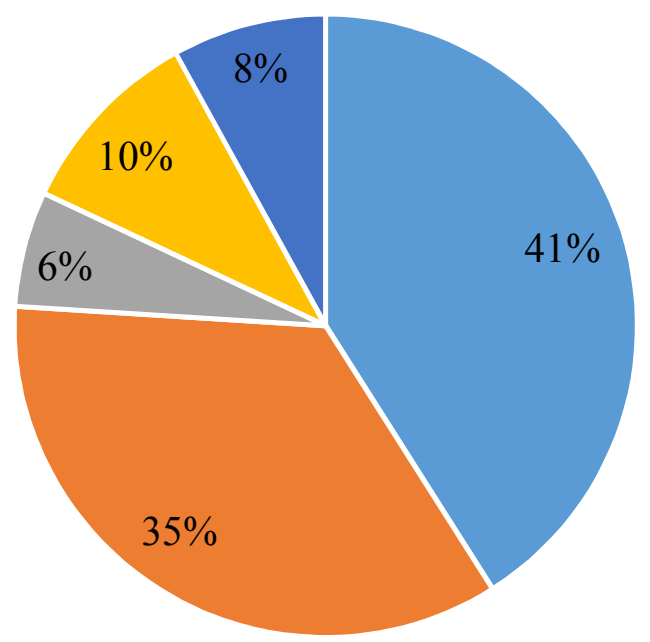

- New vehicles

- Used vehicles

- Financial services

$\square$ After sales

- Mobility/ Connectivity

Figure 2: Percentage of an automotive company's turnover at different company's departments (Wyman, 2017) 


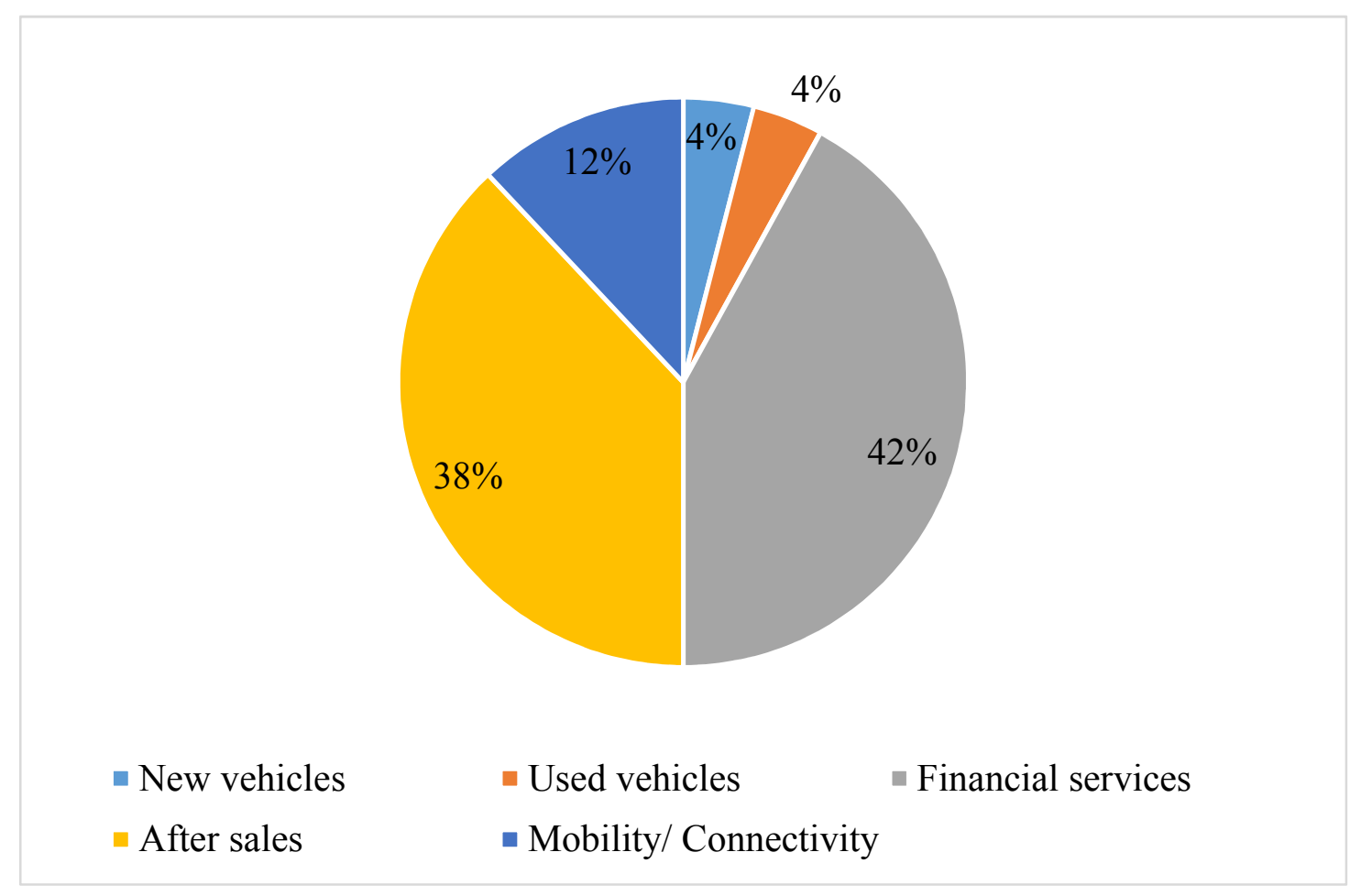

Figure 3: Percentage of an automotive company's profit at different company's departments (Wyman, 2017)

Automotive companies continuously try to figure out how they can further increase their product quality. They use customer feedback and after-sales key performance indicators (KPIs) in order to improve the company's quality management system. In their paper, Sabbagha et al. (2015) analyze the connection between a company's quality management and its after sales service. The key question the authors are addressing is whether the use of automotive after sales key performance indicators can support the quality management of a company. The most important information in this engineering article is that margins in the automotive sales business have been shrinking over the last couple of years whereas the annual sales of cars went up and is expected to increase further until the end of this century. That is because the product lifespan has been becoming longer and longer. The main conclusions of the article are that the automotive after sales business is a market segment with a high potential as the 
demand for high-quality products is rising. The author also concludes that recent literature only includes one or two elements of the KPIs (Key Performance Indicators) in a simulation of a manufacturer quality systems but rarely more. The authors prove that especially Japanese car makers achieve a high customer satisfaction rate in the customer satisfaction index survey. However, the authors also see risks for the after sales service as new technologies and longer maintenance intervals plus a new customer's philosophy (better purchase than repair) will stress the growth in the after sales market (Omar Sabbagha, 2015).

In 2014, Townsend and Calantone published an article where they took a closer look at car dealerships and their services they should provide in addition to the primary product (vehicle). The most important information in Townsend and Calantone (2014) is that there is an increasing demand for highly-sophisticated products and their product services. Furthermore, basic features and services such as Bluetooth connection, driver and passenger safety features or providing a vehicle during a longer repair under warranty, will have to become much lower in terms of costs or even be complementary in order to stay competitive (Townsend \& Calantone, 2014).

This falls in line with the study done by Parida et al. in 2014. The main purpose of this engineering article is to determine the extent and profit potential of different types of services that are offered in addition to the actual primary product. As little is known about the variety and extent of offered product-services, the authors' key question is how different types of product-services impact the business and financial situation of today's companies. The most important information in this engineering article is that companies are actively using product services to ensure economic stability 
and achieve strategic and marketing benefits. Moreover, the companies offer basic and maintenance services mostly as they therefore can establish experience in the field of customer service and are able to increase their customer loyalty. Furthermore, the authors found out that these product services are simple services or maintenance services for the most part. The authors conclude that especially lower value-adding basic services are a substantial business for companies but do not have a positive impact on companies' profit. Today's customers expect companies to offer these services complementary with the primary product and they are not willing to pay money for basic services (Vinit Parida, 2014)

In 2014, AutoTeamAmerica published an important study in order to determine future trends in the industry of automotive dealerships and to give a general overview of how the business will likely be in the year of 2025. The key questions the authors of the study address are what the dealership's activities will likely be in 2025 , how the dealership will be owned, how the size of the facility will change, how the dealership will stay profitable, how new technologies will impact their business and what their greatest concerns are. The most important information in this study are that the manufacturer's influence at the dealerships is likely to increase in the future as well as the dependency on auto maker's incentives and factory cash. Furthermore, certain areas of the store will likely be growing as car sales are predicted to grow to 17.9 million in 2025 from 16.5 in 2014 . That's why dealership groups are predicted to grow in the next decade. The authors assume that in 2025 , the average dealer group will probably have between 30 to 40 different stores. According to the authors, this type of size for a group is the most efficient for management and staffing. The study also found that 3 out of 4 
dealerships will probably not be able to be profitable without manufacturer incentives such as volume bonuses, facility money or customer satisfaction rewards. According to the authors, this is one of the main concerns for the next decade as this situation causes a high dependency on the manufacturer dealership relationship. In addition to that, new technologies will have a great impact on communication with customers and making processes more efficient. Also, there will be different generations shopping at the same dealership and the generations have different expectations. Generation $\mathrm{X}$ and Baby Boomers have a different shopping preference involving more interaction with the sales people than Generation Y (born between 1985 and 2005). They prefer less communication at the dealership and usually will do a lot of research on their own, choose a car and then approach a dealership with a certain offer. Also, Generation Y will not accept the build-to-order principle as they are not willing to wait several weeks for their car.

Figure 4 shows the answer to the question regarding which area of operations dealerships will likely see as their most profitable. Therefore, in 2025, Service and Sales and the Used Vehicle Department will continue to be the most important profit earner. An increasing average age of vehicles, the complexity of today's cars that will be the used cars of the future and improved vehicle analysis will compensate reduced maintenance intervals and increased vehicle dependability. Following the results of the study, further difficulties could be new regulations and tightened customer protection (AutoTeamAmerica , 2014). 


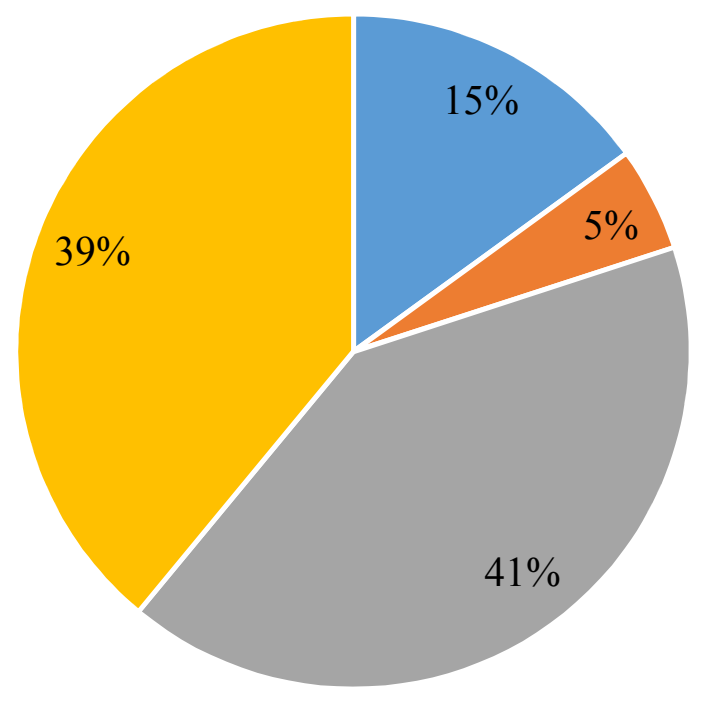

- New Vehicle Department Inc. - Parts/Sales

- Service/Sales $\quad$ - Used Vehicle Department Inc.

Figure 4: In 2025, what area of operations will be most profitable? (AutoTeamAmerica , 2014)

The growth of the after-sales market should not be taken for granted and will probably not happen without any obstacles, as was concluded in a study from PR Newswire in 2017 which underlined the importance of the automotive after-sales market. The study found that the global automotive aftermarket industry is going to grow from 300 Billion Dollars in 2015 to 680 Billion Dollars in 2024. The authors of the study named increased governmental regulation regarding vehicle safety and emission control and rising consumer awareness towards online maintenance tutorials as the main reasons for this trend. Today's consumers are more focused on increasing vehicle comfort and after-sales customization including lights, paintings, rims or spoilers than they used to be. Furthermore, the rising vehicle average age is another factor that will stimulate the aftermarket demand for parts and services as maintenance is more and more required by the law (PR Newswire Association LLC, 2017). 
Moreover, the trend towards electric mobility (e-mobility) will have an impact on the after-sales market. E-mobility is a general expression for vehicles powered by electric drivetrains such as electric vehicles (EV) and plug-in hybrid electric vehicles (PHEV) (Dombrowski \& Engel, 2014).

Thus the question arises regarding, how automotive companies and their dealerships can participate in this trend and increase their customer base. In an article by Fard et al., published in 2015, the authors determine the main factors that have an influence on customer satisfaction in the after-sales service business of car dealerships. The key question is whether there are important factors that have an impact on the satisfaction of customers when they conducted business at a car dealership. The most important information in this article is that services and customers satisfaction have a positive relationship. The main conclusion is that the cost of service, the quality and the responsiveness have the greatest impact on customer satisfaction. Furthermore, aftersales activities become more and more important and are recognized as a primary source of revenue, profit and competitiveness. Therefore, the quality of after-sales services and the measurement of customers' satisfaction are important (Shahnoush Shahrouzi Fard, 2015)

Although the Womack, Jones and Roos findings in 1990 led to many changes in the order fulfilment process of American and German car makers, Japanese car makers have continued to be very successful in the US. Figure 5 shows the US market share of the most important car makers from the US, Japan and Germany. Back in the year 1985, when Womack, Jones and Roos began their study, the two biggest American car makers General Motors (GM) and Ford had a total market share of about $62 \%$ together (GM 
$40.4 \%$ and Ford $21.3 \%)$, compared to $31 \%$ (17.2\% GM and $13.9 \%$ Ford) in February 2018. However, the two biggest Japanese makers Toyota and Nissan had a market share of about $11 \%$ together in 1985 (6\% Toyota and 5.3\% Nissan) and in 2018, they had a total of $25 \%$ (14.5\% Toyota and $10.7 \%$ Nissan). The two major German car makers Volkswagen and Mercedes basically kept their market share constant at around 3 to $4 \%$. Japanese makers were consequently growing and established a US business (Acura started business in the US in 1986, Infinity and Lexus in 1989) in the late 1980s. They experienced another boost of their US business, as oil and consequently gas prices rose significantly from 1999 until the middle of 2008 as countries like China and India had a rising demand for oil in order to fuel their economy (Mouawad, 2007).

Based on the literature review it can be stated that much has been done in the field of order fulfilment and manufacturing strategies at different automotive manufacturers. The general discussion that has been started by the results of the Womack, Jones and Roos findings in 1990, significantly changed manufacturing, planning and scheduling processes for today's auto makers. Especially European and American car makers had to redesign their production strategy and philosophy in order to gain back market share that was lost to Japanese makers that used the more efficient and better quality lean production system. American car makers such as GM changed to a new vehicle delivery system which allowed them to combine the Japanese maketo-stock system for their vehicle production and the German build-to-order system for their final vehicle configuration. 


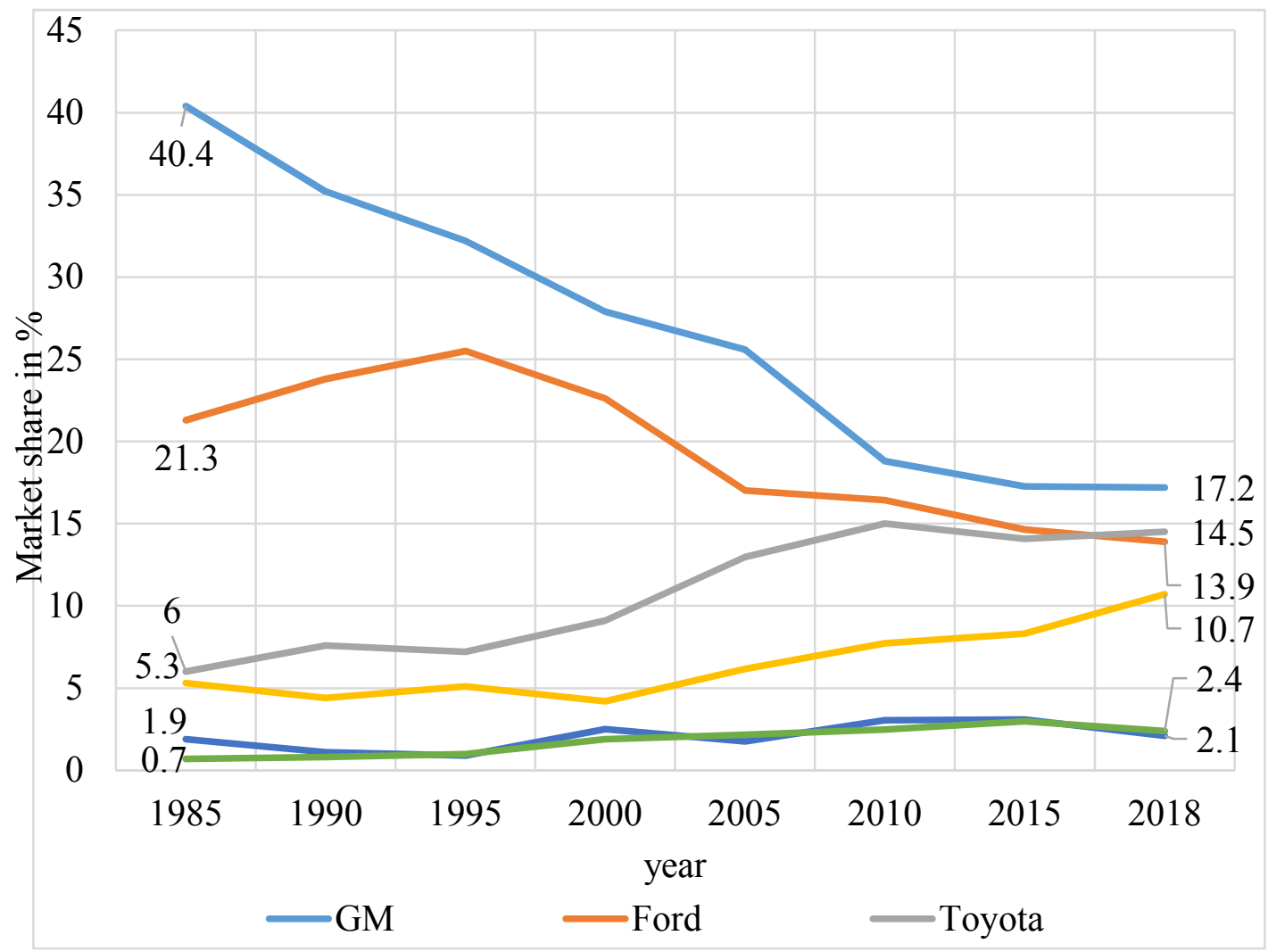

Figure 5: US market share of most important car makers from the US, Japan and Germany (Knoema, 2018) (Wall Street Journal, 2018)

Furthermore, researchers compared German and Japanese auto makers' planning and scheduling strategies with each other and discussed the possibility of combining build-to-order with make-to-stock in order to sustainably produce cars. In the course of time, auto makers and researchers realized that the after-sales business at the manufacturers' dealerships is becoming more and more profitable. Authors focused on the relationship between a car company's quality management and their dealer structure and its after sales service activities.

However, previous literature did not study well the different order fulfilment and after-sales strategies that various automobile manufacturers in the US use. As shown earlier in this chapter, previous studies were only focused on a single company or only gave general observations for one country. Furthermore, multiple country comparisons 
such as (Staeblein \& Aoki, 2014) and (Womack, Jones, \& Roos, 1990) never included after-sales activities or looked at dealership activities that are so important for today's business. Moreover, the literature that was reviewed only considered US car dealerships in general and did not distinguish between German, Japanese and American car dealerships in the US.

After studying well the literature, one can claim that a comparison of different order fulfilment strategies of German, Japanese and American automotive manufacturers in the US including their after-sales activities at their dealerships is an important area of study which will be the focus of this study. 


\section{CHAPTER 3}

\section{METHODOLOGY}

In chapter 2, it became clear that a comparison of American, German and Japanese car manufacturers including after-sales and service activities in the US is a gap in previous literature. Researchers found that differences in approaches regarding planning and scheduling at Japanese, German and American car makers occur. In order to come to such a conclusion, authors such as Womack, Jones, Roos (1990), Staeblein, Aoki (2014) and Chappell (2002) collected their data at manufacturers' plants who produced a variety of models from low-end to luxury segments by interviews with managers of the planning and scheduling department. Moreover, authors like Staeblein and Aoki (2014) did facility observations at automotive suppliers, dealerships and logistic service providers related to these makers in Japan and Germany (Staeblein \& Aoki, 2014). Other researchers such as Carter (2015), Townsend and Calantone (2014) and the authors of the study published by AutoTeamAmerica (2014) went into automotive dealerships to collect their data.

\subsection{Interview Approach}

This study follows the approach of interviewing employees at automotive dealerships. It usually requires some time in order to be able to schedule an appointment with a manager or someone that oversees the topics that are asked in the interview. This study includes the manufacturers' product sales strategies and also after sales and service strategies. 
In literature, several different interview techniques are discussed that are presented below:

\section{Structured interviews}

2. Unstructured interviews

\section{Semi-structured interviews}

Furthermore, questions that are asked in interviews can be open- or closed-ended. Openended questions are used to encourage a full and meaningful answer from the participant to capture his or her knowledge. Furthermore, they tend towards a more objective answer and are less leading compared to closed-ended questions. Closed ended questions try to get a short or single-word answer from the participant that can be compared easily to other participants' answers (MediaCollege.com, 2018).

According to Wilson (2013), a structured interview is a "verbal, [and standardized] questionnaire in which interaction is limited by a script and a fixed set of questions". The participant is asked several questions and then usually selects a response from a numerical range or a set of fixed responses. This type of interview has a specific structure that the interviewer has to follow with only slight deviation (Wilson, 2013). Usually, structured interviews are used to obtain general information about demographics, relationships or behaviors. Structured interviews are also useful to ask specific questions about a product after teaching the participant the product's major issues. Furthermore, they are used to quickly collect customer satisfaction data. After a purchase of a car, for example, all customers usually get a short questionnaire containing the question: "Are you likely to recommend our product?" Then, they have to choose a response from the fixed response "yes" or "no". Usually, most questions in a structured 
interview are closed-ended. Advantages and disadvantages of structured interviews are given in Table 2.

Table 2: Advantages and disadvantages of structured interviews (University of Portsmouth, 2018) (Wilson, 2013)

\begin{tabular}{|l|l|l|}
\hline Advantages & Disadvantages \\
\hline - Responses are easy to compare & $\begin{array}{l}\text { Interviewer has to follow the } \\
\text { - Questionnaire can be answered }\end{array}$ & questions in the questionnaire \\
online & - Structured interviews require \\
- Large sample is possible & interviewer to behave consistently \\
- Data analysis is easy and fast as & when reading questions \\
questions are structured & Rigid script makes it difficult for \\
interviewers to connect with & participant \\
\hline
\end{tabular}

The second type of interview is the unstructured interview. This is basically a conversation with the participant of the study and the interviewer where no predetermined or specific interview questions are given but only the general topic. This type of interview is very challenging, as it aims to obtain the participant's experience in the field of study without giving him any restrictions or limitations. The only thing the interviewer can do to determine the direction of the conversation is ask questions he or she prepared before the interview in order to acquire as much information as possible to fulfill the crucial goals of the study. Therefore, unstructured interviews are only used to obtain data on general themes such as the future orientation of a company or on sensitive or emotional topics. Usually, they would be used if an open conversion with a 
stakeholder of a company or a politician is held (Wilson, 2013). Advantages and disadvantages of unstructured interviews are given in Table 3.

Table 3: Advantages and disadvantages of unstructured interviews (University of Portsmouth, 2018) (Wilson, 2013)

\begin{tabular}{|c|c|}
\hline Advantages & Disadvantages \\
\hline $\begin{array}{l}\text { - Direct experience with } \\
\text { stakeholders } \\
\text { - More flexibility in how questions } \\
\text { are ordered } \\
\text { - Participants can use their own } \\
\text { words rather than chosen } \\
\text { predetermined answers }\end{array}$ & $\begin{array}{l}\text { - Interviewer needs a lot of } \\
\text { experience } \\
\text { - Analysis and interpretation of data } \\
\text { can take a long time } \\
\text { - Taking notes is challenging and if } \\
\text { audio-recording is not allowed, a } \\
\text { second person is needed to take } \\
\text { notes }\end{array}$ \\
\hline
\end{tabular}

The third type of interview is the semi-structured. This is a combination of a structured and an unstructured interview. On the one hand, the interviewer asks predefined questions in a certain order and gives the participant a choice of predetermined answers; on the other hand, the interviewer can add new questions or change the order of questions to gather further understanding of a specific topic. This procedure ensures that the interviewer can systematically gain information about a certain topic but also allows him to explore new topics or issues that are related to the actual goal of the study. Usually, a semi-structured interview is used for a topic where some basic knowledge or understanding is already given, but further details are still needed which can come from open-ended questions. The amount of structured and 
unstructured questions can depend on the environment where people are interviewed. Advantages and disadvantages of semi-structured interviews are given in Table 4.

Table 4: Advantages and disadvantages of semi-structured interviews (University of Portsmouth, 2018) (Wilson, 2013)

\begin{tabular}{|l|l|}
\hline Advantages & Disadvantages \\
\hline $\begin{array}{l}\text { Structure of questionnaire is } \\
\text { flexible }\end{array}$ & - Personal background, sex, age and \\
- In contrast to structured interview: & how willing participants are to \\
May uncover unknown facts & share their knowledge \\
- Complex topics can be addressed & - Interviewers could influence \\
easier due to flexible structure & participants answers as they \\
Digressing conversations can be & might guide them to a particular \\
redirected easier & answer \\
\hline
\end{tabular}

After taking a look at the three most important interview techniques, it becomes clear that the most appropriate one for this study is the semi-structured. It is a good combination of the structured and unstructured interview concepts and allows the interviewer to ask further questions when needed. This is particularly useful for complex topics where one question might be divided into more questions. However, if the participant digresses too far from the main topic or focuses on other issues that are not important for the study, the concept of semi-structured interviews provides a mechanism for redirecting the conversation. Considering the literature review, previous authors also used the concept of semi-structured interviews. For their study of differences between German and Japanese automakers in terms of planning and scheduling functions in the 
order fulfilment process, Staeblein and Aoki (2014) conducted 14 semi-structured interviews with automotive dealerships, logistic service providers and suppliers plus another 17 semi-structured interviews with managers from various functional departments in automotive factories such as production, development and sales. Each of these interviews lasted between 30 minutes to 3 hours (Staeblein \& Aoki, 2014). This shows that the concept of semi-structured interviews is appropriate for this research.

After choosing the right type of interview, the questionnaire has to be planned, developed and designed. Furthermore, the sample size has to be determined and eventually, the data needs to be collected. The United States General Accounting Office (1993) contains a structure that helps researchers complete the major tasks to create and execute a questionnaire-based survey. Figure 6 gives an overview of the most important steps. The first step is to plan the semi-structured interview. Here, it is important that the goal of the research is clear. In this case, it is to gain a deeper understanding of the different order fulfilment and after-sales strategies that various automobile manufacturers from Japan, Germany and the US use in the US. Therefore, semistructured interviews with managers or top managers of different car dealerships will be scheduled. The next step is to define factors that can be measured to draw conclusions. In this case, factors that were used by other researchers in this field of study such as Staeblein and Aoki (2014) or Womack, Jones and Roos (1990) or AutoTeamAmerica (2014) will be used and others, where the studied literature has not provided enough information, will be added. In the analysis of the sales and services approaches of the different car dealerships, the following factors will be considered: number of models per car maker, product variety of makers, average demand lead time (delivery time), 
average manufacturer's MSRP (manufacturer's suggested retail price), dealer inventory, warranty models, personnel training, etc.

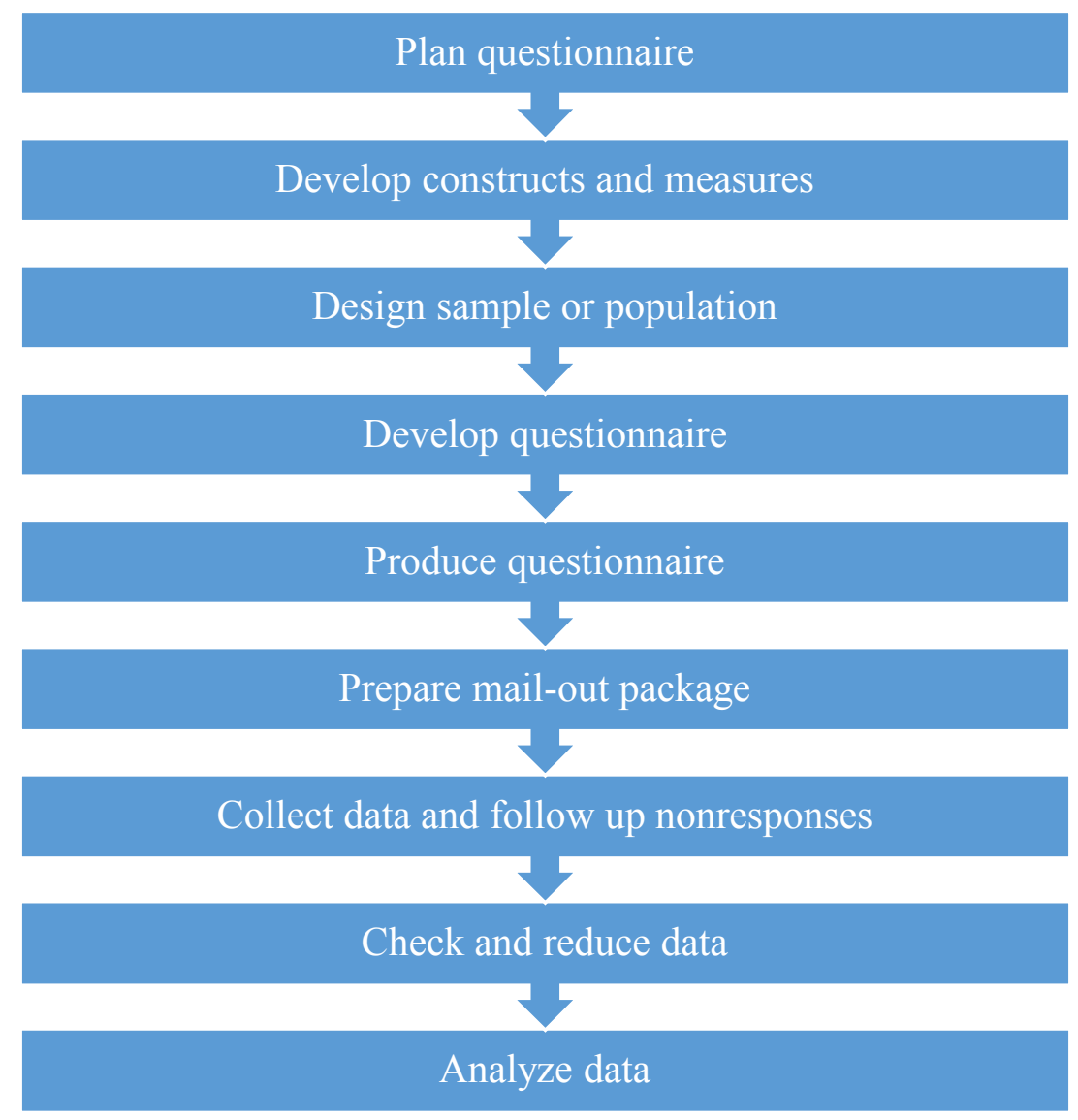

Figure 6: Major tasks for an interview using a questionnaire (United States General Accounting Office, 1993)

The next step is the design of the sample. Before the questionnaire is developed, it is important to ensure that a sufficiently large sample size can be found. Furthermore, the sample has to be selected randomly. In order to make results comparable, only car dealerships from Rhode Island are initially approached and the geographic region for the study can only be extended to surrounding areas such as Connecticut or Massachusetts if participation in Rhode Island is insufficient. Furthermore, ultra-luxury brands (Porsche and Maybach) and light vehicle makers (Smart, Daihatsu and Suzuki) were excluded from the sample size. 
As a first step, automotive dealerships need to be identified and contacted to see if they are willing to participate in the study. The sample size for German, Japanese and US car makers should be equal. In this case, it is limited by the amount of German car dealerships in Rhode Island. As there are only eight of them, the total sample size is 24 (eight German, eight Japanese and eight American car dealerships). In the next step, all German, Japanese and American car dealerships in the state of Rhode Island are listed in a spreadsheet. This spreadsheet contains the name of the dealership, address and telephone number. When more information such as an appointment for the interview or a special contact person is collected, the spreadsheet will be extended.

As there are more than eight Japanese and American car dealerships in Rhode Island, eight of the 17 Japanese and 16 American dealerships have to be selected randomly. Therefore, the computer program "Modern Dice Roller" is used. For the Japanese makers, a 17-sided dice is rolled eight times and the numbers that are rolled give the dealerships that will be interviewed. For the American car dealerships, a 16sided dice is rolled eight times to order the dealerships randomly. Figure 7 shows the "Modern Dice Roller".

\subsection{Survey Questions}

Once the correct sample size has been determined and the dealerships are selected randomly, the questionnaire can be developed. It is important that each of the interview questions is relevant to the goals of the project that were defined earlier. Every question should be connected to one of these goals. Furthermore, questions should not be too long or complex and should be in an appropriate language for the participants. 


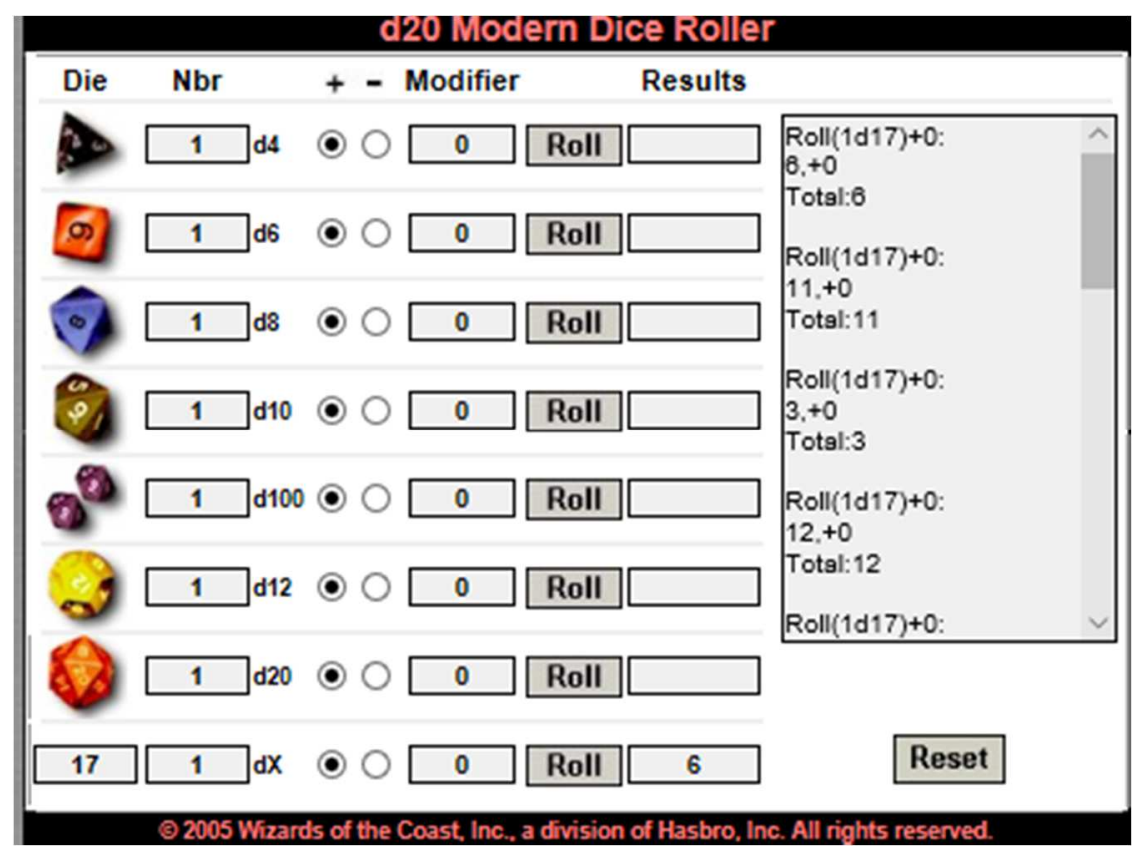

Figure 7: The Modern Dice Roller is used to randomly select 8 Japanese and American car dealerships (Hasbro Inc., 2018)

It is very important that the questions are not biased or threatening. They should not influence the participants' answers and be as neutral as possible. Moreover, the questions need to fulfil the University of Rhode Island's Institutional Review Board (IRB) requirements which ensure that the participants are not placed at undue risk and that they give uncoerced, informed consent to their participation. That is why the interview questions were based on previous studies that were presented in chapter 2 . The interview should not be shorter than 30 or longer than 120 min because interviews that are too short may not provide enough time to establish rapport and cover the topic in sufficient depth and when they are too long it may reduce the pool of qualified participants who do not want to give up their valuable work time. Furthermore, the questions should be arranged by topic and ordered according to their complexity with easy questions coming first and more complex ones later. Based on these boundary conditions the following questions will be asked in the interview: 


\section{Do you agree to proceed with the interview and begin with audio recording?}

This first question is required by the IRB committee in order to ensure that the participants are willing to continue this interview while being audio-recorded. If the participants do not wish to be audio-recorded, the interview will be continued but notes will be taken instead.

\section{How many different models does the company offer?}

The second question is the actual start of the interview. It is a general question about a topic that most of the participants are able to quickly answer. It is targeted to determine the number of products per company and eventually gives information about the product variety this maker offers. However, this question can be interpreted differently, as every participant might consider different models differently. Therefore, a description is provided under the question. It says that a model is meant to be a separate car, including different options but if there is a hybrid or electric version of this specific vehicle, it counts as two different models. Commercial vehicles are not included. This question is a closed-ended question. After taking the interviews, the number of models given during the interview was adjusted based on the definition of different car models.

\section{How many days does it take to get the car after placing an order with the auto maker if the customer cannot find the car on the lot?}

This question has been asked similarly in Staeblein and Aoki's study from 2014. It aims to examine the average demand lead time (delivery time) for the different makers which is a result of the company's managerial practice related to the order fulfilment process. Based on the literature review, it is known that Japanese and German auto makers use 
different mass customization and order fulfilment strategies. By asking this question, the connection between the makers and the dealerships should be focused.

\section{How much dealer inventory do you have?}

This question is taken from the study of Staeblein and Aoki (2014) and aims to examine whether the makers implemented the lean system not only at their production plants but also at their dealerships. This closed-ended question can be seen as an indicator of leanness as a low amount of dealer inventory is desired.

\section{What percentage of all customer orders is sold from inventory?}

This question is also taken from the study of Staebein and Aoki (2014) and connects to question 4. The answer to this question gives information about whether the maker uses an inventory-driven make-to-stock or build-to-order principle. This question is a closedended question.

\section{What dealer options do you have?}

As with questions 3, 4 and 5, this question is part of Staeblein and Aoki's study. By asking this question, the different management practices related to the order fulfilment process should be determined. As mentioned in the literature review, Japanese makers heavily use late configuration, as they customize their vehicles at their dealerships outside the car factory whereas German makers mostly produce their customized cars inside the factories. This question tries to find out if previous findings can be confirmed and to what degree car makers offer customizing options at their dealerships. 


\section{Are the dealer options decided by the dealer or the auto maker?}

This question from Staeblein and Aoki (2014) tries to determine the auto maker's influence on the dealerships. It is also an indicator of how connected car manufacturer and dealership are.

\section{Do you order option parts directly at the parts maker or at the auto maker?}

This question builds on the seventh question and aims to find out to what extent the car manufacturers influence the dealerships' business. It also shows whether car dealerships tend to procure their parts from the OEM (Original Equipment Manufacturer, here the car maker) or a third-party company. This question is also taken from Staeblein and Aoki's study (2014).

\section{Do you receive a sales quota from the auto maker?}

This question is also taken from Staeblein and Aoki's survey and focuses on the makerdealership relationship. Furthermore, the dealerships have to comment on how realistic they assume their sales quota to be.

\section{Do you receive sales incentives from the automaker?}

Question 10 is an extension of Question 9 because by asking about the sales incentives that automakers provide to their dealerships, more information about the makerdealership relationship can be obtained. It also describes the strategy that automakers use in order to make their car dealerships sell the amount of cars defined in the quota. 


\section{What are the main challenges in the after-sales-service business?}

This question is an open-ended question and addresses the main challenges and problems that are faced today in terms of the after-sales and service-business. The participants should describe the main challenges they have to deal with after they sell vehicles to their customers. This question allows the participants to mention all kind of problems they are facing today without being restricted to a certain field, e.g. product quality, customer satisfaction or personnel training.

\section{Is the average time that is needed to fix a customer service measured?}

This question aims to obtain service-related data from the after-sales and service business of the dealership. Scheduling of customer orders in the service area of dealerships is important in order to achieve a lean and fast service department The data received by this question gives information about the implementation of lean business and customer orientation in the after sales business of car dealerships. For a better understanding of the question, the interviewer adds the following explanation of the question to the participants: "If a customer gets to the dealership to make an oil change, a brake check or a filter replacement, is the average time that is needed for the work measured?"

\section{How are service personnel trained and who gets trained?}

As Womack, Jones and Roos (1990) found out, highly skilled and trained employees are a crucial factor of success for automotive companies. The same accounts for car dealerships. Highly trained personnel, especially in the service department, ensures high customer satisfaction and product quality. This open ended question tries to find out to 
what extent the car dealerships have implemented sufficient and sustainable strategy training for their employees.

\section{What kind of warranty models do you offer?}

In order to differentiate from other competitors, car makers offer different models of warranty for their products in order to increase customer attraction. This question asks the dealerships which different types of warranties customers are able to buy and what the warranty model includes, if a customer buys a car at the dealership. Furthermore, it is asked if there are also third-party companies involved in that system.

\section{How is the customer satisfaction rate measured?}

According to the findings in chapter 2, measurement of the customer satisfaction rate is very important as it provides input for the dealerships and allows them to continuously improve their business. Question 15 tries to find out how dealerships determine customers' happiness and which strategy they follow.

\section{What are the main challenges for the future and what does the dealership of tomorrow look like?}

This open-ended question allows the participant to describe, based on his experience in the car business, the main challenges for the automotive dealership industry in the future. Participants can included everything they think will have a significant impact on their business. 


\section{Are there already Battery Electric Vehicles (BEV) or Hybrid Electric Vehicles (HEV) in your show room or offered by this auto maker?}

As e-mobility will play a major role in future mobility, this question determines how automakers are preparing for this trend. As part of this question, the participant will be asked what different technologies the car makers are using in their vehicles and how successful they are right now.

\subsection{IRB Approved Procedures \& Analysis Methods}

After designing the questionnaire, approval from the IRB board is needed prior to starting with the interviews. Therefore, an Initial IRB Application has to be made which contains a detailed description about the summary of research, the scientific background, research objectives, research methods and activities and the interview questions. Moreover, an estimated time required from each participant for the interview needs to be given and detailed information about the participants needs to be provided. The Initial IRB Application also contains a description about risks, harms and discomforts related to this study, explains how the confidentiality of data is ensured and how the privacy interests of the participants are protected. To be able to estimate the time needed for a single interview, the interview questions were asked to different randomly selected people from the office and the college of engineering and answers were made up by the participants. Based on this experiment, the estimated time for the interviews at the dealerships should be between 30 to 60 minutes. IRB requires that every interview package should consist of the survey questions that are asked to the dealerships, recruitment material, and a Low Risk Survey Consent Form for Research. The recruitment material will be the first paper that the contact person at the dealership 
will read. It is basically a summary of the research, gives some scientific background, and contains a description about risks, harms and discomforts related to this study. It provides contact information about the major advisor and the department that supervises this study. The interview questions will be next. The third document the contact person at the dealership will see is the Low Risk Survey Consent Form for Research. It is basically a description of how the confidentiality of data is ensured and how the privacy interests of the participants are protected. Furthermore, it contains the information that the participants will be audio-recorded. Moreover, it provides contact information of the University of Rhode Island IRB. All three documents can be found in Appendix A.

After receiving the final IRB approval, the interview package was printed 35 times in order to have 11 extra to hand out. Based on the spreadsheet of dealership locations, multiple routes are created, using Google Maps, in order to find the most efficient connection between the randomly selected car dealerships. It is also possible that on one day, dealerships from different countries (Japan, Germany, and USA) are visited. Figure 8 shows a sample route to different dealerships. When walking into a dealership, the first contact person is usually at the reception desk where the interviewer hands over the interview package and explains the purpose of his visit. Usually, the receptionist sends the researcher to a manager or employee that could answer the questions the best. In some cases, the receptionist keeps the student's number and as soon as the person at the dealership is available, calls the researcher back. After the manager or top manager of the dealership agrees to participate in the study, the participant receives the interview package and takes a first look at the questions. 


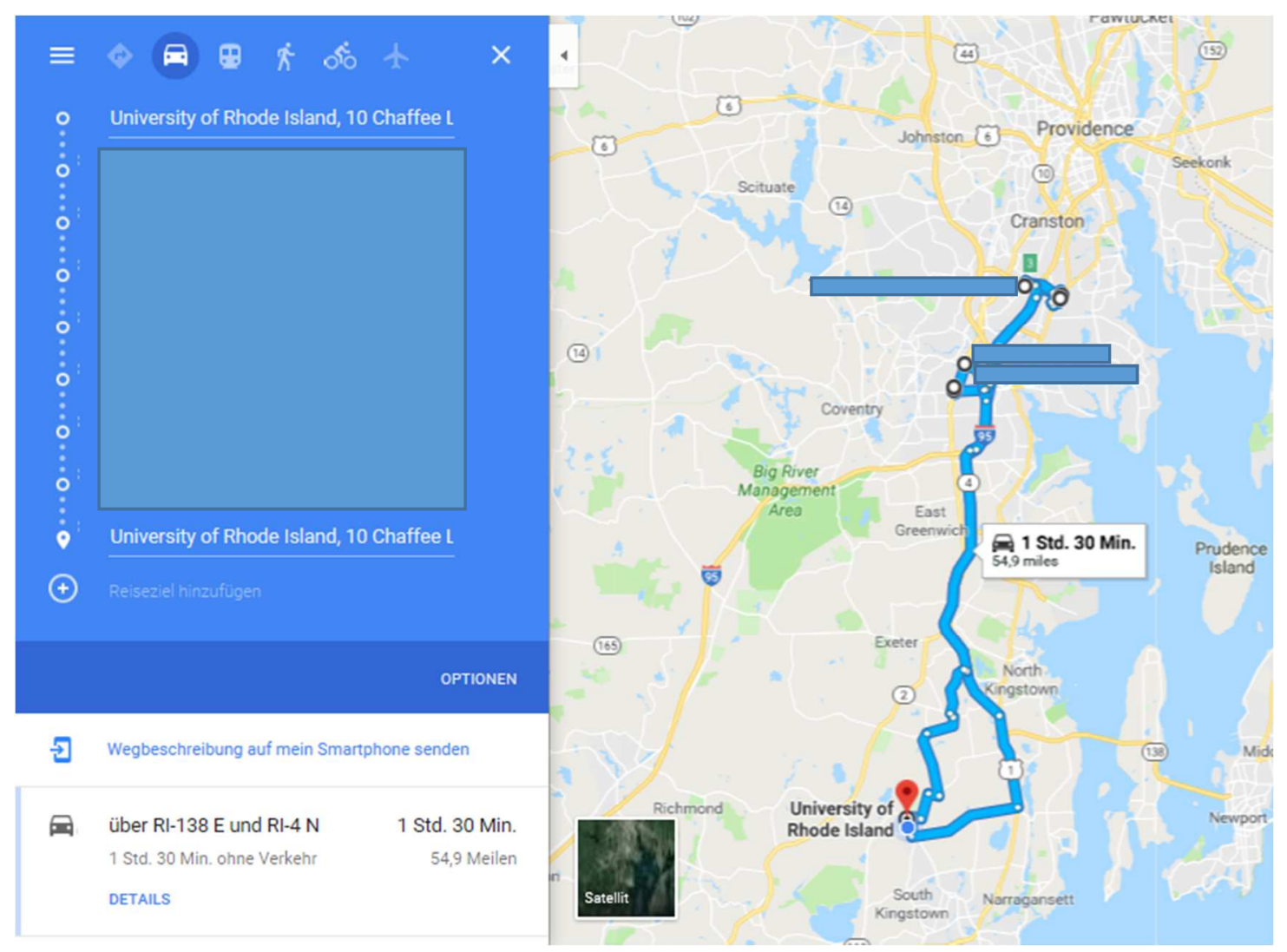

Figure 8: First route calculated by google maps to seven different car dealerships

At that point, the participant decides whether he or she wants to give the interview now or wants to schedule an appointment in order to have the interview later. If the participant decides to do the interview now, the audio-recording starts. However, if the participant wishes to schedule a separate appointment, he or she gets an e-mail confirmation for the interview appointment and 24 hours before the interview, the researcher sends another reminder.

After having scheduled and conducted various interviews, the spreadsheet is expanded to support the researcher. By using various colors, the different dealerships are marked according to their current status which makes it easier to find out which dealerships still need to be contacted or maybe have not responded yet. Furthermore, it 
shows which dealerships have already taken part in the study and where an appointment for an interview has been set up.

If the dealership declined to take part or has not responded to several interview requests, it is marked red which means the dealership will no longer be considered. If a first contact with the dealership was made and the interview package was handed over but no interview has been determined, the dealership is marked orange in the spreadsheet. If an interview is scheduled, the color is yellow. Dealerships that have successfully participated in the study are green. White-colored dealerships have not been contacted yet. Figure 9 shows an example for a spreadsheet.

To follow up to nonresponses, dealerships are visited one to three more times after visiting them the first time. Furthermore, the contact information given on the participant's business card such as his or her phone number or email-address will be used to contact the participant directly.

\begin{tabular}{lll} 
Brand & Name of the dealership & Address \\
\hline German & & \\
GE1 & Rhode Island I & 36 Main Road 01235 Newton \\
GE2 & Rhode Island II & 678 South Road 02445 Rhode Island Town \\
GE3 & Rhode Island III & 1714 West Street 02842 Faketown \\
GE4 & Rhode Island IV & 414 Main Road 01235 Newton \\
GE5 & Rhode Island V & 45 Fish Road 08894 Princeton \\
GE6 & Rhode Island VI & 32 Clara Lane 01447 West Rhode Island Town \\
GE7 & Rhode Island VII & 254 Tower Street 02879 Anytown
\end{tabular}

Figure 9: Extended spreadsheet using colors to show status of dealerships 
In order to audio-record the interviews, the recording function of a smartphone is used. After the recording is completed, every recording file is named like the dealership in the spreadsheet. If the participant does not agree to be audio-recorded, notes will be taken on a separate sheet of paper and answers will be written out in the questionnaire file on a laptop directly after the interview. Therefore, sufficient time between interviews has to be scheduled to be able to make some general notes, including questions that might be asked to the next participant. All the collected data will be saved on the University of Rhode Island's Engineering Computer Center (ECC) server. This server is encrypted and only the researcher has access to it. In addition, it will be backed up quarterly in a cloud based server.

After collecting all 24 interviews from the automotive dealerships, various methods are used to analyze the data. This includes qualitative and quantitative methods. Different types of plots will be used to illustrate the results. For this research, the statistics tool Minitab is used as this tool specifically allows the user to focus on the analysis of data and the interpretation of results. Minitab is able to execute different statistical tests, such as 2 sample t-test, a regression analysis or ANOVA (Analysis of variance). Minitab will be used to test different defined hypotheses by comparing the calculated p-value with a chosen $\alpha$-value. For this case, the $\alpha$-value is chosen to be 0.1 as the sample size is small and the standard deviation is expected to be relatively high (Perezgonzalez, 2018).

In these experiments, a multiple 2-sample t-test will be used. The Japanese makers will be compared to the Germans first and in a separate test, the Japanese will be compared to the Americans. In order to conduct the different tests, the data that 
should be compared with each other need to be selected in Minitab. Figure 10 shows a Minitab screenshot that gives an overview of the workspace. The 2-sample t-test is part of basic statistics menu. After the 2-sample t-test is selected, the two different pairs of data that will be compared with each other need to be selected. Figure 11 shows the corresponding screenshot. After selecting the different sets of data and running the test, Minitab will show the results in its output window. Figure 12 shows an example of an output window after a 2-sample t-test was run. It shows the method and gives an overview of the descriptive statistics such as the mean $\mu$ and the standard deviation stdev $\sigma$. The most important part of the output window is the test section. It shows the hypothesis and alternate hypothesis plus gives the p-value that is needed in order to determine the significance of the hypothesis. Furthermore, the confidence level is set to $90 \%$ as the $\alpha$-value equals to 0.1 . The alternative hypothesis depends on the subhypothesis made in chapter 3 . 


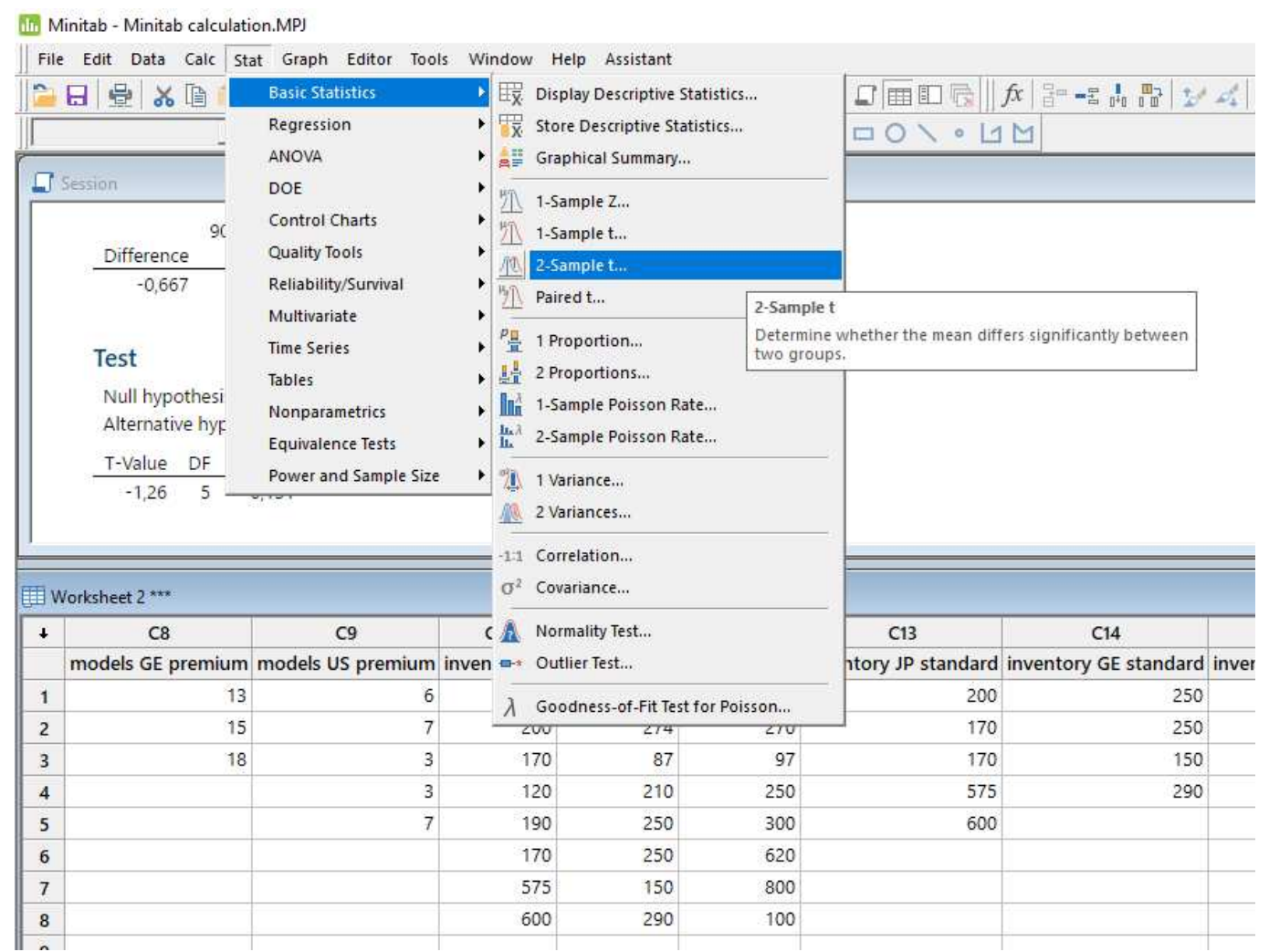

Figure 10: Minitab screenshot of the data tables and the selection of the 2-sample t test as part of basic statistics

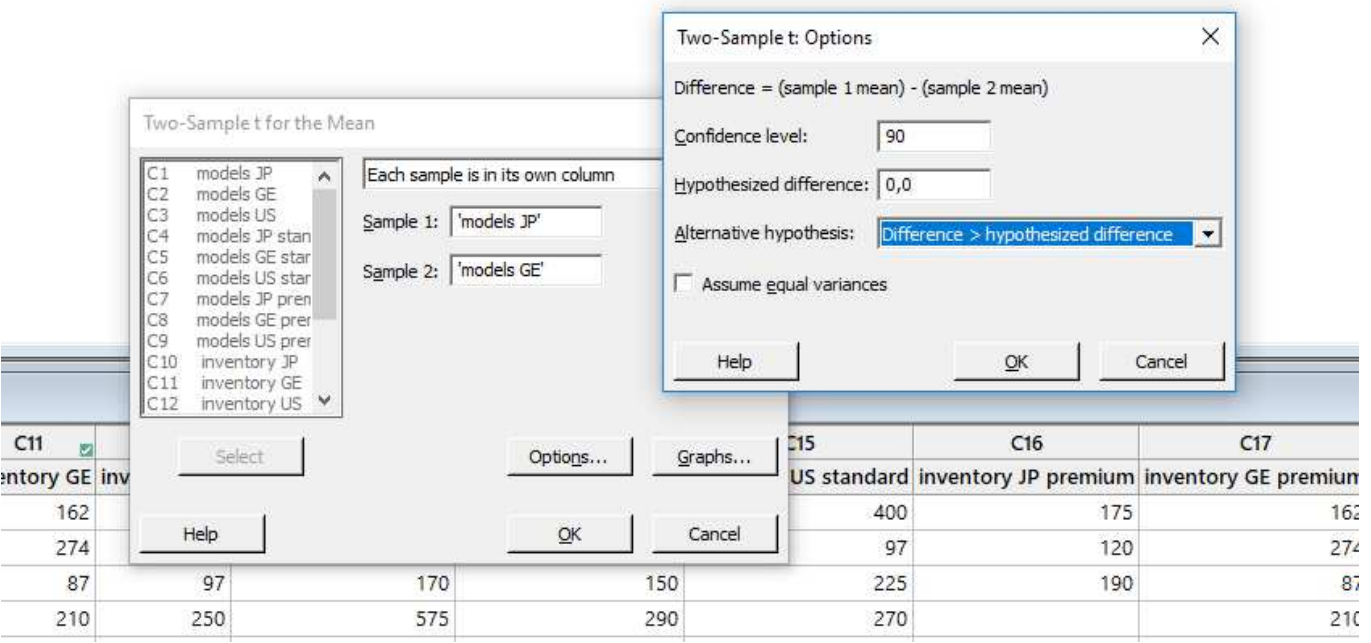

Figure 11: The two pairs of data for the 2-sample t-test are selected. 


\title{
Two-Sample T-Test and Cl: models JP; models GE
}

\author{
Method \\ $\mu_{\mathrm{s}}:$ mean of models JP \\ $\mu_{2}$ : mean of models $\mathrm{GE}$ \\ Difference: $\mu_{1}-\mu_{2}$ \\ Equal variances are not assumed for this anolysis. \\ Descriptive Statistics

\begin{tabular}{lrrrr} 
Sample & N & Mean & StDev & SE Mean \\
\hline models JP & 8 & 13,00 & 5,63 & 2,0 \\
models GE & 8 & 12,63 & 3,11 & 1,1
\end{tabular}

Test

Null hypothesis $\quad H_{0}: \mu_{1}-\mu_{2}=0$

Alternative hypothesis $H_{1}: \mu_{1}-\mu_{2}>0$

\begin{tabular}{rrr} 
T-Value & DF & p-Value \\
\hline 0,16 & 10 & 0,436
\end{tabular}

Figure 12: Output window of Minitab after running a two-sample t-test

\subsection{Standard and Luxury Classification}

It is assumed that the results will not only differ between the various makers from the US, Japan and Germany but also within single makers from one country. Therefore, car makers will be grouped into the categories "standard" and "luxury" based on the brand's philosophy and products. Table 5 gives an overview of the different makers that are being interviewed in this survey and their classification to either luxury or standard. In addition to that, the company's average MSRP is given, based on sales volume of their single models. Kelly Blue Book (KBB) provided the sales volume data (Buehler, 2018). As table 5 shows, luxury brands do not necessarily have to have a higher MSRP than standard brands such as Ford and Buick. That is because a maker 
like Ford sells more than $80 \%$ of its vehicles in the very profitable and high-priced Truck- and Large SUV-segment whereas Buick is known for its strength in premium sedans and small Crossovers that have lower average MSRPs than Trucks and Large SUVs (Wall Street Journal, 2018). Furthermore, German makers are abbreviated by GE, Japanese JP, and American US throughout the thesis. The comments section in Table 5 gives sources for the chosen classification based on the company's marketing materials and websites.

Table 5: List of automakers that are part of the study and their classification in "normal" and "luxury"

\begin{tabular}{|c|c|c|c|c|}
\hline $\begin{array}{l}\text { Maker } \\
\text { (Country) }\end{array}$ & Standard & Luxury & $\begin{array}{l}\text { Average } \\
\text { MSRP }\end{array}$ & Comments \\
\hline Acura (JP) & & $\mathrm{X}$ & $\$ 40,449$ & $\begin{array}{l}\text { Acura is the luxury vehicle } \\
\text { marque of Honda (Acura, 2018) }\end{array}$ \\
\hline Audi (GE) & & $\mathrm{X}$ & $\$ 51,270$ & $\begin{array}{l}\text { "we buil[d] the most } \\
\text { sophisticated and elegant luxury } \\
\text { performance vehicles on the road } \\
\text { today" (Audi USA, 2018) }\end{array}$ \\
\hline BMW (GE) & & $\mathrm{X}$ & $\$ 55,009$ & $\begin{array}{l}\text { "BMW USA: Luxury Sedans, } \\
\text { SUVs, Convertibles, Coupes \& } \\
\text { Wagons" (BMW USA, 2018) }\end{array}$ \\
\hline Buick (US) & & $\mathrm{X}$ & $\$ 35,365$ & $\begin{array}{l}\text { "Discover the Buick lineup of } \\
\text { luxurious, refined, and efficient } \\
\text { luxury cars, crossovers, SUVs } \\
\text { and sedans" (Buick USA, 2018) }\end{array}$ \\
\hline Cadillac (US) & & $\mathrm{X}$ & $\$ 59,249$ & $\begin{array}{l}\text { "Cadillac has been a leading } \\
\text { luxury auto brand since 1902" } \\
\text { (Cadillac, 2018) }\end{array}$ \\
\hline $\begin{array}{l}\text { Chevrolet } \\
\text { (US) }\end{array}$ & $\mathrm{x}$ & & $\$ 35,800$ & $\begin{array}{l}\text { "An innovative range of award- } \\
\text { winning, affordable and fuel- }\end{array}$ \\
\hline
\end{tabular}




\begin{tabular}{|c|c|c|c|c|}
\hline & & & & $\begin{array}{l}\text { efficient cars, trucks, and SUVs" } \\
\text { (General Motors, 2018) }\end{array}$ \\
\hline Chrysler (US) & $\mathrm{x}$ & & $\$ 36,436$ & $\begin{array}{l}\text { "Founded in } 1925 \text {, the Chrysler } \\
\text { brand today is primarily focused } \\
\text { on the minivan and full-size car } \\
\text { segments in North America" } \\
\text { (FCA, 2018) }\end{array}$ \\
\hline Dodge (US) & $\mathrm{x}$ & & $\$ 33,338$ & $\begin{array}{l}\text { "Dodge and SRT are our } \\
\text { ultimate and mainstream } \\
\text { performance brands in North } \\
\text { America." (FCA, 2018) }\end{array}$ \\
\hline Ford (US) & $\mathrm{x}$ & & $\$ 38,936$ & $\begin{array}{l}\text { "The company sells automobiles } \\
\text { and commercial vehicles under } \\
\text { the Ford brand and most luxury } \\
\text { cars under the Lincoln brand" } \\
\text { (Ford, 2018) }\end{array}$ \\
\hline GMC (US) & $\mathrm{x}$ & & $\$ 46,575$ & $\begin{array}{l}\text { "GMC }[\ldots] \text { primarily focuses on } \\
\text { trucks and utility vehicles" } \\
(\mathrm{GMC}, 2018)\end{array}$ \\
\hline Honda (JP) & $\mathrm{x}$ & & $\$ 26,585$ & $\begin{array}{l}\text { "At Honda, The Power of } \\
\text { Dreams drives us to create } \\
\text { intelligent products that enhance } \\
\text { mobility and increase the joy in } \\
\text { people's lives." (Honda USA, } \\
\text { 2018) }\end{array}$ \\
\hline Infiniti (JP) & & $X$ & $\$ 45,968$ & $\begin{array}{l}\text { "Visit the official Infiniti USA } \\
\text { Site to explore the } 2017 \text { lineup of } \\
\text { Infiniti luxury vehicles" (Infiniti, } \\
\text { 2018) }\end{array}$ \\
\hline Jeep (US) & $\mathrm{x}$ & & $\$ 34,653$ & $\begin{array}{l}\text { Jeep is a brand with its main } \\
\text { business in SUVs (Jeep, 2018) }\end{array}$ \\
\hline Lexus (JP) & & $\mathrm{x}$ & $\$ 48,279$ & $\begin{array}{l}\text { "Explore the line of Lexus } \\
\text { luxury sedans, SUVs, hybrids, }\end{array}$ \\
\hline
\end{tabular}




\begin{tabular}{|c|c|c|c|c|}
\hline & & & & $\begin{array}{lll}\text { performance cars } & \text { and } \\
\text { accessories" (Lexus, 2018) } & \end{array}$ \\
\hline Lincoln (US) & & $X$ & $\$ 46,701$ & see Ford \\
\hline Mazda (JP) & $\mathrm{x}$ & & $\$ 27,352$ & $\begin{array}{l}\text { "Despite a very positively- } \\
\text { received range of mainstream } \\
\text { cars and SUVs with a sporty } \\
\text { bend [...] (Carsalesbase.com, } \\
2018 \text { ) }\end{array}$ \\
\hline $\begin{array}{l}\text { Mercedes- } \\
\text { Benz (GE) }\end{array}$ & & $X$ & $\$ 57,359$ & $\begin{array}{l}\text { "Mercedes-Benz combines } \\
\text { luxury with performance across } \\
\text { the full line of luxury cars, } \\
\text { sedans, SUVs, coupes, roadsters, } \\
\text { convertibles \& more" } \\
\text { (Mercedes-Benz, 2018) }\end{array}$ \\
\hline Nissan (JP) & $\mathrm{x}$ & & $\$ 27,548$ & $\begin{array}{l}\text { "For Nissan, this means making } \\
\text { cars that are more efficient, more } \\
\text { beautiful, more inspiring and } \\
\text { more human than ever before." } \\
\text { (Nissan USA, 2018) }\end{array}$ \\
\hline RAM (US) & $\mathrm{x}$ & & $\$ 45,378$ & $\begin{array}{l}\text { Ram Trucks offers Pickup } \\
\text { Trucks, Work Trucks and Cargo } \\
\text { Vans (RAM, 2018) }\end{array}$ \\
\hline Toyota (JP) & $\mathrm{x}$ & & $\$ 29,598$ & $\begin{array}{l}\text { "We build cars and trucks that } \\
\text { help you and your family go } \\
\text { places reliably and safely" } \\
\text { (Toyota USA, 2018) }\end{array}$ \\
\hline $\begin{array}{l}\text { Volkswagen } \\
\text { (GE) }\end{array}$ & $\mathrm{x}$ & & $\$ 25,635$ & $\begin{array}{l}\text { "That is the key to offering a VW } \\
\text { at a price that is competitive } \\
\text { against mainstream American } \\
\text { and Asian competitors" (Carney, } \\
\text { 2018) }\end{array}$ \\
\hline
\end{tabular}


Table 5 shows that there are 9 premium automakers and 12 standard automakers that are considered in the study. Table 6 shows them summarized.

Table 6: Classification of standard and luxury car makers

\begin{tabular}{l|l}
\multicolumn{1}{c}{ Standard } & Premium \\
\hline Chevrolet & Acura \\
Chrysler & Audi \\
Dodge & BMW \\
Ford & Buick \\
GMC & Cadillac \\
Honda & Infiniti \\
Jeep & Lexus \\
Mazda & Lincoln \\
Nissan & Mercedes-Benz \\
RAM & \\
Toyota & \\
Volkswagen &
\end{tabular}

\subsection{Hypotheses}

In this section ten hypotheses are defined that are tested in this thesis in order to obtain discussable results. The hypotheses are based on findings from chapter 2. 


\section{Japanese car makers offer more models than Germans or Americans do}

This hypothesis is based on chapter 2 and the common finding that Japanese makers have a higher amount of models that they offer to their customers compared to their competitors. In order to test the hypothesis, various 2 sample t-tests will be executed in Minitab. First, Japanese makers will be compared to German makers, leading to the following sub-hypothesis:

$$
\begin{aligned}
& H_{0}: \mu_{J P}=\mu_{G E} \\
& H_{1}: \mu_{J P}>\mu_{G E}
\end{aligned}
$$

The null-hypothesis states that the number of models at JP makers and GE makers is the same, whereas $H_{1}$ means that JP makes offer a higher amount of models than GE makers. In order to prove hypothesis $1 H_{1}$ needs to be found true. If $H_{1}$ is false, hypothesis 1 is false too. If the p-value for this comparison is bigger than the $\alpha$-value (0.1), the null-hypothesis is true, otherwise it is false. In a second test, the number of models at JP and US makers are compared with each other, using the following hypothesis:

$$
\begin{aligned}
& H_{0}: \mu_{J P}=\mu_{U S} \\
& H_{1}: \mu_{J P}>\mu_{U S}
\end{aligned}
$$

Although not necessarily needed, GE and US makers are also compared with each other as previous literature usually focused on comparing other makers to JP makers. Therefore, the following hypothesis is randomly chosen: 


$$
\begin{aligned}
& H_{0}: \mu_{G E}=\mu_{U S} \\
& H_{1}: \mu_{G E}>\mu_{U S}
\end{aligned}
$$

In the next step, the standard car makers are compared with each other, leading to the following sub-hypotheses:

$$
\begin{aligned}
& H_{0}: \mu_{\text {JPstand }}=\mu_{G E s t a n d} \\
& H_{1}: \mu_{\text {JPstand }}>\mu_{G E s t a n d} \\
& H_{0}: \mu_{\text {JPstand }}=\mu_{U S s t a n d} \\
& H_{1}: \mu_{\text {JPstand }}>\mu_{U S \text { stand }} \\
& H_{0}: \mu_{G E \text { stand }}=\mu_{U S \text { stand }} \\
& H_{1}: \mu_{G E s t a n d}>\mu_{U S s t a n d}
\end{aligned}
$$

In the next step, the luxury car makers are compared with each other, leading to the following sub-hypotheses:

$$
\begin{aligned}
& H_{0}: \mu_{\text {JPlux }}=\mu_{\text {GElux }} \\
& H_{1}: \mu_{\text {JPlux }}>\mu_{\text {GElux }}
\end{aligned}
$$




$$
\begin{aligned}
& H_{0}: \mu_{J P l u x}=\mu_{U S l u x} \\
& H_{1}: \mu_{J P l u x}>\mu_{U S l u x} \\
& H_{0}: \mu_{G E l u x}=\mu_{U S l u x} \\
& H_{1}: \mu_{G E l u x}>\mu_{U S l u x}
\end{aligned}
$$

Finally, the standard overall and luxury overall makers are compared with each other:

$$
\begin{aligned}
& H_{0}: \mu_{\text {stand }}=\mu_{\text {lux }} \\
& H_{1}: \mu_{\text {stand }}>\mu_{\text {lux }}
\end{aligned}
$$

\section{Japanese delivery time is lower than German or American delivery time}

Based on chapter 2 it is expected that JP makers have the lowest standard lead time (delivery time) as their processes are fast, effective and lean. This hypothesis aims to prove this finding. At first, Japanese makers will be compared to German makers, leading to the following sub-hypothesis:

$$
\begin{aligned}
& H_{0}: \mu_{\text {JPtime }}=\mu_{\text {GEtime }} \\
& H_{1}: \mu_{\text {JPtime }}<\mu_{\text {GEtime }}
\end{aligned}
$$

The null-hypothesis states that the delivery time at JP makers and GE makers is the same, whereas $H_{1}$ means that JP makers have a lower lead time than GE makers. After that, JP and US makers are compared: 


$$
\begin{aligned}
& H_{0}: \mu_{\text {JPtime }}=\mu_{\text {UStime }} \\
& H_{1}: \mu_{\text {JPtime }}<\mu_{\text {UStime }}
\end{aligned}
$$

The following hypothesis is chosen to compare German and US delivery times:

$$
\begin{aligned}
& H_{0}: \mu_{\text {GEtime }}=\mu_{\text {UStime }} \\
& H_{1}: \mu_{\text {GEtime }}<\mu_{\text {UStime }}
\end{aligned}
$$

In the next step, the standard car makers are compared with each other, leading to the following sub-hypotheses:

$$
\begin{aligned}
& H_{0}: \mu_{\text {JPtimestand }}=\mu_{\text {GEtimestand }} \\
& H_{1}: \mu_{\text {JPtimestand }}<\mu_{\text {GEtimestand }} \\
& H_{0}: \mu_{\text {JPtimestand }}=\mu_{\text {UStimestand }} \\
& H_{1}: \mu_{\text {JPtimestand }}<\mu_{\text {UStimestand }} \\
& H_{0}: \mu_{\text {GEtimestand }}=\mu_{\text {UStimestand }} \\
& H_{1}: \mu_{\text {GEtimestand }}<\mu_{\text {UStimestand }}
\end{aligned}
$$

In the next step, the luxury car makers are compared with each other, leading to the following sub-hypotheses: 


$$
\begin{aligned}
& H_{0}: \mu_{\text {JPtimelux }}=\mu_{\text {UStimelux }} \\
& H_{1}: \mu_{\text {JPtimelux }}<\mu_{\text {UStimelux }} \\
& H_{0}: \mu_{\text {JPtimelux }}=\mu_{\text {GEtimelux }} \\
& H_{1}: \mu_{\text {JPtimelux }}<\mu_{\text {GEtimelux }} \\
& H_{0}: \mu_{\text {GEtimelux }}=\mu_{\text {UStimelux }} \\
& H_{1}: \mu_{\text {GEtimelux }}<\mu_{\text {UStimelux }}
\end{aligned}
$$

Finally, the standard and luxury makers are compared with each other:

$$
\begin{aligned}
& H_{0}: \mu_{\text {timestand }}=\mu_{\text {timelux }} \\
& H_{1}: \mu_{\text {timestand }}<\mu_{\text {timelux }}
\end{aligned}
$$

\section{German car makers have a lower percentage of cars sold from inventory}

This hypothesis aims to prove the common fact that German car makers use more build-to-order approaches instead of make-to-stock and therefore sell less inventory-based vehicles than JP and US makers. Therefore, it is expected that their percentage of vehicles sold from the inventory is lower than at JP or US makers. Consequently, the first sub-hypothesis is: 


$$
\begin{aligned}
& H_{0}: \mu_{G E \%}=\mu_{J P \%} \\
& H_{1}: \mu_{G E \%}<\mu_{J P \%}
\end{aligned}
$$

For the US and GE, the sub-hypothesis is:

$$
\begin{aligned}
& H_{0}: \mu_{G E \%}=\mu_{U S \%} \% \\
& H_{1}: \mu_{G E \%}<\mu_{U S \%}
\end{aligned}
$$

And the US is also compared to Japan:

$$
\begin{aligned}
& H_{0}: \mu_{U S \%}=\mu_{J P \%} \\
& H_{1}: \mu_{U S \%}<\mu_{J P \%}
\end{aligned}
$$

In the next step, the standard car makers are compared with each other, leading to the following sub-hypotheses:

$$
\begin{aligned}
& H_{0}: \mu_{G E \% \text { stand }}=\mu_{J P \% \text { stand }} \\
& H_{1}: \mu_{G E \% \text { stand }}<\mu_{J P \% \text { stand }} \\
& H_{0}: \mu_{G E \% \text { stand }}=\mu_{U S \% s t a n d} \\
& H_{1}: \mu_{G E \% \text { stand }}<\mu_{U S \% s t a n d} \\
& H_{0}: \mu_{J P \% \text { stand }}=\mu_{U S \% \text { stand }} \\
& H_{1}: \mu_{J P \% \text { stand }}>\mu_{U S \% \text { stand }}
\end{aligned}
$$


In the next step, the luxury car makers are compared with each other, leading to the following sub-hypotheses:

$$
\begin{aligned}
& H_{0}: \mu_{G E \% l u x}=\mu_{J P \% l u x} \\
& H_{1}: \mu_{G E \% l u x}<\mu_{J P \% l u x} \\
& H_{0}: \mu_{G E \% l u x}=\mu_{U S \% l u x} \\
& H_{1}: \mu_{G E \% l u x}<\mu_{U S \% l u x} \\
& H_{0}: \mu_{J P \% l u x}=\mu_{U S \% l u x} \\
& H_{1}: \mu_{J P \% l u x}>\mu_{U S \% l u x}
\end{aligned}
$$

Finally, the standard and luxury makers are compared with each other:

$$
\begin{aligned}
& H_{0}: \mu_{\text {stand } \%}=\mu_{\text {lux } \%} \\
& H_{1}: \mu_{\text {stand } \%}<\mu_{\text {lux } \%}
\end{aligned}
$$

\section{The MSRP of Japanese standard and premium makers is the lowest compared to US or GE car makers}

This hypothesis aims to prove the common fact that JP car makers do not only offer a great variety of different model but also very competitive and inexpensive prices. Therefore, it is expected that the average JP MSRP is lower than of GE or US makers. Consequently, the first sub-hypothesis is: 


$$
\begin{aligned}
& H_{0}: \mu_{J P M S R P}=\mu_{G E M S R P} \\
& H_{1}: \mu_{J P M S R P}<\mu_{G E M S R P} \\
& H_{0}: \mu_{J P M S R P}=\mu_{U S M S R P} \\
& H_{1}: \mu_{J P M S R P}<\mu_{U S M S R P} \\
& H_{0}: \mu_{G E M S R P}=\mu_{U S M S R P} \\
& H_{1}: \mu_{G E M S R P}<\mu_{U S M S R P}
\end{aligned}
$$

Standard makers:

$$
\begin{aligned}
& H_{0}: \mu_{J P s t a n d M S R P}=\mu_{G E s t a n d M S R P} \\
& H_{1}: \mu_{J P s t a n d M S R P}<\mu_{\text {GEstandMSRP }} \\
& H_{0}: \mu_{J P s t a n d M S R P}=\mu_{U S s t a n d M S R P} \\
& H_{1}: \mu_{J P s t a n d M S R P}<\mu_{U S \operatorname{standMSRP}}
\end{aligned}
$$




$$
\begin{gathered}
H_{0}: \mu_{\text {GEstandMSRP }}=\mu_{\text {USstandMSRP }} \\
H_{1}: \mu_{\text {GEstandMSRP }}<\mu_{\text {USstandMSRP }}
\end{gathered}
$$

Luxury makers:

$$
\begin{aligned}
& H_{0}: \mu_{\text {JPluxMSRP }}=\mu_{\text {GEluxMSRP }} \\
& H_{1}: \mu_{\text {JPluxMSRP }}<\mu_{\text {GEluxMSRP }} \\
& H_{0}: \mu_{\text {JPluxMSRP }}=\mu_{\text {USluxMSRP }} \\
& H_{1}: \mu_{\text {JPluxMSRP }}<\mu_{\text {USluxMSRP }} \\
& H_{0}: \mu_{\text {GEluxMSRP }}=\mu_{\text {USluxMSRP }} \\
& H_{1}: \mu_{\text {GEluxMSRP }}<\mu_{U S l u x M S R P}
\end{aligned}
$$

\section{German makers have the most extended dealer options}

As part of their build-to-order strategy, German car makers offer a huge variety of different options that customers can choose when they design their own car. With this question, it is tested whether GE dealerships do also offer a higher and more extended variety of different dealer options than their JP and US competitors. In order to do so, three different types of dealer options are distinguished. The first type is the basic one. It contains a limited amount of standard, inexpensive cosmetic options such as the installation of roof racks, a tow hitch, a navigation system, a remote starter, mats and 
rugs, bigger wheels and spoilers. Car dealerships that answer question 6 from the questionnaire by indicating that they do not have many dealer options and then list a couple of the named options, are considered as offering basic options. Also makers that offer packages instead of single options will be part of that group. The second group (extended) contains dealerships that offer advanced, more expensive cosmetic options to their packages such as heated seats, leather, a moon roof and air ride suspensions. The third group, extended plus, also offers performance and tuning packages and usually has basic and extended options as packages. Depending on the category of the answer, the dealership might either get 1,2 or 3 points (first, second or third group). Furthermore, standard and luxury makers are distinguished. At the end, all points are summed and the average value is calculated. The average gives a tendency of the dealer options offered by the different makers also distinguished by standard and luxury makers. In order to compare the different car dealerships with each other, a 2 sample ttest is used to statistically determine significant differences. First, JP and GE car dealerships are compared with each other. In order to do so, a null-hypothesis needs to be defined. As it is assumed that the average German car dealership offers more extended dealer options, the alternate hypothesis is $\mu_{\text {JPoptn }}<\mu_{\text {GEoptn }}$

$$
\begin{aligned}
& H_{0}: \mu_{\text {JPoptn }}=\mu_{\text {GEopt } n} \\
& H_{1}: \mu_{\text {JPoptn }}<\mu_{\text {GEoptn }}
\end{aligned}
$$




$$
\begin{aligned}
& H_{0}: \mu_{\text {USoptn }}=\mu_{\text {GEoptn }} \\
& H_{1}: \mu_{\text {USoptn }}<\mu_{\text {GEoptn }}
\end{aligned}
$$

$$
\begin{aligned}
& H_{0}: \mu_{\text {USoptn }}=\mu_{\text {JPoptn }} \\
& H_{1}: \mu_{\text {USoptn }}<\mu_{\text {JPoptn }}
\end{aligned}
$$

Now standard makers are considered:

$$
\begin{aligned}
& H_{0}: \mu_{\text {JPstandoptn }}=\mu_{\text {GEstandoptn }} \\
& H_{1}: \mu_{\text {JPstandoptn }}<\mu_{\text {GEstandoptn }} \\
& H_{0}: \mu_{\text {USstandoptn }}=\mu_{\text {GEstandoptn }} \\
& H_{1}: \mu_{\text {USstandoptn }}<\mu_{\text {GEstandoptn }} \\
& H_{0}: \mu_{\text {UStandoptn }}=\mu_{\text {JPstandoptn }} \\
& H_{1}: \mu_{\text {UStandoptn }}<\mu_{\text {JPstandoptn }}
\end{aligned}
$$

Now luxury makers are considered: 


$$
\begin{aligned}
& H_{0}: \mu_{\text {JPluxoptn }}=\mu_{\text {GEluxoptn }} \\
& H_{1}: \mu_{\text {JPluxoptn }}<\mu_{\text {GEluxptn }} \\
& H_{0}: \mu_{\text {USluxoptn }}=\mu_{\text {GEluxoptn }} \\
& H_{1}: \mu_{\text {USluxoptn }}<\mu_{\text {GEluxoptn }} \\
& H_{0}: \mu_{\text {USluxoptn }}=\mu_{\text {JPluxoptn }} \\
& H_{1}: \mu_{\text {USluxoptn }}<\mu_{\text {JPluxoptn }}
\end{aligned}
$$

\section{Japanese car dealerships sell the most cars per dealership compared to US or GE car dealerships}

This hypothesis aims to prove one of Womack, Jones and Roos findings (1990). It is a common belief that JP car dealerships are leaner and therefore more effective and faster than GE and US car dealerships. In order to determine how fast and efficient dealerships are, Womack, Jones and Roos (1990) calculated the annual sales volume per dealership. For this study, the annual US sales volume is divided by the number of dealerships in the US. The higher the number, the more vehicles are sold and the more effective the dealership network is. Based on the average dealer inventory, the inventory turns can be calculated and compared to Staeblein and Aoki's (2015) findings. Based 
on the definition in chapter 2 , the inventory turns are defined as $\frac{\text { Throughput }}{\text { Average Inventory }}$ or in this case as $\frac{\text { Cars sold per dealership }}{\text { Cars on the lot }}$

\section{Japanese makers follow a significantly different approach in personnel training than US or GE car dealerships}

Following the results from Womack, Jones and Roos (1990), part of the success of Japanese car makers was the idea of continuous improvement, not only in terms of production but also in personnel training. Japanese makers made personnel training as a crucial part of their business system and implemented it in a lean and efficient way. This hypothesis aims to prove this finding by comparing the different personnel training strategies. In order to do so, a methodology similar to the previous hypothesis is used. The training methods and strategies listed by the dealerships in the interview are classified in three different categories: Category 1 contains "online in-store and rarely out-of-store"-training methods where the dealership usually trains personnel in-store and online. Category 2 contains a "both online in-store and out-of-store on a regular basis" strategy where car dealerships follow a mix of in-store and out-of-store trainings. Category 3-dealerships follow a "usually off-site at special training facilities, rarely instore training"-strategy. Depending on which strategy the dealership follows, it gets 1 , 2 or 3 points. At the end, all points are summed and the average value is calculated. In order to compare the different strategies, several sub-hypotheses are defined and the results of a 2-paired t-test are used to draw conclusions. 
First, a null hypothesis for the JP and GE car dealerships is needed. As an alternate sub-hypothesis it is randomly taken that JP car dealerships have a lower score than GE car dealerships:

$$
\begin{aligned}
& H_{0}: \mu_{\text {JPtrain }}=\mu_{\text {GEtrain }} \\
& H_{1}: \mu_{\text {JPtrain }}<\mu_{\text {GEtrain }} \\
& H_{0}: \mu_{\text {JPtrain }}=\mu_{\text {UStrain }} \\
& H_{1}: \mu_{\text {JPtrain }}<\mu_{\text {UStrain }} \\
& H_{0}: \mu_{\text {GEtrain }}=\mu_{\text {UStrain }} \\
& H_{1}: \mu_{\text {GEtrain }}<\mu_{\text {UStrain }}
\end{aligned}
$$

Now standard makers are considered:

$$
\begin{aligned}
& H_{0}: \mu_{\text {JPstandtrain }}=\mu_{\text {GEstandtrain }} \\
& H_{1}: \mu_{\text {JPstandtrain }}<\mu_{\text {GEstandtrain }} \\
& H_{0}: \mu_{\text {JPstandtrain }}=\mu_{\text {USstandtrain }} \\
& H_{1}: \mu_{\text {JPstandtrain }}<\mu_{\text {USstandtrain }}
\end{aligned}
$$




$$
\begin{aligned}
& H_{0}: \mu_{\text {GEstandtrain }}=\mu_{\text {UStandtrain }} \\
& H_{1}: \mu_{\text {GEstandtrain }}<\mu_{\text {UStandtrain }}
\end{aligned}
$$

Now luxury makers are considered:

$$
\begin{aligned}
& H_{0}: \mu_{\text {JPluxtrain }}=\mu_{\text {GEluxtrain }} \\
& H_{1}: \mu_{\text {JPluxtrain }}<\mu_{\text {GEluxtrain }} \\
& H_{0}: \mu_{\text {JPluxtrain }}=\mu_{U S l u x t r a i n} \\
& H_{1}: \mu_{J P l u x t r a i n}<\mu_{U S l u x t r a i n} \\
& H_{0}: \mu_{\text {GEluxtrain }}=\mu_{U S l u x t r a i n} \\
& H_{1}: \mu_{\text {GEluxtrain }}<\mu_{U S l u x t r a i n} \\
& H_{0}: \mu_{\text {trainstand }}=\mu_{\text {trainlux }} \\
& H_{1}: \mu_{\text {trainstand }}<\mu_{\text {trainlux }}
\end{aligned}
$$




\section{Japanese car dealerships offer the best warranty models}

This hypothesis is derived from the fact that Japanese car makers are usually leaders in several customer satisfaction indexes. Therefore, it is assumed that their warranty models are better than those of their competitors. In question 14 of the survey, the car dealerships are asked about the warranty models they offer. As a result, the different offers of "bumper-to-bumper"- and powertrain and engine-warranties will be compared in terms of mileage and years and plotted. Always the best offer of JP, GE and US car dealerships will be compared to the others and eventually the best overall warranty will be identified. It is expected that JP makers, both luxury and standard, offer the highest mileage and highest amount of years of coverage.

\section{Japanese car dealerships are more customer-related than their US and GE competitors}

In the literature it has been said that JP car makers and their dealerships focus more on their customers compared to their GE and US competitors and that is why they usually receive top rankings in various customer satisfaction indexes. In order to prove that, all 24 different interviews will be analyzed in terms of important key words that the participants use. Based on this analysis, these words will be grouped into different categories and on the basis of the percentual distribution of these categories, conclusions will be drawn. 


\section{Japanese makers are leading in e-mobility}

With this last hypothesis the researcher wants to determine whether JP car makers are not only leading in terms of lean manufacturing but also have the best products and technologies for the e-mobility. Therefore, the relatively open-ended questions 16 and 17 are analyzed in terms of key words and repetitive expressions. The answers to these questions will be scaled between -1 and 1 whereas -1 means that the dealership is totally opposed to the use of EVs (electric vehicles) and PHEV (plug-in hybrid electric vehicle) s as part of their brand's future and 1 is the most positive answer. Based on this analysis different conclusions will be drawn.

After defining 10 different hypotheses, Table 7 gives an overview of all hypothesis and sub-hypothesis. For the results in chapter 4, this table will be expanded by two more columns that show the calculated p-value and the results in words. 
Table 7: All hypotheses and sub-hypothesis summarized

\begin{tabular}{|c|c|c|}
\hline Hypothesis & \multicolumn{2}{|c|}{ Sub-hypothesis } \\
\hline \multirow{8}{*}{$\begin{array}{l}\text { Japanese car } \\
\text { makers offer } \\
\text { more models } \\
\text { than Germans } \\
\text { or Americans } \\
\text { do }\end{array}$} & 1.a & $\begin{array}{l}H_{0}: \mu_{J P}=\mu_{G E} \\
H_{1}: \mu_{J P}>\mu_{G E}\end{array}$ \\
\hline & $1 . b$ & $\begin{array}{l}H_{0}: \mu_{J P}=\mu_{U S} \\
H_{1}: \mu_{J P}>\mu_{U S}\end{array}$ \\
\hline & 1.c & $\begin{array}{l}H_{0}: \mu_{G E}=\mu_{U S} \\
H_{1}: \mu_{G E}>\mu_{U S}\end{array}$ \\
\hline & 1.d & $\begin{array}{l}H_{0}: \mu_{J P s t a n d}=\mu_{G E s t a n d} \\
H_{1}: \mu_{J P s t a n d}>\mu_{G E s t a n d}\end{array}$ \\
\hline & 1.e & $\begin{array}{l}H_{0}: \mu_{\text {JPstand }}=\mu_{\text {UStand }} \\
H_{1}: \mu_{\text {JPstand }}>\mu_{U S s t a n d}\end{array}$ \\
\hline & 1.f & $\begin{array}{l}H_{0}: \mu_{G E s t a n d}=\mu_{U S s t a n d} \\
H_{1}: \mu_{G E s t a n d}>\mu_{U S s t a n d}\end{array}$ \\
\hline & $1 . \mathrm{g}$ & $\begin{array}{l}H_{0}: \mu_{\text {JPlux }}=\mu_{\text {GElux }} \\
H_{1}: \mu_{\text {JPlux }}>\mu_{G E l u x}\end{array}$ \\
\hline & {$[\ldots]$} & {$[\ldots]$} \\
\hline$[\ldots]$ & {$[\ldots]$} & {$[\ldots]$} \\
\hline
\end{tabular}




\section{CHAPTER 4}

\section{FINDINGS}

The following chapter contains the results that were found. The 10 hypotheses made in chapter 3 are checked and the results will be summarized in tables after each hypothesis. The analysis of the first hypothesis and its sub-hypotheses will be explained in detail, whereas the explanation of the other hypothesis testing will be less detailed in order to avoid duplication of writing.

\subsection{Hypothesis 1}

\section{Japanese car makers offer more models than Germans or Americans do}

Table 8 shows the different JP, GE and US makers that were interviewed and the number of models they sell in the US. It is basically the answer to question 2 . In the 8 different interviews at JP, GE and US car dealerships, 7 different JP brands, 4 different GE brands and 10 different US brands were interviewed. US makers are special because compared to their JP and GE competitors, they sometimes offer more than one brand at one dealership such as Dodge, Ram, Chrysler \& Jeep or Buick \& GMC. That is why there are more brands interviewed than the number of interviews. Out of these 7 JP makers, 2 were luxury and the other 5 were standard. For the GE, 3 were luxury and 1 standard and for the US, 3 were luxury and 7 were standard. Table 8 also gives the mean value of different models $\mu$ and the standard deviation $\sigma$. Therefore, the average JP maker offers 13 different models, compared to 14 different models at an average GE maker and only 8 at a US maker. However, GE makers not only have the highest mean but also the smallest standard deviation compared to US makers that have the lowest 
mean value and the highest standard deviation. That means that the various US brands have a significantly different amount of models compared to the Germans where the makers seem to have a more similar amount of different models. These results can also be seen in figure 13 that illustrates the worst (lowest amount of models), the best (highest amount of models) and the average amount of models for the different makers. Figure 14 and 15 give an overview of the standard and luxury makers.

Table 8: Number of different models at JP, GE and US car makers, luxury makers are bold

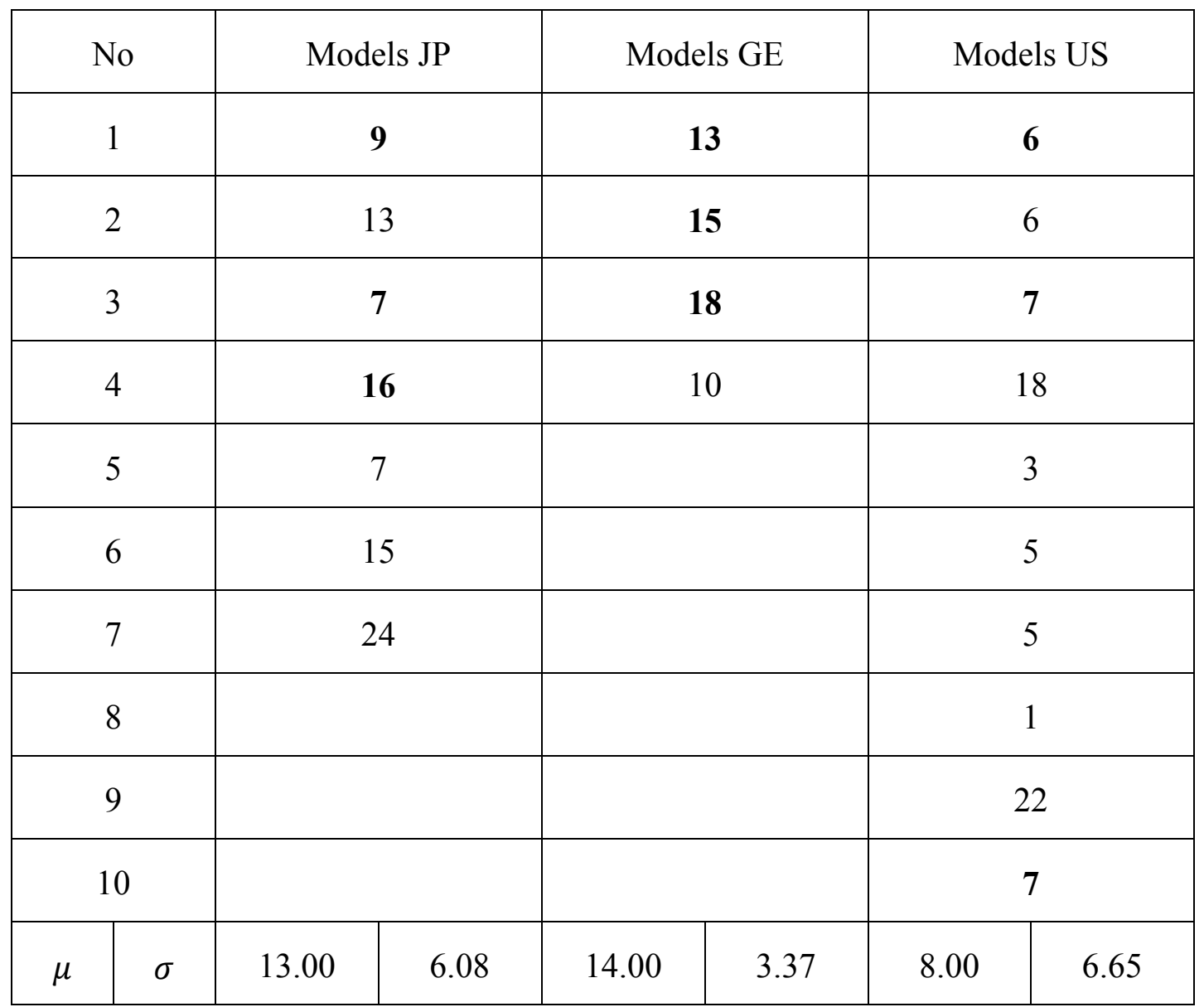




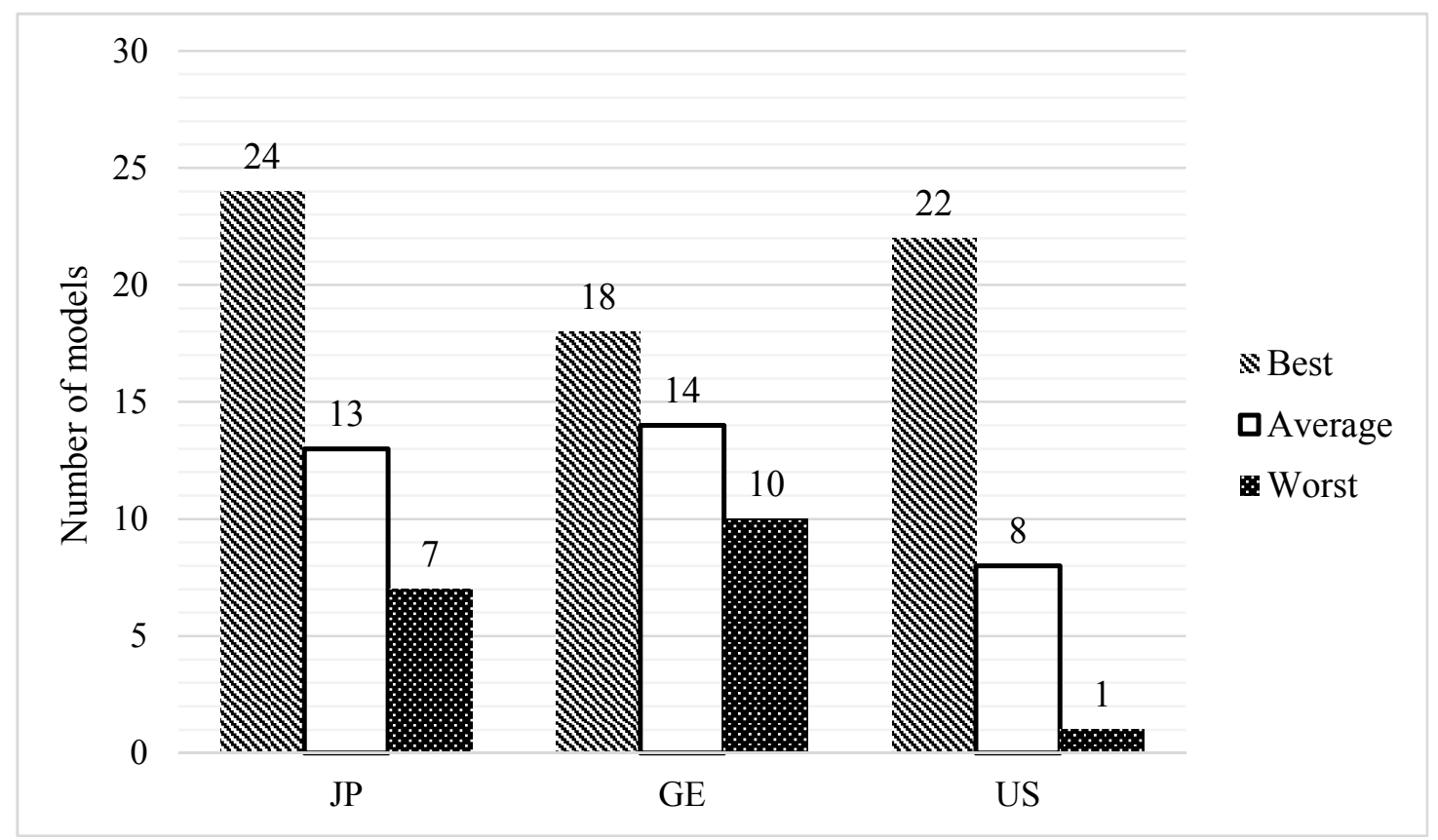

Figure 13: Number of models offered by car manufacturers, every maker

Based on figure 16 and 17 , one can see that the results look different when standard and luxury makers are distinguished. According to figure 14, JP standard makers have the highest mean of number of models, whereas US standard makers have the lowest mean of numbers of different models. Furthermore, figure 14 underlines the finding that the different US standard makers have a huge variety of numbers of models that they offer ( 1 to 22 different models). As there is only one standard GE car maker, the standard deviation is 0 . Figure 15 shows the number of models of luxury makers. Except for the GE luxury makers, the average number of models offered by luxury makers is lower than by standard makers. Furthermore, the spread between lowest and highest number of models offered by the maker is much lower for the US luxury makers in particular. 


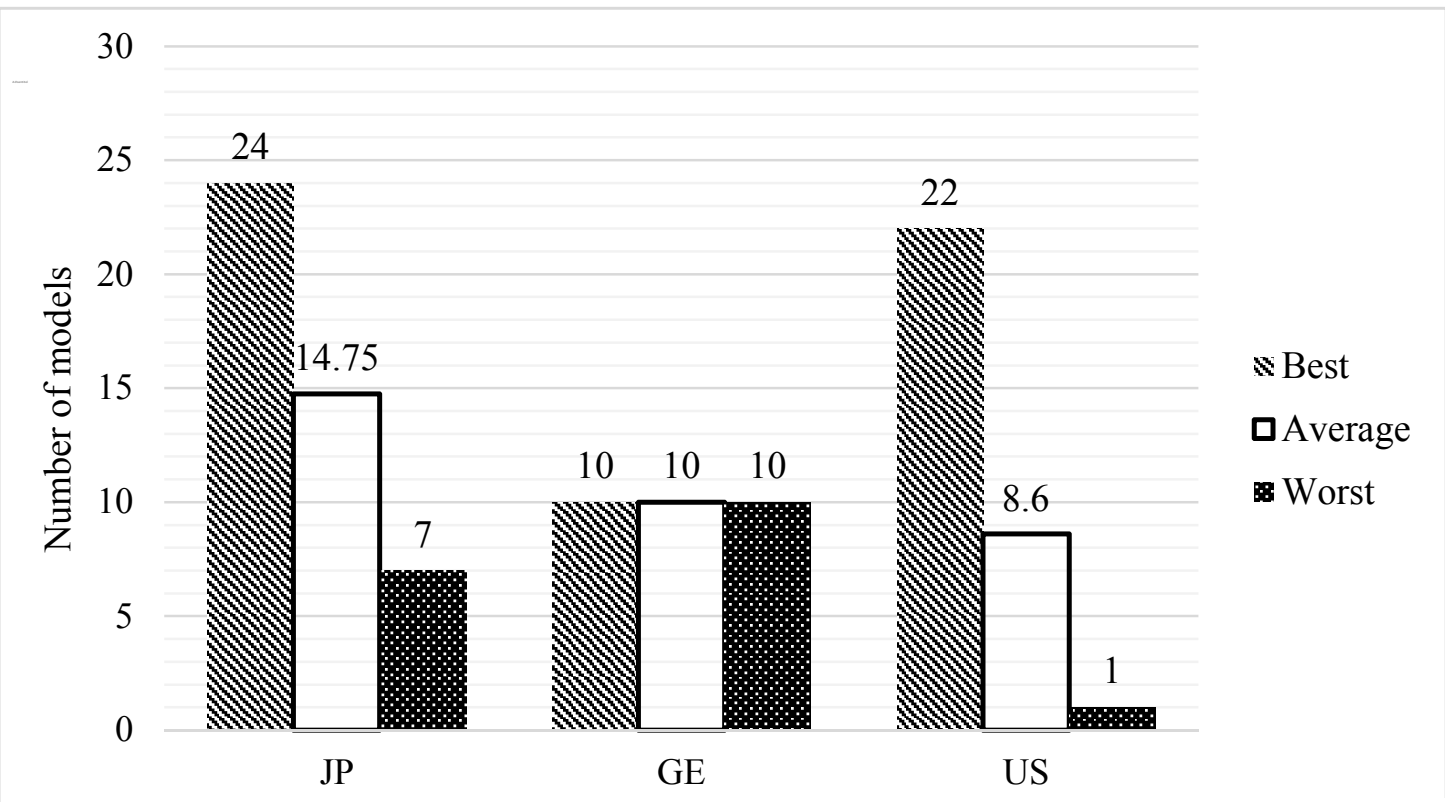

Figure 14: Number of models offered by car manufacturers, standard

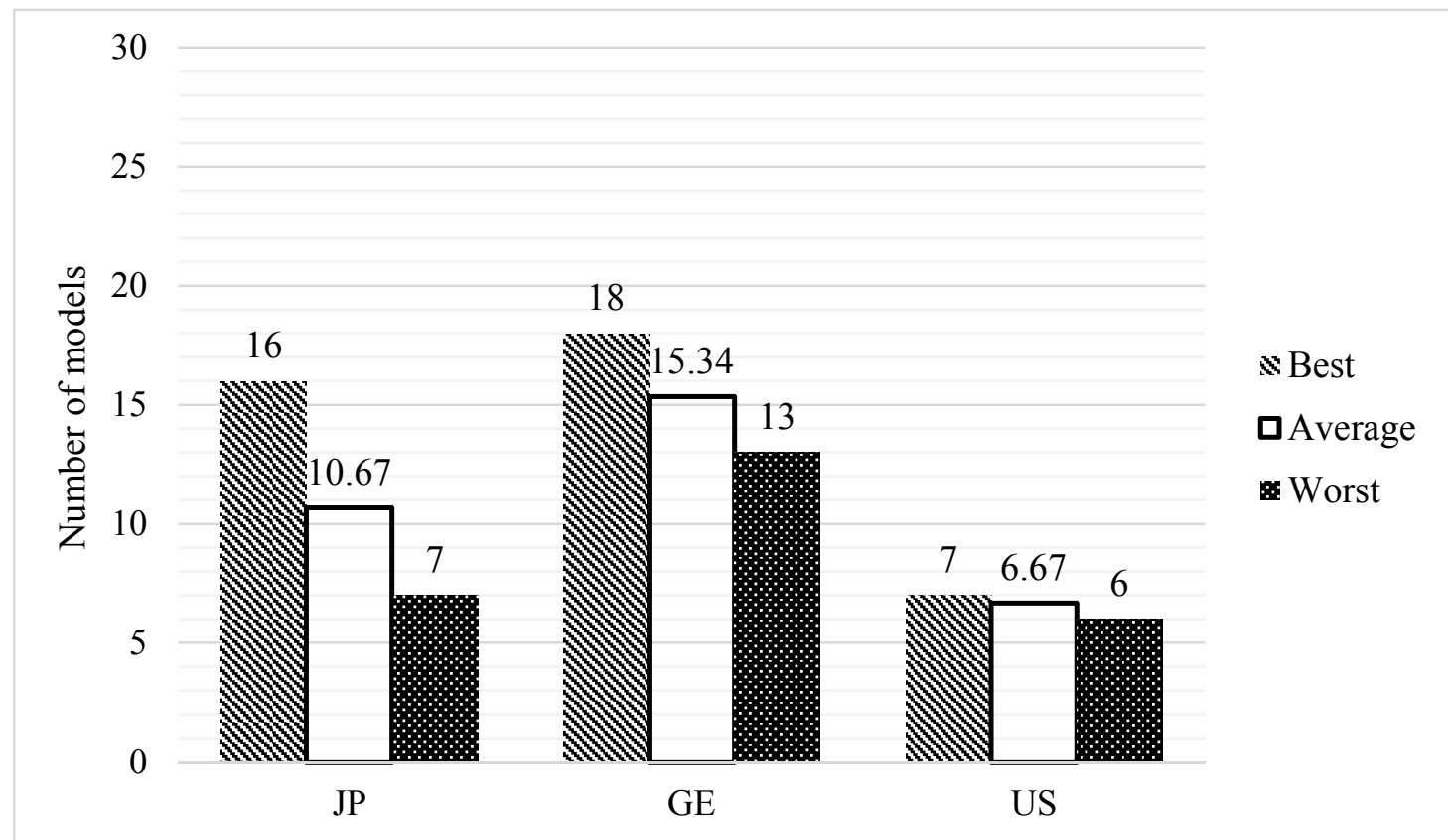

Figure 15: Number of models offered by car manufacturers, luxury 
In order to be able to find statistically significant data, chapter 3 described how sub-hypotheses were tested. First, sub-hypothesis 1 .a will be tested, using a two-sample t-test for models JP and models GE:

$$
\begin{aligned}
& H_{0}: \mu_{J P}=\mu_{G E} \\
& H_{1}: \mu_{J P}>\mu_{G E}
\end{aligned}
$$

Figure 16 shows the output window from Minitab with mean, stdev and p-value.

\title{
Two-Sample T-Test and Cl: models JP; models GE
}

\author{
Method \\ $\mu_{1}$ : mean of models JP \\ $\mu_{2}$ : mean of models $\mathrm{GE}$ \\ Difference: $\mu_{1}-\mu_{2}$ \\ Equal variances are not assumed for this analysis. \\ Descriptive Statistics

\begin{tabular}{lrrrr} 
Sample & N & Mean & StDev & SE Mean \\
\hline models JP & 7 & 13,00 & 6,08 & 2,3 \\
models GE & 4 & 14,00 & 3,37 & 1,7
\end{tabular} \\ Estimation for Difference

\begin{tabular}{rr} 
Difference & $\begin{array}{r}90 \% \text { Lower Bound } \\
\text { for Difference }\end{array}$ \\
\hline$-1,00$ & $-4,98$
\end{tabular}

\section{Test}

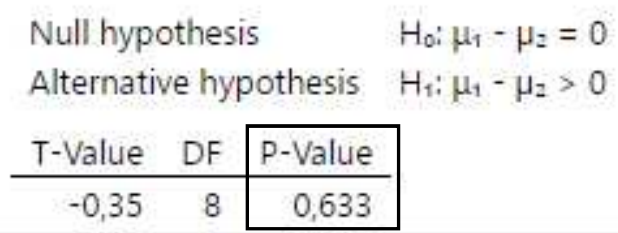

Figure 16: Minitab output for two-sample t-test comparison models JP and models GE 
As seen in figure 16, the p-value equals to 0.633 . As the p-value is larger than $\alpha=0.10$, the test failed to reject $H_{0}$ and therefore, $H_{0}$ is true. This means that there is no significant difference between the amount of models offered at Japanese and German car dealerships.

The next test is a two-sample t-test for models JP and models US. Here subhypothesis $1 . b$ is used:

$$
\begin{aligned}
& H_{0}: \mu_{J P}=\mu_{U S} \\
& H_{1}: \mu_{I P}>\mu_{U S}
\end{aligned}
$$

\begin{tabular}{|c|c|c|}
\hline \multirow{2}{*}{\multicolumn{3}{|c|}{$\begin{array}{l}\text { Null hypothesis } \\
\text { Alternative hypothesis }\end{array}$}} \\
\hline & & \\
\hline$T$-Value & DF & $P$-value \\
\hline 1,60 & 13 & 0,066 \\
\hline
\end{tabular}

Test

Figure 17: Test section of the Minitab output window

As seen in figure 17, Minitab calculates a p-value of 0.066 . The p-value is smaller than $\alpha$ which means that $H_{0}$ is to be rejected and $H_{0}$ is false. Consequently, $H_{1}$ is true and the amount of models at Japanese makers is larger than at US makers. Following these steps, sub-hypotheses 1.c, 1.d, 1.e, 1.f, 1.g, 1.h, 1.i, and 1.j will be checked by the same procedure and table 9 shows the results of hypothesis 1 . If the pvalue is between 0.10 and 0.12 , the alternate hypothesis cannot be fully denied, but there is still a certain tendency. That is why p-values between 0.10 and 0.12 are considered as "moderately significant" and the alternate hypothesis tends to be true. Significant pvalues are colored grey, moderately significant light grey. 
Table 9: JP makers offer more models than US or GE, summary

\begin{tabular}{|c|c|c|c|}
\hline \multicolumn{2}{|r|}{ Sub-hypothesis } & p-value & Conclusion \\
\hline 1.a & $\begin{array}{l}H_{0}: \mu_{J P}=\mu_{G E} \\
H_{1}: \mu_{J P}>\mu_{G E}\end{array}$ & 0.633 & $\begin{array}{l}\text { No significant difference between } \\
\text { the amount of models offered at JP } \\
\text { and GE car dealerships }\end{array}$ \\
\hline $1 . b$ & $\begin{array}{l}H_{0}: \mu_{J P}=\mu_{U S} \\
H_{1}: \mu_{J P}>\mu_{U S}\end{array}$ & 0.066 & $\begin{array}{l}\text { JP car dealerships offer significantly } \\
\text { more models than US car } \\
\text { dealerships }\end{array}$ \\
\hline 1.c & $\begin{array}{l}H_{0}: \mu_{G E}=\mu_{U S} \\
H_{1}: \mu_{G E}>\mu_{U S}\end{array}$ & 0.025 & $\begin{array}{l}\text { GE car dealerships offer } \\
\text { significantly more models than US } \\
\text { car dealerships }\end{array}$ \\
\hline 1.d & $\begin{array}{l}H_{0}: \mu_{J P s t a n d}=\mu_{G E s t a n d} \\
H_{1}: \mu_{J P s t a n d}>\mu_{G E s t a n d}\end{array}$ & 0.135 & $\begin{array}{l}\text { No significant difference between } \\
\text { the amount of models offered at JP } \\
\text { and GE standard car dealerships }\end{array}$ \\
\hline 1.e & $\begin{array}{l}H_{0}: \mu_{\text {JPstand }}=\mu_{U S s t a n d} \\
H_{1}: \mu_{\text {JPstand }}>\mu_{U \text { Sstand }}\end{array}$ & 0.113 & $\begin{array}{l}\text { JP standard car dealerships tend to } \\
\text { offer more models than US standard } \\
\text { car dealerships }\end{array}$ \\
\hline 1.f & $\begin{array}{l}H_{0}: \mu_{G E s t a n d}=\mu_{U S s t a n d} \\
H_{1}: \mu_{G E s t a n d}>\mu_{U S s t a n d}\end{array}$ & 0.328 & $\begin{array}{l}\text { No significant difference between } \\
\text { the amount of models offered at GE } \\
\text { and US standard car dealerships }\end{array}$ \\
\hline $1 . g$ & $\begin{array}{l}H_{0}: \mu_{J P l u x}=\mu_{G E l u x} \\
H_{1}: \mu_{J P l u x}>\mu_{G E l u x}\end{array}$ & $\begin{array}{c}0.886 \\
\text { (alternate } \\
0.114)\end{array}$ & $\begin{array}{l}\text { GE luxury car dealerships tend to } \\
\text { offer more models than JP luxury } \\
\text { car dealerships }\end{array}$ \\
\hline 1.h & $\begin{array}{l}H_{0}: \mu_{\text {JPlux }}=\mu_{U S l u x} \\
H_{1}: \mu_{J P l u x}>\mu_{U S l u x}\end{array}$ & 0.141 & $\begin{array}{l}\text { No significant difference between } \\
\text { the amount of models offered at JP } \\
\text { and US luxury car dealerships }\end{array}$ \\
\hline $1 . \mathrm{i}$ & $\begin{array}{l}H_{0}: \mu_{G E l u x}=\mu_{U S l u x} \\
H_{1}: \mu_{G E l u x}>\mu_{U S l u x}\end{array}$ & 0.014 & $\begin{array}{l}\text { GE luxury car dealerships offer } \\
\text { significantly more models than US } \\
\text { luxury car dealerships }\end{array}$ \\
\hline $1 . \mathrm{j}$ & $\begin{array}{l}H_{0}: \mu_{\text {stand }}=\mu_{\text {lux }} \\
H_{1}: \mu_{\text {stand }}>\mu_{\text {lux }}\end{array}$ & 0.52 & $\begin{array}{l}\text { No significant difference between } \\
\text { the amount of models offered at } \\
\text { standard and luxury car dealerships }\end{array}$ \\
\hline
\end{tabular}


Based on the results in table 9, it cannot be said that JP car makers offer more models than US or GE car dealerships in general. However, sub-hypothesis 1.b, 1.c, and 1.i were found to be significant. According to that, JP car dealerships offer significantly more models than US car dealerships, GE car dealerships offer significantly more models than US car dealerships and GE luxury car dealerships offer significantly more models than US luxury car dealerships. Moreover, 1.e and the alternate of 1.g showed some tendency, as their p-value is close to the $\alpha$-value. Therefore, JP standard car dealerships tend to offer more models than US standard car dealerships and GE luxury car dealerships tend to offer more models than JP luxury car dealerships. Thus, hypothesis 1 is only partly correct.

\subsection{Hypothesis 2}

\section{Japanese delivery time is lower than German or American delivery time}

Table 10 shows the delivery time of the different makers that were interviewed. Here, there are eight data points per nation because car dealerships that offer several brands would just give one answer for all of their brands. If the participants answered with a range, the middle value was taken. For example, if the answer was 6 to 10 weeks, 8 weeks would be taken. Luxury makers are bold printed. The first " 10 " in the US maker column is actually the answer of a dealership that offers standard and luxury brands. Therefore, the "10" counts both for US standard and US luxury makers.

Following the results from figure 18 , it becomes clear that the mean delivery time is comparable between the three different countries whereas the GE makers tend to have a slightly higher range of delivery time than their JP and US competitors. 
Furthermore, the spread between lowest (best) and highest (worst) delivery time is comparable between JP and US makers, only one GE car dealership indicated that the worst delivery time could be significantly higher than at JP or US car dealerships.

Table 10: Delivery time in weeks at JP, GE and US makers. Note: luxury makers are in bold, $\%$ means this maker does not offer delivery from manufacturer but only sells from the lot.

\begin{tabular}{|c|c|c|c|c|c|c|c|}
\hline \multicolumn{2}{|c|}{ Maker No } & \multicolumn{2}{|c|}{ JP } & \multicolumn{2}{|c|}{ GE } & \multicolumn{2}{|c|}{ US } \\
\hline & & \multicolumn{2}{|c|}{10} & \multicolumn{2}{|c|}{12} & \multicolumn{2}{|c|}{10} \\
\hline & & \multicolumn{2}{|c|}{12} & \multicolumn{2}{|c|}{5.5} & \multicolumn{2}{|c|}{7} \\
\hline & & \multicolumn{2}{|c|}{10} & \multicolumn{2}{|c|}{6.5} & \multicolumn{2}{|c|}{7} \\
\hline & & \multicolumn{2}{|c|}{5} & \multicolumn{2}{|c|}{9} & \multicolumn{2}{|c|}{6} \\
\hline & & \multicolumn{2}{|c|}{7} & \multicolumn{2}{|c|}{20} & \multicolumn{2}{|c|}{7} \\
\hline & & \multicolumn{2}{|c|}{6} & \multicolumn{2}{|c|}{8} & \multicolumn{2}{|c|}{7} \\
\hline & & \multicolumn{2}{|c|}{$\%$} & \multicolumn{2}{|c|}{8} & \multicolumn{2}{|c|}{10} \\
\hline & & \multicolumn{2}{|c|}{$\%$} & \multicolumn{2}{|c|}{$\%$} & \multicolumn{2}{|c|}{13} \\
\hline \multicolumn{8}{|c|}{9} \\
\hline \multicolumn{2}{|c|}{10} & & & & & & \\
\hline$\mu$ & $\sigma$ & 8.33 & 2.73 & 9.86 & 4.92 & 8.38 & 2.39 \\
\hline
\end{tabular}

Figure 19 shows the delivery time for the standard makers. Compared to the overall delivery time shown in figure 18, figure 19 indicates that there are larger differences in the mean delivery time between the different makers from JP, GE and the US. GE standard car makers seem to have the highest mean delivery time, whereas JP makers tend to have the lowest. Figure 20 shows the delivery time of the luxury makers. It can be seen that US and JP luxury car makers have a higher delivery time than their 
standard makers, whereas for the Germans, it is the other way around. Furthermore, the standard deviation between the best and worst delivery times at luxury makers is smaller than at the standard makers.

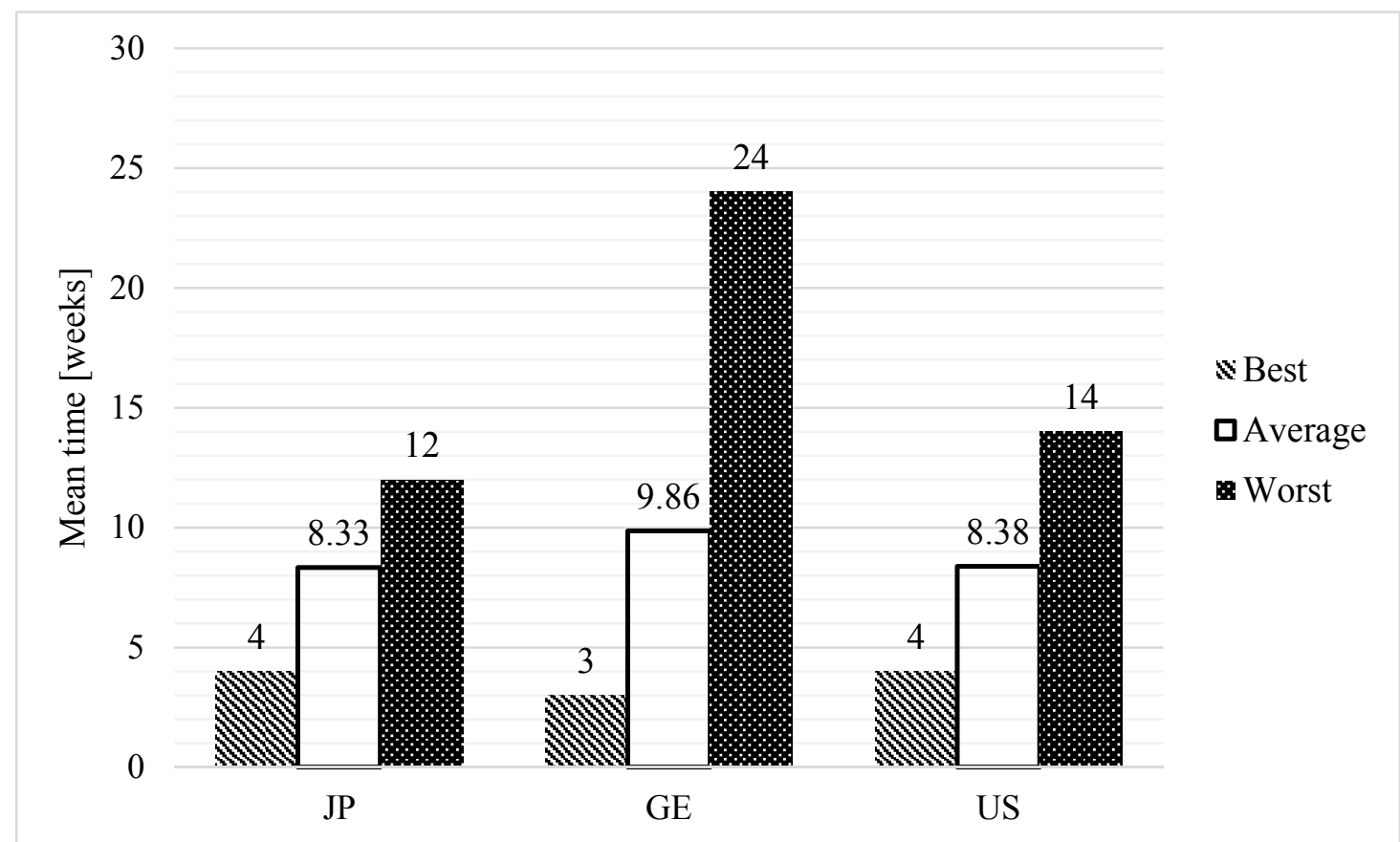

Figure 18: Time to get car after placing an order at the auto maker (mean time), all makers

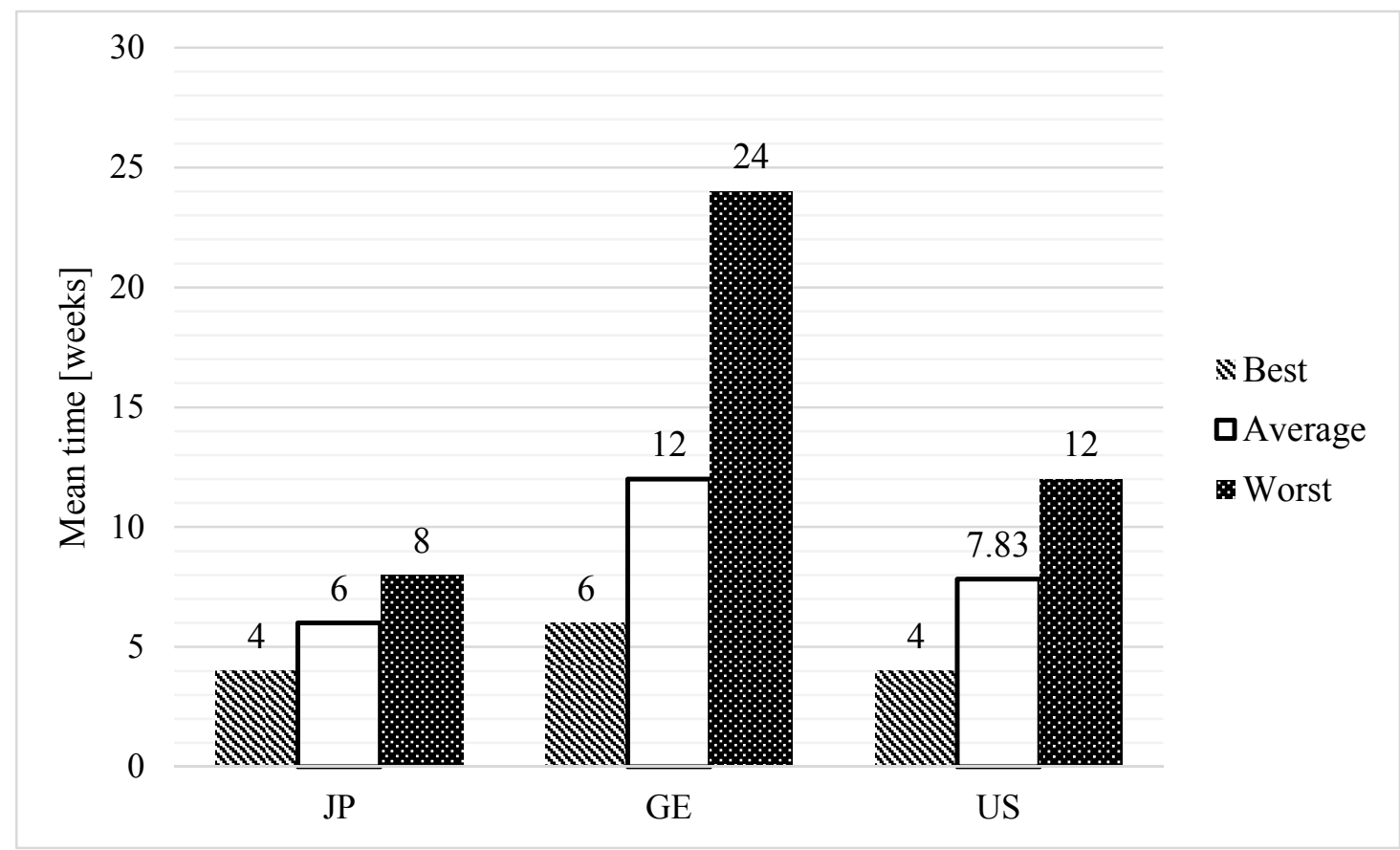

Figure 19: Time to get car after placing an order at the auto maker (mean time), standard 


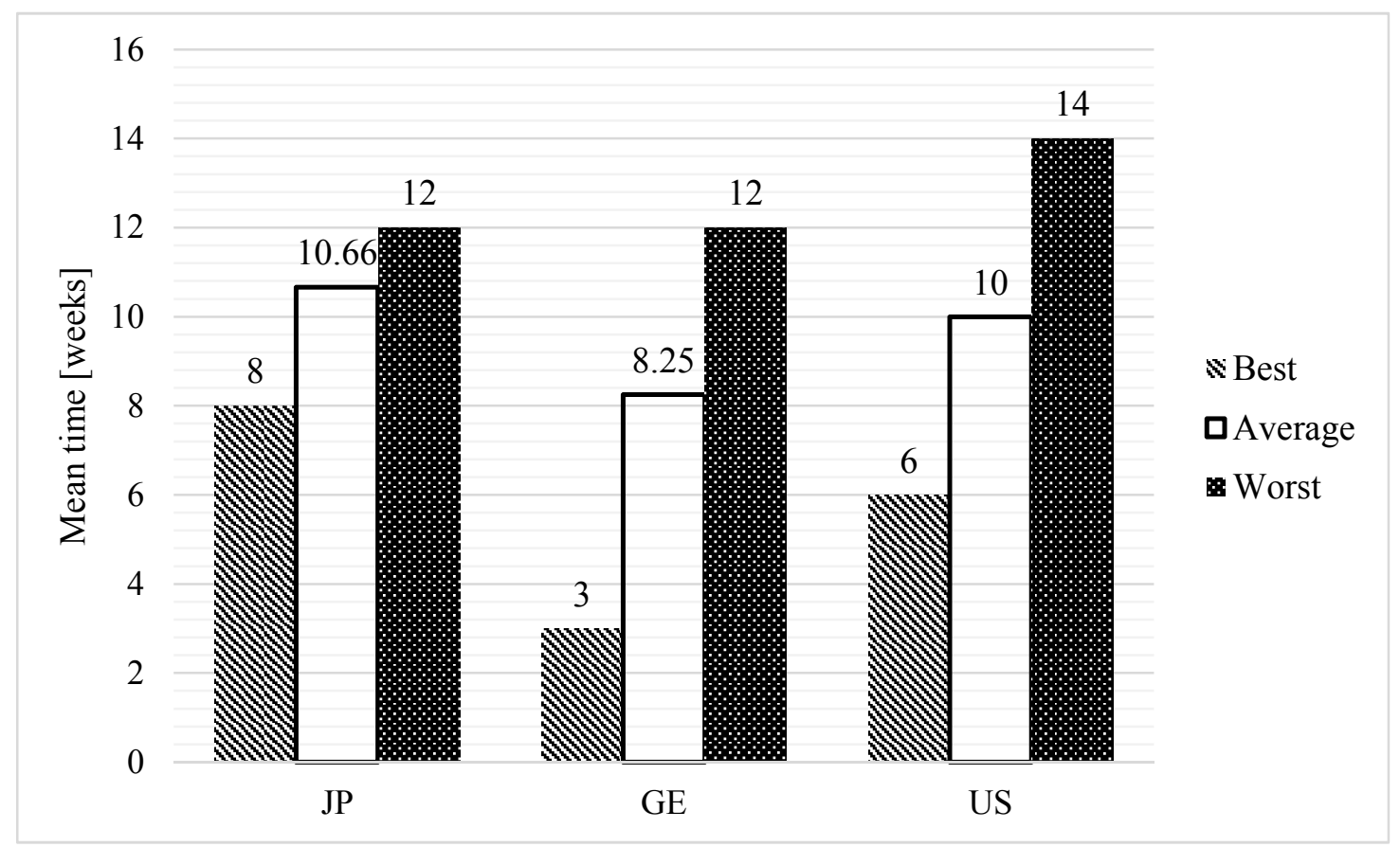

Figure 20: Time to get car after placing an order at the auto maker (mean time), luxury

In order to gain statistically proven results, all sub-hypotheses will be checked using Minitab. Table 11 shows the results. Based on these results, it cannot be said that JP delivery time is lower than GE or US delivery time. As already seen for hypothesis 1, standard and luxury makers need to be distinguished in order to gain further results. Then, it becomes clear that JP standard car dealerships have a lower delivery time than US standard car dealerships and that JP luxury car dealerships have a higher delivery time than GE luxury car dealerships. These are the only significant conclusions that could be drawn for this hypothesis. All other comparisons did not lead to significant results. 
Table 11: JP delivery time is lower than US or GE, summary

\begin{tabular}{|c|c|c|c|}
\hline & Sub-hypothesis & p-value & Conclusion \\
\hline 2.a & $\begin{array}{l}H_{0}: \mu_{\text {JPtime }}=\mu_{\text {GEtime }} \\
H_{1}: \mu_{\text {JPtime }}<\mu_{\text {GEtime }}\end{array}$ & 0.25 & $\begin{array}{l}\text { No significant difference } \\
\text { between the delivery time of JP } \\
\text { and GE car dealerships }\end{array}$ \\
\hline 2.b & $\begin{array}{l}H_{0}: \mu_{\text {JPtime }}=\mu_{\text {UStime }} \\
H_{1}: \mu_{\text {JPtime }}<\mu_{\text {UStime }}\end{array}$ & 0.488 & $\begin{array}{l}\text { No significant difference } \\
\text { between the delivery time of JP } \\
\text { and US car dealerships }\end{array}$ \\
\hline 2.c & $\begin{array}{l}H_{0}: \mu_{\text {GEtime }}=\mu_{\text {UStime }} \\
H_{1}: \mu_{\text {GEtime }}<\mu_{\text {UStime }}\end{array}$ & 0.756 & $\begin{array}{l}\text { No significant difference } \\
\text { between the delivery time of } \\
\text { GE and US car dealerships }\end{array}$ \\
\hline 2.d & $\begin{array}{l}H_{0}: \mu_{\text {JPtimestand }}=\mu_{\text {GEtimestand }} \\
H_{1}: \mu_{\text {JPtimestand }}<\mu_{\text {GEtimestand }}\end{array}$ & 0.138 & $\begin{array}{l}\text { No significant difference } \\
\text { between the delivery time of JP } \\
\text { and GE standard car } \\
\text { dealerships }\end{array}$ \\
\hline 2.e & $\begin{array}{l}H_{0}: \mu_{\text {JPtimestand }}=\mu_{\text {UStimestand }} \\
H_{1}: \mu_{\text {JPtimestand }}<\mu_{\text {UStimestand }}\end{array}$ & 0.045 & $\begin{array}{l}\text { JP standard car dealerships } \\
\text { have a lower delivery time than } \\
\text { US stan. car dealerships }\end{array}$ \\
\hline 2.f & $\begin{array}{l}H_{0}: \mu_{\text {GEtimestand }}=\mu_{U S t i m e s t a n d} \\
H_{1}: \mu_{\text {GEtimestand }}<\mu_{\text {UStimestand }}\end{array}$ & 0.794 & $\begin{array}{l}\text { No significant difference } \\
\text { between the delivery time of } \\
\text { GE and US standard car } \\
\text { dealerships }\end{array}$ \\
\hline $2 . \mathrm{g}$ & $\begin{array}{l}H_{0}: \mu_{\text {JPtimelux }}=\mu_{\text {GEtimelux }} \\
H_{1}: \mu_{\text {JPtimelux }}<\mu_{\text {GEtimelux }}\end{array}$ & $\begin{array}{c}0.90 \\
\text { (alternate } \\
0.10)\end{array}$ & $\begin{array}{l}\text { JP luxury car dealerships have } \\
\text { a higher delivery time than GE } \\
\text { lux. car dealerships }\end{array}$ \\
\hline 2.h & $\begin{array}{l}H_{0}: \mu_{\text {JPtimelux }}=\mu_{\text {UStimelux }} \\
H_{1}: \mu_{\text {JPtimelux }}<\mu_{\text {UStimelux }}\end{array}$ & 0.623 & $\begin{array}{l}\text { No significant difference } \\
\text { between the delivery time of JP } \\
\text { and US luxury car dealerships }\end{array}$ \\
\hline $2 . \mathrm{i}$ & $\begin{array}{l}H_{0}: \mu_{\text {GEtimelux }}=\mu_{\text {UStimelux }} \\
H_{1}: \mu_{\text {GEtimelux }}<\mu_{\text {UStimelux }}\end{array}$ & 0.241 & $\begin{array}{l}\text { No significant difference } \\
\text { between the delivery time of } \\
\text { GE and US luxury car } \\
\text { dealerships }\end{array}$ \\
\hline $2 . j$ & $\begin{array}{l}H_{0}: \mu_{\text {timestand }}=\mu_{\text {timelux }} \\
H_{1}: \mu_{\text {timestand }}<\mu_{\text {timelux }}\end{array}$ & 0.223 & $\begin{array}{l}\text { No significant difference } \\
\text { between the delivery time of } \\
\text { standard and luxury car } \\
\text { dealerships }\end{array}$ \\
\hline
\end{tabular}




\subsection{Hypothesis 3}

3. German car makers have a lower percentage of cars sold from the inventory

Table 12 shows the percentage of cars that are directly sold from the dealers' inventories. As in chapter 2, there are eight data points per nation as car dealerships that sell more than one brand gave one percentage for all brands.

Table 12: Vehicles sold from inventory in \% at different makers, luxury in bold

\begin{tabular}{|c|c|c|c|c|c|c|}
\hline Maker No & \multicolumn{2}{|c|}{$\mathrm{JP}[\%]$} & \multicolumn{2}{|c|}{ GE $[\%]$} & \multicolumn{2}{|c|}{ US [\%] } \\
\hline 1 & \multicolumn{2}{|c|}{99.00} & \multicolumn{2}{|c|}{75.00} & \multicolumn{2}{|c|}{85.00} \\
\hline 2 & \multicolumn{2}{|c|}{85.00} & \multicolumn{2}{|c|}{60.00} & \multicolumn{2}{|c|}{95.00} \\
\hline 3 & \multicolumn{2}{|c|}{90.00} & \multicolumn{2}{|c|}{75.00} & \multicolumn{2}{|c|}{90.00} \\
\hline 4 & \multicolumn{2}{|c|}{80.00} & \multicolumn{2}{|c|}{50.00} & \multicolumn{2}{|c|}{90.00} \\
\hline 5 & \multicolumn{2}{|c|}{80.00} & \multicolumn{2}{|c|}{85.00} & \multicolumn{2}{|c|}{75.00} \\
\hline 6 & \multicolumn{2}{|c|}{87.50} & \multicolumn{2}{|c|}{70.00} & \multicolumn{2}{|c|}{80.00} \\
\hline 7 & \multicolumn{2}{|c|}{98.00} & \multicolumn{2}{|c|}{95.00} & \multicolumn{2}{|c|}{95.00} \\
\hline 8 & \multicolumn{2}{|c|}{85.00} & \multicolumn{2}{|c|}{90.00} & \multicolumn{2}{|c|}{95.00} \\
\hline \multicolumn{7}{|l|}{9} \\
\hline 10 & & & & & & \\
\hline$\sigma$ & 88.06 & 7.28 & 75.00 & 15.1 & 88.13 & 7.53 \\
\hline
\end{tabular}


The first " 85 " in the US dealership column is actually the answer of a dealership that offers standard and luxury brands. Therefore, the " 85 " counts both for US standard and US luxury makers.

Figure 21 shows the data from table 12 in a plot where the percentage of vehicles sold from the inventory is on the $\mathrm{x}$-axis and the number of models is on the $\mathrm{y}$-axis. Based on figure 21, it becomes clear that there are big differences between JP and US on the one side and GE car dealerships on the other side. Whereas JP and US dealerships seem to be randomly distributed between $75 \%$ and $99 \%$ and furthermore independent from the amount of models the dealership offers, GE dealerships tend to sell less vehicles from their inventory the more models they offer.

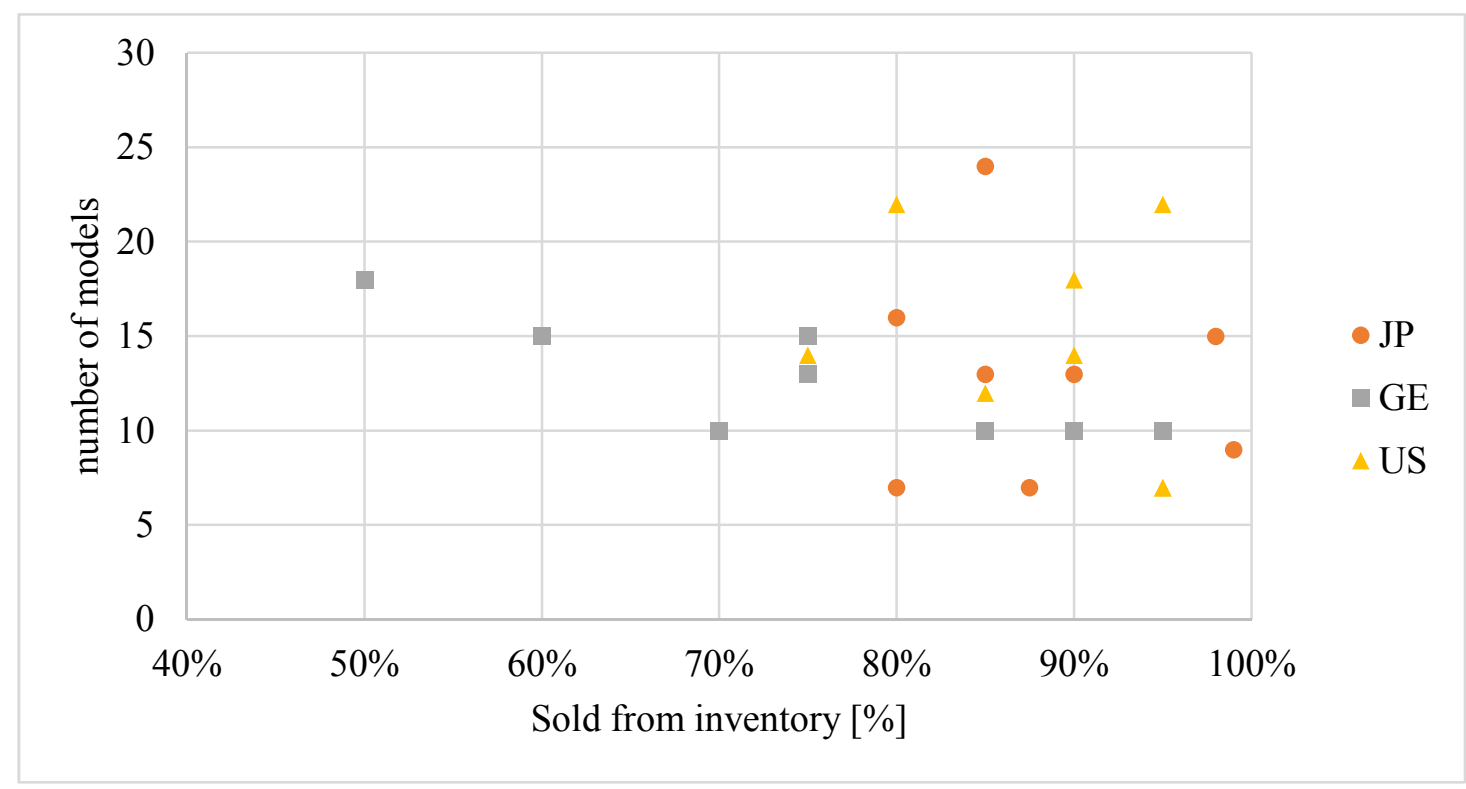

Figure 21: Number of models over cars sold from inventory

If luxury and premium car dealerships are considered separately, a big gap between them can be identified as figures 22 and 23 show. Standard dealerships tend to sell a high percentage of their vehicles from their inventory, independent from the 
amount of models that they offer. The same accounts for JP and US luxury car makers where the findings from hypothesis 1 can be seen again as US luxury makers offer significantly less models compared to their GE luxury competitors (figure 23). Furthermore, GE luxury makers seem to be different as they sell fewer cars from their own inventory the more different models they offer.

The mean and the stdev of the percentage of cars sold from the dealers' inventory for the standard makers are

$$
\begin{aligned}
& \mu_{J P \% \text { stand }}=89.10 \% \sigma_{J P \% \text { stand }}=5.39 \% \\
& \mu_{G E \% \text { stand }}=85.00 \% \sigma_{G E \% \text { stand }}=10.8 \% \\
& \mu_{U S \% \text { stand }}=85.83 \% \sigma_{U S \% \text { stand }}=7.36 \%
\end{aligned}
$$

It can be seen that Japanese makers have the highest mean value and the lowest standard deviation, whereas Germans have the lowest $\%$ and the biggest standard deviation. However, all three standard makers seem to have a similar percentage of vehicles sold from the inventory.

The mean and the stdev of the percentage of cars sold from the dealers' inventory for the luxury makers are

$$
\begin{aligned}
& \mu_{J P \% l u x}=86.30 \% \sigma_{J P \% l u x}=11.00 \% \\
& \mu_{G E \% l u x}=65.00 \% \sigma_{G E \% l u x}=12.2 \% \\
& \mu_{U S \% l u x}=91.67 \% \sigma_{U S \% l u x}=5.77 \%
\end{aligned}
$$


It can be seen that US luxury makers have the highest mean value and the lowest standard deviation, whereas Germans luxury makers have the lowest $\%$ and the biggest standard deviation. So far, both results confirm hypothesis 3 . In order to gain statistically proven results, the different sub-hypotheses will be tested and table 13 shows the results.

The results from this test show that generally speaking, GE car dealerships sell a lower percentage of cars from their inventory compared to their JP or US competitors. That confirms hypothesis 3. However, when luxury and standard car dealerships are distinguished, it can be found that only GE luxury dealerships have a significantly lower percentage of cars sold from their inventory compared to JP or US luxury car dealerships. Furthermore, the percentage of vehicles sold from the lot of luxury car dealerships is lower than of car dealerships selling standard vehicles. All the other tests were found to be not significant. That shows that GE car dealerships indeed tend to sell a lower percentage of their car straight from their inventory, and in particular German luxury dealerships. When standard car dealerships were compared with each other, no significant differences could be identified. 


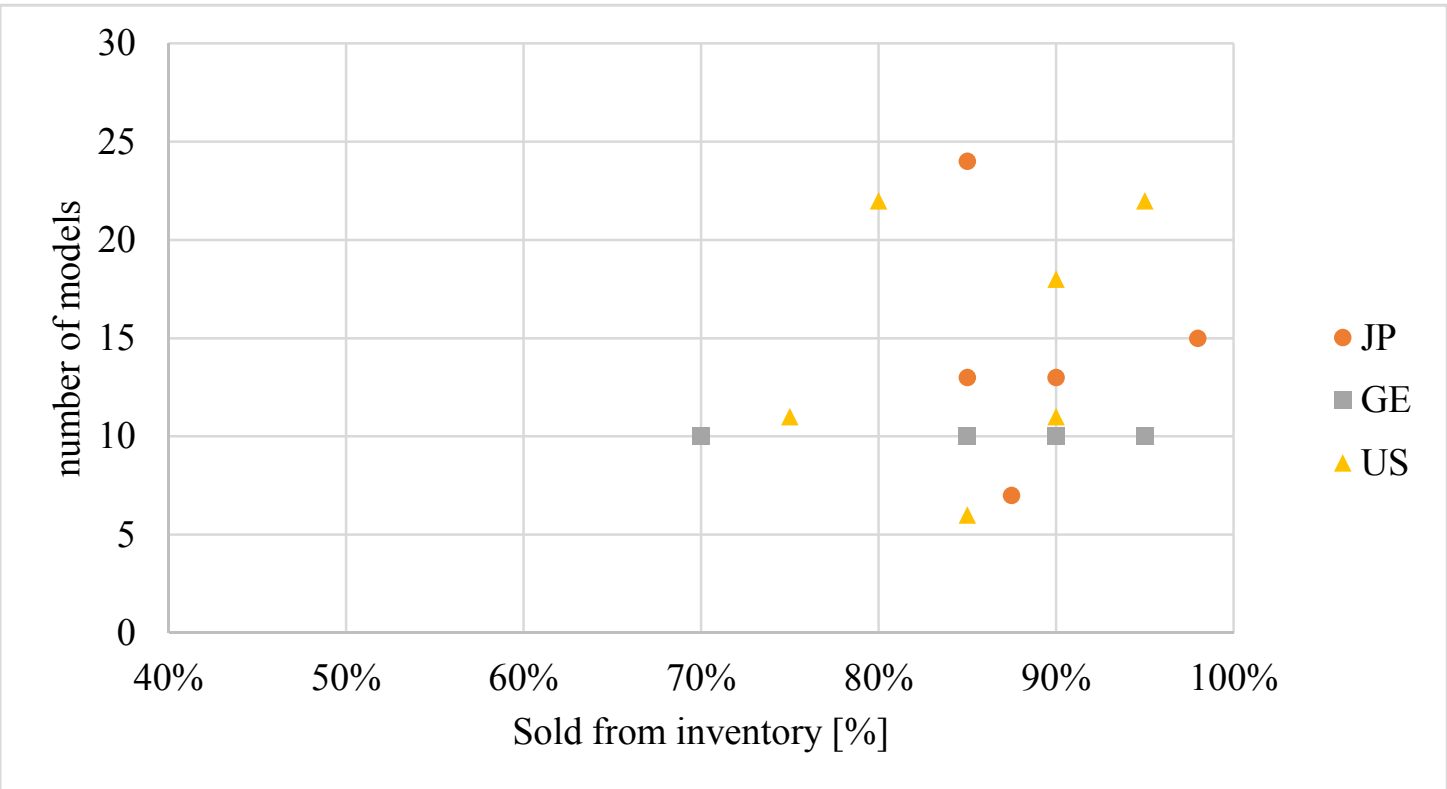

Figure 22: Number of models over cars sold from inventory, standard

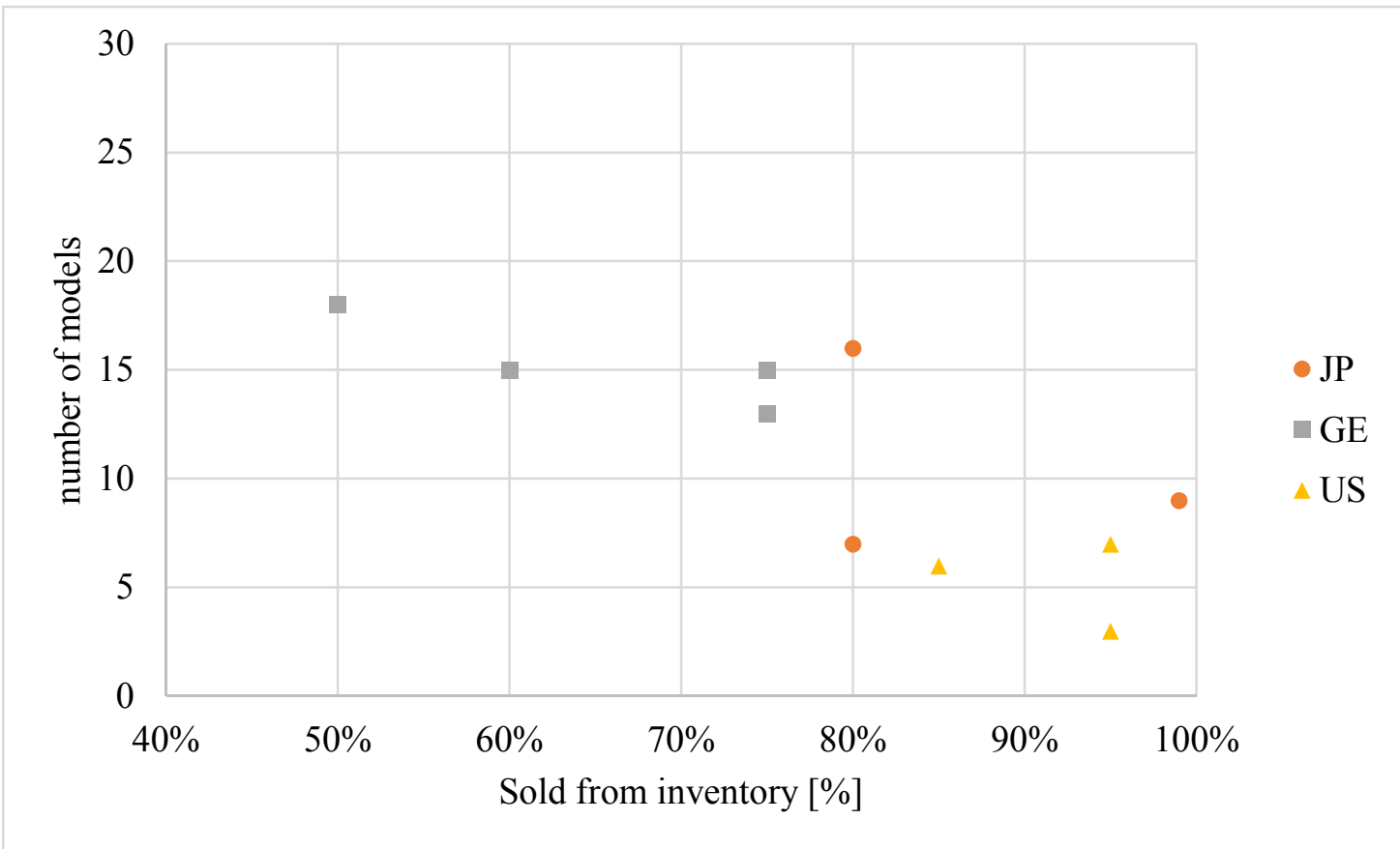

Figure 23: Number of models over cars sold from inventory, luxury 
Table 13: GE have lower percentage of cars sold from the inventory than JP or US, summary

\begin{tabular}{|c|c|c|c|}
\hline \multicolumn{2}{|r|}{ Sub-hypothesis } & p-value & Conclusion \\
\hline 3.a & $\begin{array}{l}H_{0}: \mu_{G E \%}=\mu_{J P \%} \\
H_{1}: \mu_{G E \%}<\mu_{J P \%}\end{array}$ & 0.026 & $\begin{array}{l}\text { The percentage of vehicles sold } \\
\text { from the lot of GE car dealerships } \\
\text { is significantly lower than from JP } \\
\text { car dealerships. }\end{array}$ \\
\hline 3.b & $\begin{array}{l}H_{0}: \mu_{G E \%}=\mu_{U S \%} \\
H_{1}: \mu_{G E \%}<\mu_{U S \%}\end{array}$ & 0.026 & $\begin{array}{l}\text { The percentage of vehicles sold } \\
\text { from the lot of GE car dealerships } \\
\text { is significantly lower than at US } \\
\text { car dealerships. }\end{array}$ \\
\hline 3.c & $\begin{array}{l}H_{0}: \mu_{U S \%}=\mu_{J P \%} \\
H_{1}: \mu_{U S \%}<\mu_{J P \%}\end{array}$ & 0.507 & $\begin{array}{l}\text { No significant difference between } \\
\text { the percentages of vehicles sold } \\
\text { from the lot of US car dealerships } \\
\text { and JP car dealerships. }\end{array}$ \\
\hline 3.d & $\begin{array}{l}H_{0}: \mu_{G E \% \text { stand }}=\mu_{J P \% \text { stand }} \\
H_{1}: \mu_{G E \% \text { stand }}<\mu_{J P \% \text { stand }}\end{array}$ & 0.263 & No significant difference \\
\hline 3.e & $\begin{array}{l}H_{0}: \mu_{G E \% \text { stand }}=\mu_{U S \% \text { stand }} \\
H_{1}: \mu_{G E \% \text { stand }}<\mu_{U S \% \text { stand }}\end{array}$ & 0.450 & No significant difference \\
\hline $3 . f$ & $\begin{array}{l}H_{0}: \mu_{J P \% \text { stand }}=\mu_{U S \% \text { stand }} \\
H_{1}: \mu_{J P \% \text { stand }}>\mu_{U S \% \text { stand }}\end{array}$ & 0.211 & No significant difference \\
\hline $3 . g$ & $\begin{array}{l}H_{0}: \mu_{G E \% l u x}=\mu_{J P \% l u x} \\
H_{1}: \mu_{G E \% l u x}<\mu_{J P \% l u x}\end{array}$ & 0.036 & $\begin{array}{l}\text { The percentage of luxury vehicles } \\
\text { sold from the lot of GE car } \\
\text { dealerships is significantly lower } \\
\text { than at JP car dealerships. }\end{array}$ \\
\hline $3 . \mathrm{h}$ & $\begin{array}{l}H_{0}: \mu_{G E \% \text { lux }}=\mu_{U S \% l u x} \\
H_{1}: \mu_{G E \% \text { lux }}<\mu_{U S \% l u x}\end{array}$ & 0.009 & $\begin{array}{l}\text { The percentage of luxury vehicles } \\
\text { sold from the lot of GE car } \\
\text { dealerships is significantly lower } \\
\text { than at US car dealerships. }\end{array}$ \\
\hline $3 . \mathrm{i}$ & $\begin{array}{l}H_{0}: \mu_{J P \% l u x}=\mu_{U S \% l u x} \\
H_{1}: \mu_{J P \% l u x}>\mu_{U S \% l u x}\end{array}$ & 0.745 & No significant difference \\
\hline $3 . \mathrm{j}$ & $\begin{array}{l}H_{0}: \mu_{\% \text { stand }}=\mu_{\% \text { lux }} \\
H_{1}: \mu_{\% \text { stand }}<\mu_{\% \text { lux }}\end{array}$ & $\begin{array}{c}0.90 \\
\text { (alternate } \\
0.10 \text { ) }\end{array}$ & $\begin{array}{l}\text { The percentage of vehicles sold } \\
\text { from the lot of luxury car } \\
\text { dealerships is lower than of car } \\
\text { dealerships selling standard } \\
\text { vehicles }\end{array}$ \\
\hline
\end{tabular}




\subsection{Hypothesis 4}

\section{The MSRP of Japanese standard and premium makers is the lowest compared to US or GE car makers}

Figure 24 gives an overview of the different MSRPs in Dollars from the JP, GE and US car makers (Buehler, 2018). It shows the lowest MSRP, the highest and the average MSRP in \$. Based on this figure, JP's and GE's lowest MSRP's are around \$26,000, whereas the lowest US MSRP starts at over $\$ 33,000$. Furthermore, US makers offer the brand with the highest MSRP, followed by the GEs, followed with a significant gap of almost $\$ 10,000$, by the JPs. However, the average MSRP of all GE makers is the highest, followed by US and Japanese makers. That is because Japanese makers are strong in inexpensive segments such as compacts, sedans and small crossovers for everyone, whereas US car makers make the majority of their business in the more expensive midsize and full-size truck- and SUV-segments. Three out of the four German car makers 
(Audi, BMW and Mercedes-Benz) are known for offering high-priced luxury products in almost all segments which drives up the average MSRP.

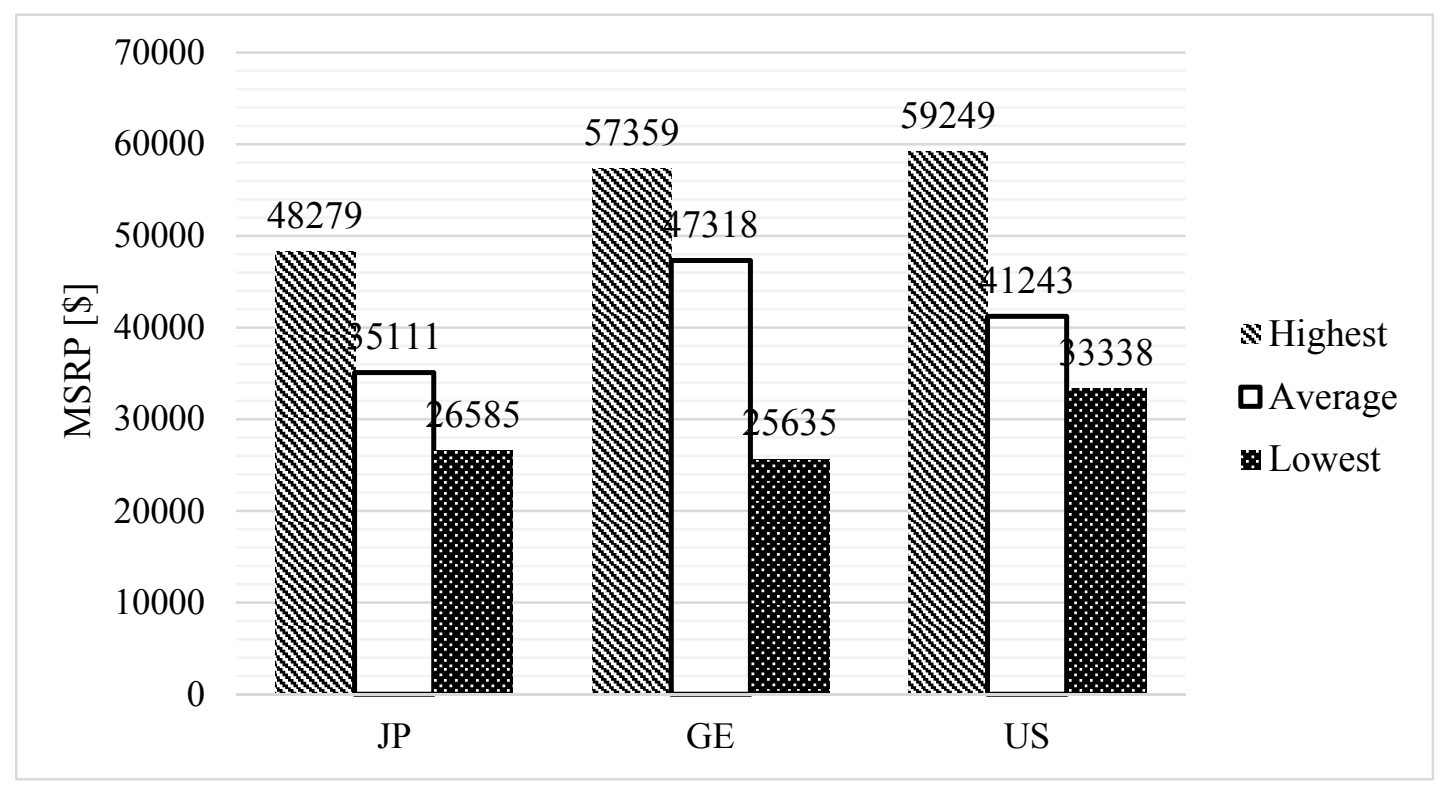

Figure 24: MSRP in \$ of the different makers, according to (Buehler, 2018)

Table 14 considers standard and luxury makers and gives the standard deviation (StDev) and the range of the different MSRPs. By comparing the standard makers with each other, it can be seen that US standard makers have a much higher mean compared to JP and GE makers. Furthermore, JP standard makers have a low standard deviation and their range is only $\$ 3,000$ which means that the majority of JP standard makers are focused on offering vehicles for this inexpensive segment and their customers. The same accounts for the only GE standard maker.

If the premium makers are considered, it becomes clear that there is a distinct difference between luxury and standard mean MSRP. That can especially be seen between GE standard and German luxury makers (difference of around $\$ 30,000$ ) and Japanese standard and luxury makers $(\$ 17,000)$. Surprisingly, US standard and luxury 
makers have a gap of less than $\$ 8,000$. Moreover, US luxury makers have the biggest range and standard deviation of their MSRPs. That indicates that the three US luxury makers all follow a completely different model and price policy and are targeting a different segment of customers. GE luxury makers instead have the lowest range and standard deviation which indicates that all GE luxury makers follow a similar, high price policy and define themselves as luxury makers.

Table 14: MSRP of different makers according to (Buehler, 2018)

\begin{tabular}{|l|c|c|l|c|c|}
\hline Variable & Mean & StDev & Minimum & Maximum & Range \\
\hline $\begin{array}{l}\text { MSRP JP } \\
\text { standard }\end{array}$ & $\$ 27,771$ & $\$ 1,287$ & $\$ 26,585$ & $\$ 29,598$ & $\$ 3,013$ \\
\hline $\begin{array}{l}\text { MSRP GE } \\
\text { standard }\end{array}$ & $\$ 25,635$ & $\$ 0$ & $\$ 25,635$ & $\$ 25,635$ & $\$ 0$ \\
\hline $\begin{array}{l}\text { MSRP US } \\
\text { standard }\end{array}$ & $\$ 39,113$ & $\$ 5,642$ & $\$ 33,338$ & $\$ 46,575$ & $\$ 13,237$ \\
\hline $\begin{array}{l}\text { MSRP JP } \\
\text { premium }\end{array}$ & $\$ 44,899$ & $\$ 4,023$ & $\$ 40,449$ & $\$ 48,279$ & $\$ 7,830$ \\
\hline $\begin{array}{l}\text { MSRP GE } \\
\text { premium }\end{array}$ & $\$ 54,546$ & $\$ 3,071$ & $\$ 51,270$ & $\$ 57,359$ & $\$ 6,089$ \\
\hline $\begin{array}{l}\text { MSRP US } \\
\text { premium }\end{array}$ & $\$ 47,105$ & $\$ 11,947$ & $\$ 35,365$ & $\$ 59,249$ & $\$ 20,884$ \\
\hline
\end{tabular}

Based on these first results, it becomes clear that different car makers use different strategies to gain customers. German and especially Japanese standard car makers are very focused on inexpensive car segments with a clear distinction between their luxury and standard brands. All German luxury makers are focused on offering high-priced vehicles and therefore have a very well-defined premium model range. However, some US luxury makers have lower MSRPs than their standard makers 
because they focus on well-equipped and comfortable sedans and crossovers, whereas some standard makers have their main business in big and more expensive SUVs and trucks.

Figures 25 and 26 include the number of different models over the MSRP [\$] for the luxury and standard makers. It underlines the findings from table 14 that US standard makers have a much higher average MSRP than JP or GE standard car makers. It also shows that the amount of different models offered by the car maker does not influence the average MSRP. The same accounts for the JP standard makers. Figure 26 underlines the results from table 14, as the spread between the minimum average MSRP and the maximum average MSRP of US luxury makers is very high whereas that of GE luxury makers is comparatively small. It also points out that GE luxury makers are all covering the $\$ 50,000$ plus vehicles whereas JP luxury makers serve the mid-priced vehicles and US luxury makers have a maker offering the low-price, mid-price and high-price segment. Table 15 shows the results of the different sub-hypotheses tested for significance in Minitab defined in chapter 3. 


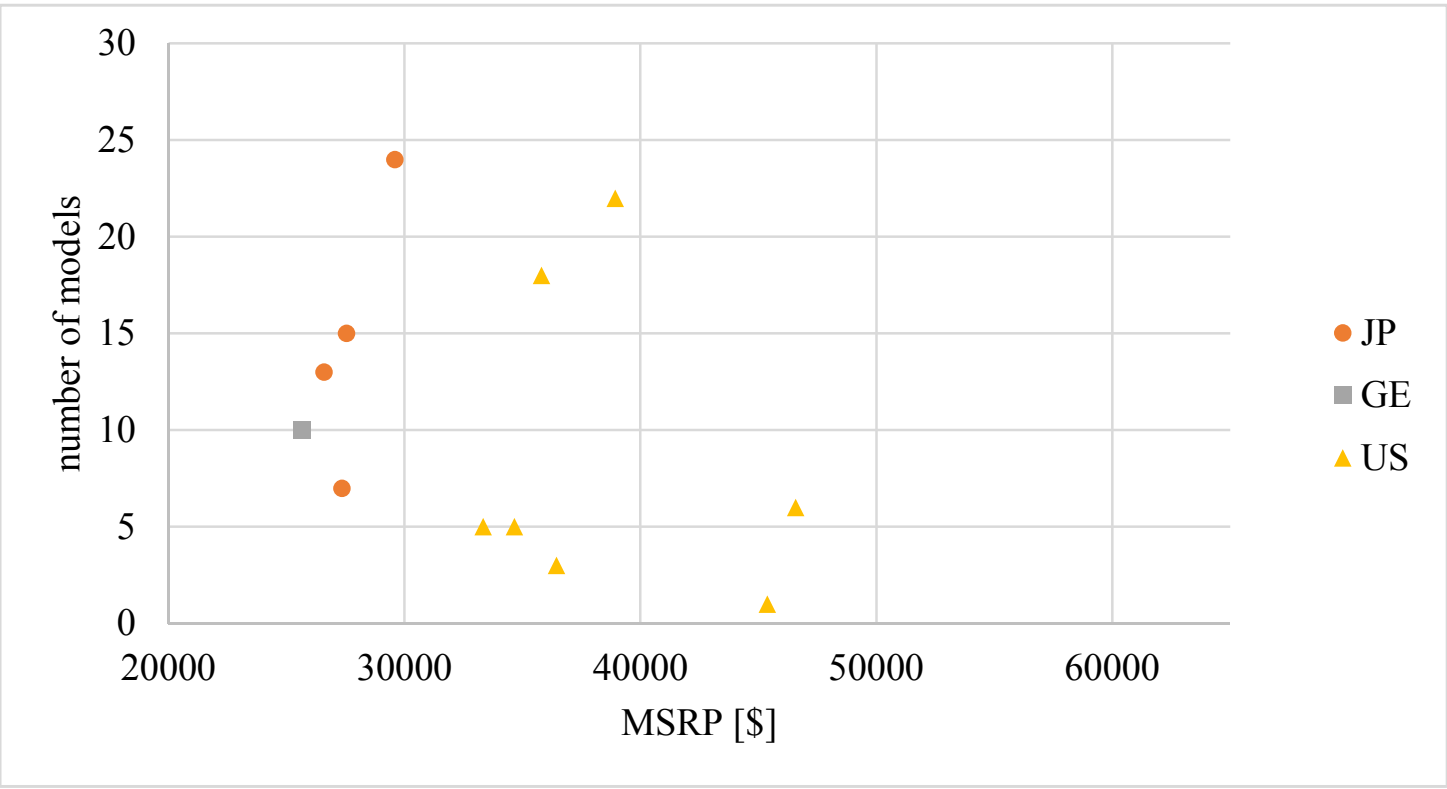

Figure 25: Number of different models from standard makers over MSRP [\$]

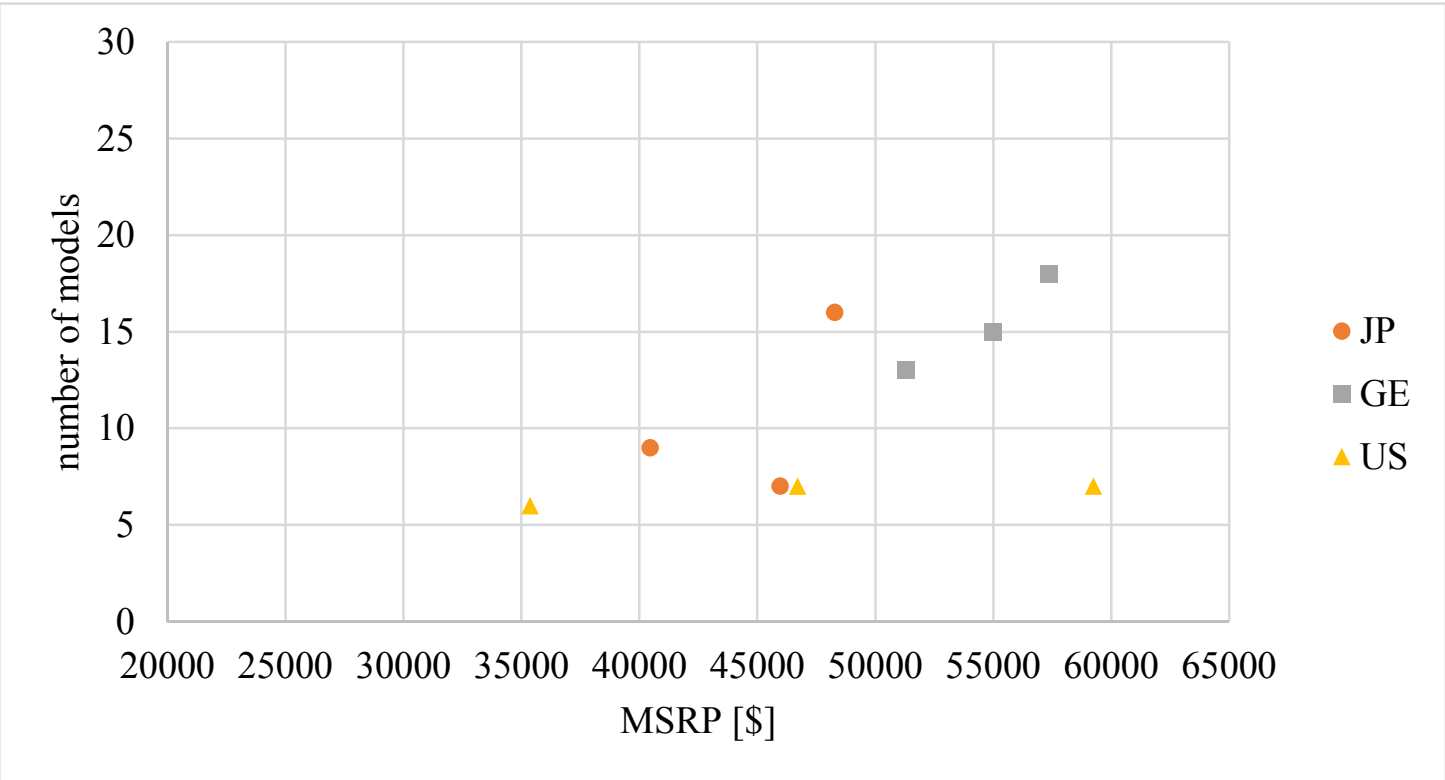

Figure 26: Number of different models from luxury makers over MSRP [\$] 
Table 15: JP MSRP is the lowest, summary

\begin{tabular}{|c|c|c|c|}
\hline \multicolumn{2}{|r|}{ Sub-hypothesis } & p-value & Conclusion \\
\hline 4.a & $\begin{array}{l}H_{0}: \mu_{J P M S R P}=\mu_{G E M S R P} \\
H_{1}: \mu_{J P M S R P}<\mu_{G E M S R P}\end{array}$ & 0.000 & $\begin{array}{l}\text { The average MSRP of vehicles } \\
\text { sold from the lot of JP car } \\
\text { dealerships is significantly lower } \\
\text { than from GE car dealerships. }\end{array}$ \\
\hline 4.b & $\begin{array}{l}H_{0}: \mu_{J P M S R P}=\mu_{U S M S R P} \\
H_{1}: \mu_{J P M S R P}<\mu_{U S M S R P}\end{array}$ & 0.000 & $\begin{array}{l}\text { The average MSRP of vehicles } \\
\text { sold from the lot of JP car } \\
\text { dealerships is significantly lower } \\
\text { than from US car dealerships. }\end{array}$ \\
\hline 4.c & $\begin{array}{l}H_{0}: \mu_{G E M S R P}=\mu_{U S M S R P} \\
H_{1}: \mu_{G E M S R P}<\mu_{U S M S R P}\end{array}$ & $\begin{array}{c}1.000 \\
\text { Alternate: } \\
0.000\end{array}$ & $\begin{array}{l}\text { The average MSRP of vehicles } \\
\text { sold from the lot of GE car } \\
\text { dealerships is significantly higher } \\
\text { than from US car dealerships. }\end{array}$ \\
\hline 4.d & $\begin{array}{l}H_{0}: \mu_{J P s t a n d M S R P}=\mu_{G E s t a n d M S R P} \\
H_{1}: \mu_{J P s t a n d M S R P}<\mu_{G E s t a n d M S R P}\end{array}$ & $\begin{array}{c}0.977 \\
\text { Alternate: } \\
0.0233\end{array}$ & $\begin{array}{l}\text { The average MSRP of standard } \\
\text { vehicles sold from the lot of JP car } \\
\text { dealerships is significantly higher } \\
\text { than from GE car dealerships. }\end{array}$ \\
\hline 4.e & $\begin{array}{l}H_{0}: \mu_{J P S t a n d M S R P}=\mu_{U S s t a n d M S R P} \\
H_{1}: \mu_{J P s t a n d M S R P}<\mu_{U S s t a n d M S R P}\end{array}$ & 0.001 & $\begin{array}{l}\text { The average MSRP of standard } \\
\text { vehicles sold from the lot of JP car } \\
\text { dealerships is significantly lower } \\
\text { than from US car dealerships. }\end{array}$ \\
\hline 4.f & $\begin{array}{l}H_{0}: \mu_{G E S t a n d M S R P}=\mu_{U S s t a n d M S R P} \\
H_{1}: \mu_{G E S t a n d M S R P}<\mu_{U S s t a n d M S R P}\end{array}$ & 0.000 & $\begin{array}{l}\text { The average MSRP of standard } \\
\text { vehicles sold from the lot of GE } \\
\text { car dealerships is significantly } \\
\text { lower than from US car } \\
\text { dealerships. }\end{array}$ \\
\hline $4 . g$ & $\begin{array}{l}H_{0}: \mu_{\text {JPluxMSRP }}=\mu_{\text {GEluxMSRP }} \\
H_{1}: \mu_{\text {JPluxMSRP }}<\mu_{\text {GEluxMSRP }}\end{array}$ & 0.023 & $\begin{array}{l}\text { The average MSRP of luxury } \\
\text { vehicles sold from the lot of JP car } \\
\text { dealerships is significantly lower } \\
\text { than from GE car dealerships }\end{array}$ \\
\hline 4.h & $\begin{array}{l}H_{0}: \mu_{J P l u x M S R P}=\mu_{U S l u x M S R P} \\
H_{1}: \mu_{J P l u x M S R P}<\mu_{U S l u x M S R P}\end{array}$ & 0.395 & There is no significant difference \\
\hline 4.i & $\begin{array}{l}H_{0}: \mu_{\text {GEluxMSRP }}=\mu_{\text {USluxMSRP }} \\
H_{1}: \mu_{\text {GEluxMSRP }}<\mu_{\text {USluxMSRP }}\end{array}$ & 0.797 & There is no significant difference \\
\hline
\end{tabular}


According to the results of table 15, the average MSRP of vehicles sold from the lot of JP car dealerships is significantly lower than from GE and US car dealerships which confirms hypothesis 4 . However, if the different luxury and standard makers are considered, differences can be noticed. For example, the average MSRP of standard vehicles sold from the lot of JP car dealerships is significantly higher than from GE car dealerships. However, that is because there is only one German standard car maker who is focused on sedans and does not offer more expensive trucks and SUVs like the JP makers who offer products in multiple car segments. So the validity of this subhypothesis may be limited. Furthermore, there is no significant difference between the average MSRP of luxury vehicles sold from the lot of JP car dealerships and US car dealerships. However, GE luxury car makers have a significantly higher average MSRP compared to their competitors from JP and the US. To summarize, it can be said that JP makers offer very competitive, inexpensive standard vehicles but also luxury vehicles. GE luxury makers are more expensive than their JP and US competitors which is part of their strategy as they define themselves as high-class luxury makers. 


\subsection{Hypothesis 5}

\section{German makers have the most extended dealer options}

As mentioned in chapter 3, the answers from the different dealerships given in the interviews will be put into three different categories. Category 1 is for basic options, 2 is for extended and 3 for extended plus. At the end, all numbers are summed up and the average value is calculated. Table 16 gives an overview of the different dealer options that Japanese car dealerships offer. The left column of the table lists the dealer options named in the interview with the dealership and the right two classify these options by giving either 1,2 or 3 points. Furthermore, standard and luxury makers are distinguished.

The average value for Japanese car dealerships is 1.5. JP standard car dealerships have a value of 1.8 and luxury dealerships have a value of 1 . Based on these results, it can be said that JP standard car dealerships offer a higher amount of customization at the dealership than JP luxury car dealerships. That is because Japanese luxury makers offer already fully equipped vehicles where usually only standard aesthetic features can be added. Extended options are usually not available as the maker offers them in different packages or has possible upgrades such as leather and heated seats already included. Also, Japanese dealerships do not really offer performance packages so customers usually would have to go to a separate company.

Table 17 shows the dealer options of German car dealerships. The average value of German car dealership is 2, of German standard car dealerships 1.5 and of luxury car 
dealerships 2.75 . This seems to be different than the JP car dealerships. Generally speaking, German dealerships tend to offer more extended dealer options than Japanese.

Table 16: Dealer options at Japanese car dealerships

\begin{tabular}{|c|c|c|c|}
\hline Dealer options & All & Standard & Luxury \\
\hline $\begin{array}{l}\text { a lot of accessories but no leather } \\
\text { (warranty), DVD and navigation with } \\
\text { special accessories }\end{array}$ & 2 & 2 & \\
\hline $\begin{array}{l}\text { not so many actually, mats, roofs, rugs } \\
\text { navigation or SD }\end{array}$ & 1 & 1 & \\
\hline $\begin{array}{l}\text { a lot of options but send cars out, leather, } \\
\text { spoiler, moon roof }\end{array}$ & 2 & 2 & \\
\hline $\begin{array}{l}\text { lux: very nice equipped, have already } \\
\text { running boards, grills, all weather mats, } \\
\text { more packages }\end{array}$ & 1 & & 1 \\
\hline $\begin{array}{l}\text { lux: wheels, moldings, trailer hitches, } \\
\text { port options, accessories }\end{array}$ & 1 & & 1 \\
\hline a lot of options, moldings, exhaust tips & 2 & 2 & \\
\hline $\begin{array}{l}\text { lux: well equipped, only change roof rails } \\
\text { or remote starters }\end{array}$ & 1 & & 1 \\
\hline a lot of accessories such as rims, sunroofs & 2 & 2 & \\
\hline Avg. Level & 1.5 & 1.8 & 1 \\
\hline
\end{tabular}

However, standard and luxury car dealerships need to be distinguished. German standard car dealerships offer a bit less extended dealer options than Japanese makers, especially because German standard makers would rather offer a higher trim level instead of fulfilling single dealer options at the dealership. However, German luxury makers offer a significantly higher amount of extended and extended plus dealer options than Japanese. That is because German luxury makers usually offer dealer made performance updates, extended accessories and a huge variety of options. Although they try to bundle these options into packages, they will still offer single options that they will add at the dealership. 
Table 17: Dealer options at German car dealerships

\begin{tabular}{|l|c|c|c|}
\hline Dealer options & & Standard & Luxury \\
\hline $\begin{array}{l}\text { lux: many options but we try to bundle } \\
\text { them in packages }\end{array}$ & 2 & 2 \\
\hline $\begin{array}{l}\text { lux: car cosmetics and accessories, } \\
\text { exhaust pipes, wheels, spoilers, } \\
\text { navigation system, add performance }\end{array}$ & 3 & 3 \\
\hline $\begin{array}{l}\text { lux: very minimal, tech options from the } \\
\text { factory, little customization at the } \\
\text { dealership but a lot of cosmetics and also } \\
\text { tuning and performance updates }\end{array}$ & 1 & 1 & 3 \\
\hline $\begin{array}{l}\text { wheels, tires, roof rages, recommend to } \\
\text { take the higher trim }\end{array}$ & 1 & 1 & 3 \\
\hline $\begin{array}{l}\text { small accessories, but if leather take } \\
\text { higher trim }\end{array}$ & 3 & 2 & 2 \\
\hline $\begin{array}{l}\text { lux: mats, running boards, roof rags, } \\
\text { performance updates }\end{array}$ & $\mathbf{2}$ & $\mathbf{1 . 5}$ & $\mathbf{2 . 7 5}$ \\
\hline $\begin{array}{l}\text { roof top, tow hitches, rear locks, heated } \\
\text { seats, leather }\end{array}$ & 2 & \\
\hline $\begin{array}{l}\text { not a lot of accessories and customization } \\
\text { usually order higher trim level }\end{array}$ & 1 & & \\
\hline
\end{tabular}

Table 18 shows the dealer options of American car dealerships. Car dealerships that offer luxury and standard brands in their dealership gave an answer for their standard and luxury brand so in this case, two numbers per interview were given, one for the luxury and one for the standard maker. First of all, the average dealership gets a score of 1.75 which is right between Japanese and German car dealerships. However, the standard US car dealerships have the highest value of all three (2). The main reason for that is the big truck and SUV-business. Especially trucks are vehicles that are usually highly customized by their customers. Usually a big part of the trucks are equipped with extra options such as leather, covers, bed liners, heavy duty accessory etc. Furthermore, the brand Jeep has a high amount of customization in their vehicles as customers change wheels, suspensions, etc. However, US premium car dealerships usually do not customize their vehicles with extended options such as Germans. Similar to the 
Japanese, they would just offer different trim levels and customers would customize their own car by choosing a higher trim level.

Table 18: Dealer options at American car dealerships

\begin{tabular}{|c|c|c|c|}
\hline Dealer options & & Standard & Luxury \\
\hline $\begin{array}{l}\text { accessory, DVD, leather, covers, bed } \\
\text { liners, remote starter, lot of customization }\end{array}$ & 2 & 2 & \\
\hline $\begin{array}{l}\text { options and accessory such as tires, } \\
\text { suspensions, air ride suspensions, LED, } \\
\text { etc. }\end{array}$ & 2 & 2 & \\
\hline $\begin{array}{l}\text { lux: offer more packages, three trims, } \\
\text { change color, wheels, grills }\end{array}$ & 1 & & 1 \\
\hline $\begin{array}{l}\text { a lot of customization, suspensions, life } \\
\text { kits, heavy duty accessory, remote } \\
\text { starters, lux:; packages }\end{array}$ & 2 & 2 & 1 \\
\hline Leather, sun roofs, covers, mats, etc. & 2 & 2 & \\
\hline steps, covers, all weather floor mats & 1 & 1 & \\
\hline $\begin{array}{l}\text { lux: cars are fully equipped, moon roof, } \\
\text { change color }\end{array}$ & 1 & & 1 \\
\hline $\begin{array}{l}\text { a lot of different options: add leather, } \\
\text { roof tops, seats, paintings, performance }\end{array}$ & 3 & 3 & \\
\hline Avg. Level & 1.75 & 2 & 1 \\
\hline
\end{tabular}

Table 19 shows the results of the Minitab calculations that were done in order to test statistical significance of the data.

Based on the results in table 19, it can generally be concluded that GE car dealerships offer more extended options compared to their JP competitors. However, GE car dealerships do not offer more extended dealer options than US car dealerships but about the same variety of options. In terms of standard makers, GE standard car dealerships offer less dealer options than US standard car dealerships. That is because US standard makers have a strong SUV- and truck-model range and they offer huge variation and customization on them. Furthermore, GE luxury car dealerships offer more extended dealer options than JP and US luxury dealers which underlines the strength of GE luxury makers. Therefore, hypothesis 5 is only true for the luxury makers. 
Table 19: GE makers have most extended dealer options, summary

\begin{tabular}{|c|c|c|c|}
\hline \multicolumn{2}{|r|}{ Sub-hypothesis } & \multirow{2}{*}{$\begin{array}{c}\mathrm{p} \text {-value } \\
0.100\end{array}$} & \multirow{2}{*}{$\begin{array}{l}\text { Conclusion } \\
\text { GE car dealerships offer } \\
\text { more extended dealer } \\
\text { options than JP }\end{array}$} \\
\hline $5 . \mathrm{a}$ & $\begin{array}{l}H_{0}: \mu_{\text {JPoptn }}=\mu_{\text {GEoptn }} \\
H_{1}: \mu_{\text {JPoptn }}<\mu_{\text {GEoptn }}\end{array}$ & & \\
\hline $5 . \mathrm{b}$ & $\begin{array}{l}H_{0}: \mu_{\text {USoptn }}=\mu_{\text {GEoptn }} \\
H_{1}: \mu_{\text {USoptn }}<\mu_{\text {GEoptn }}\end{array}$ & 0.369 & $\begin{array}{l}\text { US and GE car dealerships } \\
\text { offer the same variety of } \\
\text { dealer options. }\end{array}$ \\
\hline 5.c & $\begin{array}{l}H_{0}: \mu_{\text {USoptn }}=\mu_{\text {JPoptn }} \\
H_{1}: \mu_{\text {JPoptn }}<\mu_{\text {JPoptn }}\end{array}$ & 0.854 & $\begin{array}{l}\text { US and JP car dealerships } \\
\text { offer the same variety of } \\
\text { dealer options. }\end{array}$ \\
\hline $5 . \mathrm{d}$ & $\begin{array}{l}H_{0}: \mu_{\text {JPstandoptn }}=\mu_{\text {GEstandoptn }} \\
H_{1}: \mu_{\text {JPstandoptn }}<\mu_{\text {GEstandoptn }}\end{array}$ & 0.784 & $\begin{array}{l}\mathrm{JP} \text { and GE standard car } \\
\text { dealerships offer the same } \\
\text { variety of dealer options. }\end{array}$ \\
\hline 5.e & $\begin{array}{l}H_{0}: \mu_{\text {UStandoptn }}=\mu_{\text {GEstandoptn }} \\
H_{1}: \mu_{\text {UStandoptn }}<\mu_{\text {GEostandptn }}\end{array}$ & $\begin{array}{c}0.881 \\
\text { alternate: } \\
0.119\end{array}$ & $\begin{array}{l}\text { US standard car dealerships } \\
\text { tend to offer more extended } \\
\text { dealer options than GE } \\
\text { standard dealers. }\end{array}$ \\
\hline 5.f & $\begin{array}{l}H_{0}: \mu_{\text {USstandoptn }}=\mu_{\text {JPstandoptn }} \\
H_{1}: \mu_{\text {USstandoptn }}<\mu_{\text {JPstandoptn }}\end{array}$ & 0.721 & $\begin{array}{l}\text { US and JP standard car } \\
\text { dealerships offer the same } \\
\text { variety of dealer options. }\end{array}$ \\
\hline $5 . g$ & $\begin{array}{l}H_{0}: \mu_{\text {JPluxoptn }}=\mu_{\text {GEluxoptn }} \\
H_{1}: \mu_{\text {JPluxoptn }}<\mu_{\text {GEluxoptn }}\end{array}$ & 0.003 & $\begin{array}{l}\text { GE luxury car dealerships } \\
\text { offer more extended dealer } \\
\text { options than JP luxury } \\
\text { dealers. }\end{array}$ \\
\hline $5 . \mathrm{h}$ & $\begin{array}{l}H_{0}: \mu_{\text {USluxoptn }}=\mu_{\text {GEluxoptn }} \\
H_{1}: \mu_{\text {USluxoptn }}<\mu_{\text {GEluxoptn }}\end{array}$ & 0.003 & $\begin{array}{l}\text { GE luxury car dealerships } \\
\text { offer more extended dealer } \\
\text { options than US luxury } \\
\text { dealers. }\end{array}$ \\
\hline $5 . \mathrm{i}$ & $\begin{array}{l}H_{1}: \mu_{\text {USluxoptn }}=\mu_{\text {JPluxoptn }} \\
H_{0}: \mu_{\text {USluxoptn }}<\mu_{\text {JPluxoptn }}\end{array}$ & 0.50 & $\begin{array}{l}\text { US and JP luxury car } \\
\text { dealerships offer the same } \\
\text { variety of dealer options. }\end{array}$ \\
\hline
\end{tabular}




\subsection{Hypothesis 6}

\section{Japanese car dealerships sell the most cars per dealership compared to US or GE car dealerships}

In order to determine how fast and efficient dealerships are, Staeblein and Aoki compared different dealership systems in the US, EU and Japan with each other by dividing the annual sales volume by the amount of car dealerships. Table 20 shows the results of that calculation that was made for US, JP and GE standard and luxury car dealerships in the US. However, for US car dealerships no data was given for the number of luxury and standard dealerships when they were part of one company (for example Lincoln and Ford would give a total number of dealerships instead of their single brands Lincoln and Ford). Therefore, only GE and JP car dealerships can be compared in terms of standard and luxury car dealerships whereas JP, GE and US car dealerships can only be compared in terms of total sales per dealerships.

Finally, it turns out that JP standard car dealerships sell more than 1,400 vehicles per dealership in a year which is much more than GE standard car dealerships (485). This is positive for the JP dealerships as standard car dealerships quickly want to sell their vehicles in order to gain customers and therefore profit. On the other hand, JP luxury car dealerships sell only about half of the vehicles per dealership than standard car dealerships do which is comprehensible as luxury car dealerships should not focus on selling as many vehicles as possible but on customer service and a longer counseling process with the customer. However, GE luxury car dealerships are able to annually sell about 300 vehicles per dealership more than JP luxury car dealerships which is definitely remarkable. The results underline the strength of JP makers in the standard 
segment and of GE luxury brands in the luxury segment. If standard and luxury makers are not distinguished, it can be calculated that US car dealerships sell the least amount of cars per dealership compared to their JP competitors which sell almost more than double the amount of cars per dealership. That shows than JP car dealerships have successfully established their lean business system not only in their factories but also in their car dealerships. However, the high density of US car dealerships can also be a positive aspect for customers as it is easier for them to find a dealership in their neighborhood.

Based on these results, the inventory turns are calculated as they are a direct indicator of leanness. In order to calculate the inventory turns, information about the cars sold per dealership and the cars on the lot need to be known. The cars sold per dealership was calculated in table 20 and the cars on the lot are basically the dealer inventory which is question 4 of the interview. Based on this data, the average dealer inventory for standard and luxury makers at JP, US and GE car dealerships can be calculated and the results can be seen in table 21 .

Using the equation for the inventory turns $=\frac{\text { Cars sold per dealership }}{\text { Cars on the lot }}$ gives the average inventory turns in table 22 . Based on the results in table 22 , it can be seen that the average inventory turns for all makers (luxury and standard) is the highest at the JP car dealerships (4.2), followed by the GEs (3.7) and the US (2.4). That indicates that JP makers still have a much leaner and eventually faster dealership system with small inventories which saves time and money. 
Table 20: Car sales per dealership

\begin{tabular}{|c|c|c|c|c|}
\hline Producer & $\begin{array}{l}\text { Number of } \\
\text { dealerships in } \\
\text { the US }\end{array}$ & $\begin{array}{l}\text { US sales } \\
\text { volume }\end{array}$ & $\begin{array}{l}\text { Car sales per } \\
\text { Dealership in } \\
\text { the US }\end{array}$ & Sources \\
\hline \multirow{3}{*}{ German } & Standard: 700 & 339,676 & 485 & $\begin{array}{l}\text { (Automotive News, } \\
\text { 2018) }\end{array}$ \\
\hline & Luxury: 931 & 904,436 & 971 & $\begin{array}{c}\text { (Audi USA, 2018) } \\
\text { (BMW USA, 2018) } \\
\text { (Mercedes-Benz, } \\
\text { 2018) }\end{array}$ \\
\hline & Total: 1,631 & $1,244,112$ & 763 & \\
\hline \multirow{3}{*}{ Japanese } & $\begin{array}{c}\text { Standard: } \\
3,736\end{array}$ & $5,345,523$ & 1,431 & $\begin{array}{c}\text { (Honda USA, 2018) } \\
\text { (AutoNews, 2018) } \\
\text { (Nissan USA, 2018) } \\
\text { (Undercoffler, 2018) }\end{array}$ \\
\hline & Luxury: 908 & 613,246 & 675 & $\begin{array}{l}\text { (Infiniti, 2018) (John } \\
\text { Lippert, 2018) }\end{array}$ \\
\hline & Total: 4,644 & $5,958,769$ & 1,283 & \\
\hline American & Total: $11,325^{1}$ & $7,598,288$ & 671 & $\begin{array}{c}\text { (Buick USA, 2018) } \\
\text { (Rosevear, 2018) } \\
\text { (AutoTrader, 2018) } \\
\text { (Vellequette, 2018) } \\
\text { (DeBord, 2018) }\end{array}$ \\
\hline
\end{tabular}

Table 21: Average dealer inventory at different makers, luxury and standard makers distinguished

\begin{tabular}{|l|l|l|}
\hline Nation & Standard & Luxury \\
\hline JP & 343 & 162 \\
\hline GE & 235 & 183 \\
\hline US & 308 & 190 \\
\hline
\end{tabular}

${ }^{1}$ No distinction between luxury and standard because data only exists for entire companies and not single brands 
Table 22: Average inventory turns at different makers, luxury and standard makers distinguished

\begin{tabular}{|l|l|l|l|}
\hline Nation & Standard & Luxury & All \\
\hline JP & 4.2 & 4.2 & 4.2 \\
\hline GE & 2.1 & 5.3 & 3.7 \\
\hline US & - & - & 2.4 \\
\hline
\end{tabular}

When standard and luxury makers are considered, it turns out that GE luxury makers have the highest inventory turn, whereas JP standard maker have an inventory turn that is more than double the size of a GE standard car dealership. The results further emphasize the strength of JP standard car dealerships and GE luxury car dealerships in their segment. 


\subsection{Hypothesis 7}

\section{Japanese makers follow a significantly different approach in personnel training than US or GE car dealerships}

This section compares the different strategies and concepts to train and develop the dealership's personnel. The left column of table 23 lists the training methods and strategies named in the interview with the dealership and the right two distinguish between standard and luxury makers. In order to classify the answers given in the interviews, the answers will be grouped into category 1,2 or 3 . As mentioned in the methodology section, level 1 is for an "online in-store and rarely out-of-store" strategy, level 2 is for a "both online in-store and out-of-store on a regularly basis" strategy and level 3 for a "usually off-site at special training facilities, rarely in-store training" strategy. At the end, all numbers are summed and the average value is calculated.

Consequently, the average value for Japanese car dealerships is 1.5. Standard car dealerships have a value of 1.6 and luxury dealerships 1.33. Based on these results it can be concluded that there is no large difference in the training strategies of JP standard and luxury car dealerships and that Japanese dealerships prefer online in-store training compared to off-site training at special facilities.

Table 24 shows the results for German car dealerships. The average value for German car dealerships is 2.13. Standard car dealerships have a value of 2.25 and luxury dealerships of 2. Based on these results it can be concluded that there is no large difference in the training strategies of GE standard and luxury car dealerships. However, GE car dealerships tend to use much more out-of-store and off-site training facilities 
than JP car dealerships. In other words, Japanese dealerships prefer online in-store training compared to off-site training at special facilities which Germans also consider as part of their education and training strategy.

\section{Table 23: Training of personnel at Japanese car dealerships}

\begin{tabular}{|c|c|c|c|}
\hline Training of personnel & & Standard & Luxury \\
\hline virtual academy, online, in the dealership & 1 & 1 & \\
\hline $\begin{array}{l}\text { certain training when they start, then } \\
\text { complete more courses online }\end{array}$ & 1 & 1 & \\
\hline $\begin{array}{l}\text { online tests, very rarely offside classes, } \\
\text { but mostly dealership }\end{array}$ & 1 & 1 & \\
\hline $\begin{array}{l}\text { lux: OEM send field people, plus walk } \\
\text { around, sometimes travel to take different } \\
\text { tests }\end{array}$ & 2 & & 2 \\
\hline $\begin{array}{l}\text { lux: manufacturer, at dealership training, } \\
\text { webinars, managers are responsible to } \\
\text { improve learning process }\end{array}$ & 1 & & 1 \\
\hline $\begin{array}{l}\text { OEM-certified online and offsite } \\
\text { trainings }\end{array}$ & 2 & 2 & \\
\hline lux: online tests, self-drives, at dealership & 1 & & 1 \\
\hline trainer offsite at headquarter & 3 & 3 & \\
\hline Avg. Level & $\overline{1.5}$ & $\overline{1.6}$ & 1.33 \\
\hline
\end{tabular}

Table 25 shows the results for US car dealerships. The average value for US car dealerships is 1.25 . Standard car dealerships have a value of 1.17 and luxury dealerships of 1.33. Here, it can also be concluded that there is no big difference in the training strategies of US standard and luxury car dealerships.

However, US car dealerships use much more online and in-store training than GE car dealerships do and even tend to use more online and in-store training than their JP competitors. In order to gain statistically proven data, 2-paired t-tests in Minitab are executed. Table 26 shows the results. 
Table 24: Training of personnel at German car dealerships

\begin{tabular}{|l|c|c|c|}
\hline Training of personnel & & Standard & Luxury \\
\hline $\begin{array}{l}\text { lux: OEM sends them out and they stay } 2 \\
\text { to 3 days and get trained }\end{array}$ & 3 & 3 \\
\hline $\begin{array}{l}\text { lux: in-house and out-house training } \\
\text { every month }\end{array}$ & 2 & 2 & 2 \\
\hline $\begin{array}{l}\text { lux: in-house and out-house training } \\
\text { every month }\end{array}$ & 2 & 2 & 2 \\
\hline in-store and out-store training every year & 2 & 2 & \\
\hline do in-store and also out-store training & 1 & & 1 \\
\hline lux: in-store and look at our competitors & 3 & 3 & \\
\hline they go to special training facilities & 2 & 2 & $\mathbf{2}$ \\
\hline $\begin{array}{l}\text { in-store and out-store training every year, } \\
\text { a lot of them are web-based }\end{array}$ & $\mathbf{2 . 1 3}$ & $\mathbf{2 . 2 5}$ & \\
\hline \multicolumn{1}{|c|}{ Avg. Level } & & \\
\hline
\end{tabular}

Table 25: Training of personnel at American car dealerships

\begin{tabular}{|c|c|c|c|}
\hline Training of personnel & & Standard & Luxury \\
\hline once a month, in-store training & 1 & 1 & \\
\hline $\begin{array}{l}\text { in-house and out-house but more in- } \\
\text { house }\end{array}$ & 1 & 1 & \\
\hline $\begin{array}{l}\text { lux: It's in store but also out store. The } \\
\text { sales people they go out and ride and } \\
\text { drive the car. }\end{array}$ & 1 & & 1 \\
\hline in-store and online & 1 & 1 & \\
\hline $\begin{array}{l}\text { trained in store by dealership and by the } \\
\text { company online }\end{array}$ & 1 & 1 & 1 \\
\hline $\begin{array}{l}\text { every month so comes in and we do } \\
\text { online tests }\end{array}$ & 1 & 1 & \\
\hline $\begin{array}{l}\text { lux: online tests, special tests at the } \\
\text { manufacturer }\end{array}$ & 2 & & 2 \\
\hline $\begin{array}{l}\text { online-tests, university and also go to the } \\
\text { headquarters }\end{array}$ & 2 & 2 & \\
\hline Avg. Level & 1.25 & 1.17 & 1.33 \\
\hline
\end{tabular}


Table 26: JP follow different approach in personnel training, summary

\begin{tabular}{|c|c|c|c|}
\hline & Sub-hypothesis & p-value & Conclusion \\
\hline 7.a & $\begin{array}{l}H_{0}: \mu_{\text {JPtrain }}=\mu_{\text {GEtrain }} \\
H_{1}: \mu_{\text {JPtrain }}<\mu_{\text {GEtrain }}\end{array}$ & 0.049 & $\begin{array}{l}\text { JP car dealerships do more } \\
\text { online, in-store training than } \\
\text { GE car dealerships. }\end{array}$ \\
\hline 7.b & $\begin{array}{l}H_{0}: \mu_{\text {JPtrain }}=\mu_{\text {UStrain }} \\
H_{1}: \mu_{\text {JPtrain }}<\mu_{\text {UStrain }}\end{array}$ & 0.779 & $\begin{array}{l}\text { There is no significant } \\
\text { difference }\end{array}$ \\
\hline 7.c & $\begin{array}{l}H_{0}: \mu_{\text {GEtrain }}=\mu_{U S t r a i n} \\
H_{1}: \mu_{\text {GEtrain }}<\mu_{U S t r a i n}\end{array}$ & $\begin{array}{l}0.996 \\
\text { alternate: } \\
0.004\end{array}$ & $\begin{array}{l}\text { US car dealerships do more } \\
\text { online, in-store training than } \\
\text { GE car dealerships. }\end{array}$ \\
\hline 7.d & $\begin{array}{l}H_{0}: \mu_{J P s t a n d t r a i n}=\mu_{G E s t a n d t r a i n} \\
H_{1}: \mu_{J P s t a n d t r a i n}<\mu_{G E s t a n d t r a i n}\end{array}$ & 0.109 & $\begin{array}{l}\text { JP standard car dealerships } \\
\text { tend to do more online, in-store } \\
\text { training than GE standard car } \\
\text { dealerships. }\end{array}$ \\
\hline 7.e & $\begin{array}{l}H_{0}: \mu_{J P s t a n d t r a i n}=\mu_{U S s t a n d t r a i n} \\
H_{1}: \mu_{J P s t a n d t r a i n}<\mu_{U S t \text { standrain }}\end{array}$ & 0.818 & $\begin{array}{l}\text { There is no significant } \\
\text { difference }\end{array}$ \\
\hline 7.f & $\begin{array}{l}H_{0}: \mu_{\text {GEstandtrain }}=\mu_{\text {UStandtrain }} \\
H_{1}: \mu_{\text {GEstandtrain }}<\mu_{\text {UStandtrain }}\end{array}$ & $\begin{array}{l}0.992 \\
\text { alternate: } \\
0.008\end{array}$ & $\begin{array}{l}\text { US standard car dealerships do } \\
\text { more online, in-store training } \\
\text { than GE standard car } \\
\text { dealerships. }\end{array}$ \\
\hline 7.g & $\begin{array}{l}H_{0}: \mu_{\text {JPluxtrain }}=\mu_{\text {GEluxtrain }} \\
H_{1}: \mu_{\text {JPluxtrain }}<\mu_{\text {GEluxtrain }}\end{array}$ & 0.131 & $\begin{array}{l}\text { There is no significant } \\
\text { difference }\end{array}$ \\
\hline 7.h & $\begin{array}{l}H_{0}: \mu_{J P l u x t r a i n}=\mu_{U S l u x t r a i n} \\
H_{1}: \mu_{\text {JPluxtrain }}<\mu_{U S l u x t r a i n}\end{array}$ & 0.500 & $\begin{array}{l}\text { There is no significant } \\
\text { difference }\end{array}$ \\
\hline $7 . \mathrm{i}$ & $\begin{array}{l}H_{0}: \mu_{\text {GEluxtrain }}=\mu_{U S l u x t r a i n} \\
H_{1}: \mu_{\text {GEluxtrain }}<\mu_{U S l u x t r a i n}\end{array}$ & 0.869 & $\begin{array}{l}\text { There is no significant } \\
\text { difference }\end{array}$ \\
\hline $7 . \mathrm{j}$ & $\begin{array}{l}H_{0}: \mu_{\text {standtrain }}=\mu_{\text {luxtrain }} \\
H_{1}: \mu_{\text {standtrain }}<\mu_{\text {luxtrain }}\end{array}$ & 0.500 & $\begin{array}{l}\text { There is no significant } \\
\text { difference }\end{array}$ \\
\hline
\end{tabular}


Based on the results of table 26 , it can be found that different makers follow significantly different training strategies for their personnel. JP car dealerships for example do more online, in-store training than GE car dealerships. The same accounts for US car dealerships. If standard and luxury makers are distinguished, it becomes clear that JP standard car dealerships tend to do more online, in-store training than GE standard car dealerships, whereas US standard car dealerships do more online, in-store training than GE standard car dealerships. All luxury makers tend to follow the same strategy for their personnel. Therefore, the hypothesis that JP car dealerships use a significantly different approach than GE or US car dealerships is wrong as it could rather be found that GE car dealerships use a significantly different approach than their US and JP competitors. Generally speaking, JP and US car dealerships tend to follow a more online, in-store personnel training strategy whereas GE car dealerships try to use off-site training at special training facilities which indicates a stronger connection to their car manufacturer. 


\subsection{Hypothesis 8}

\section{Japanese car dealerships offer the best warranty models}

The following chapter compares the different warranty models with each other. In this case, only the best models are compared with each other in order to determine whose model is actually the best. Figure 27 shows the best "bumper-to-bumper"coverage for the standard makers whereas the first y-axis shows the years of coverage and the second y-axis the miles of coverage. According to the results, the best standard car maker's warranty is offered by a German car maker. It covers 6 years and 72,000 miles whereas the best JP and US standard car maker warranty only covers 3 years and 36,000 miles.

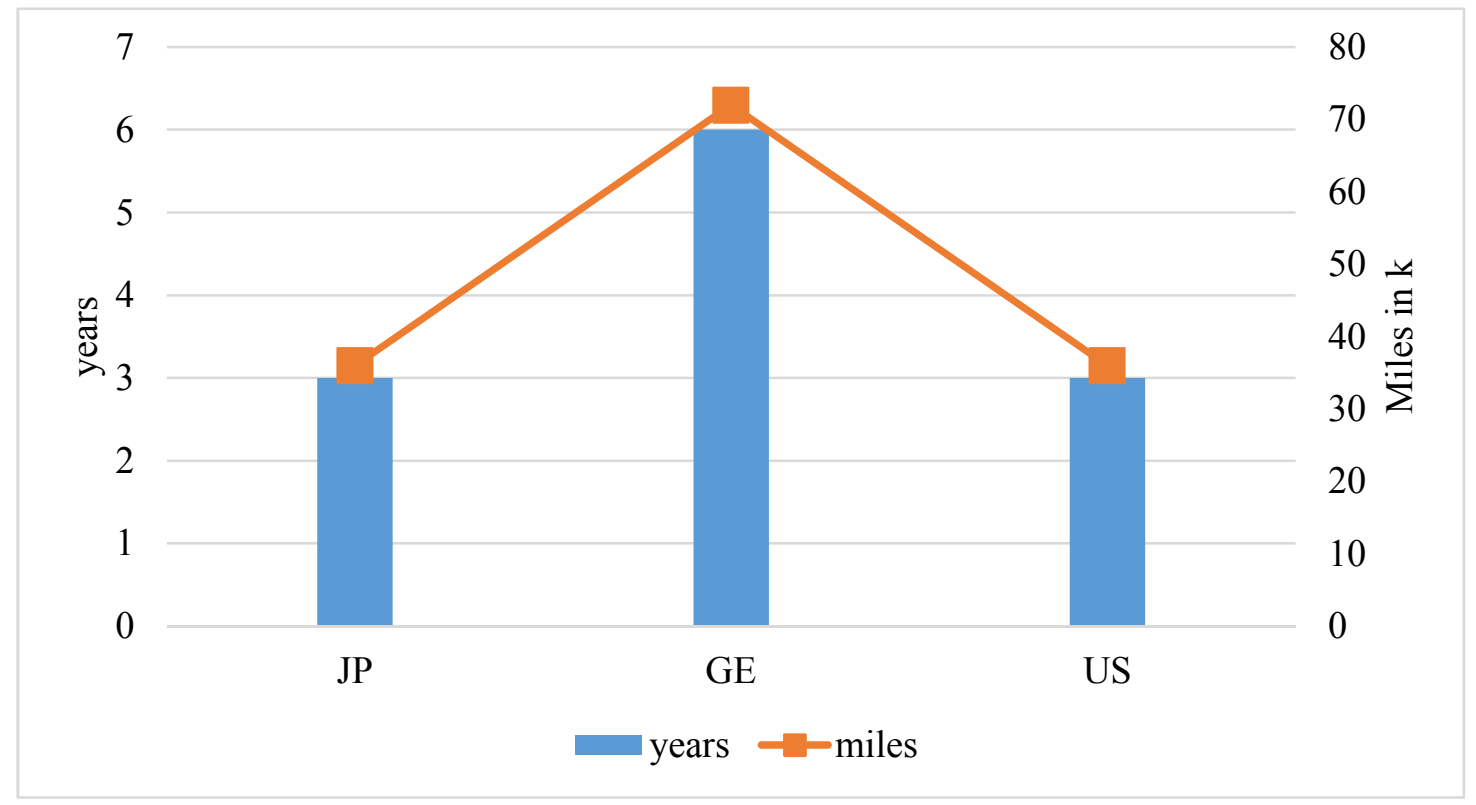

Figure 27: "Bumper-to-bumper"-coverage, standard makers

Figure 28 shows the "bumper-to-bumper"-coverage for the luxury vehicles. However, the offers of the different makers do not seem to vary as much as the standard 
makers offer do. All three countries offer a 4 years warranty with a 50,000 miles coverage except the best JP luxury maker, who offers 60,000 miles.

After comparing the different "bumper-to-bumper"-coverages, powertrain and

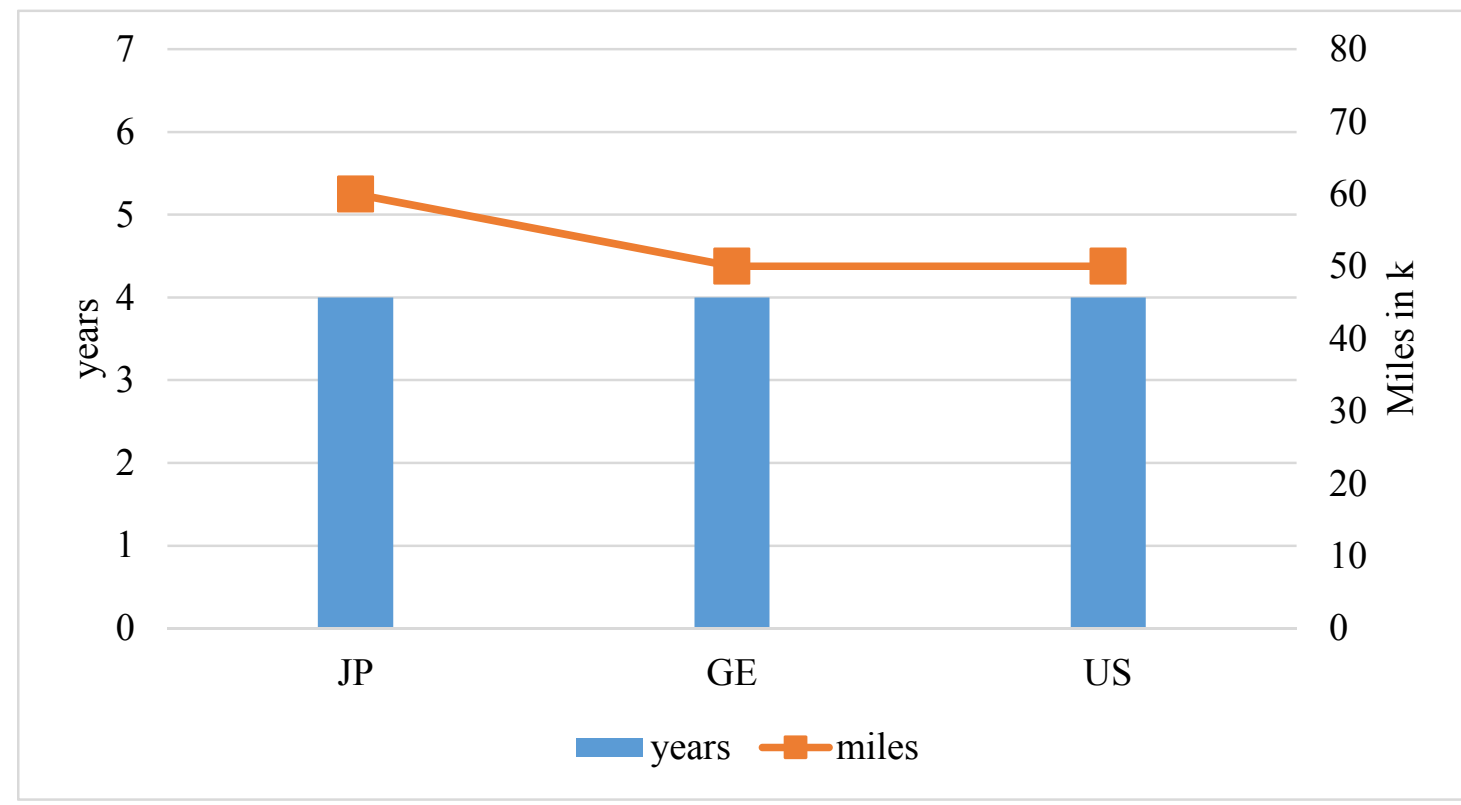

Figure 28: "Bumper-to-bumper"-coverage, luxury makers

transmission-warranties are compared with each other, similar to the "bumper-tobumper"-coverages.

Figure 29 shows that the German standard car dealerships not only offer the best "bumper-to-bumper"-coverage but also the best powertrain and transmission-warranty. The GE dealership offers a 6 year 72,000 miles warranty, whereas both JP and US standard car dealerships offer 5 year and 60,000 miles as their best model. However, figure 30 shows that the powertrain and transmission coverage for all luxury makers is the same (6 years and 70,000 miles).

To summarize, hypothesis 8 which said that JP car makers would offer the best warranty models, is wrong. For the standard makers, the GE maker had the best offer in 
both cases (bumper-to-bumper and powertrain and transmission-warranty). For the luxury makers it was found that all best offers of the different makers were the same for the powertrain and transmission and only for the bumper-to-bumper-warranty, JP luxury makers offer 60,000 miles coverage instead of 50,000 miles like GE and US luxury car dealerships.

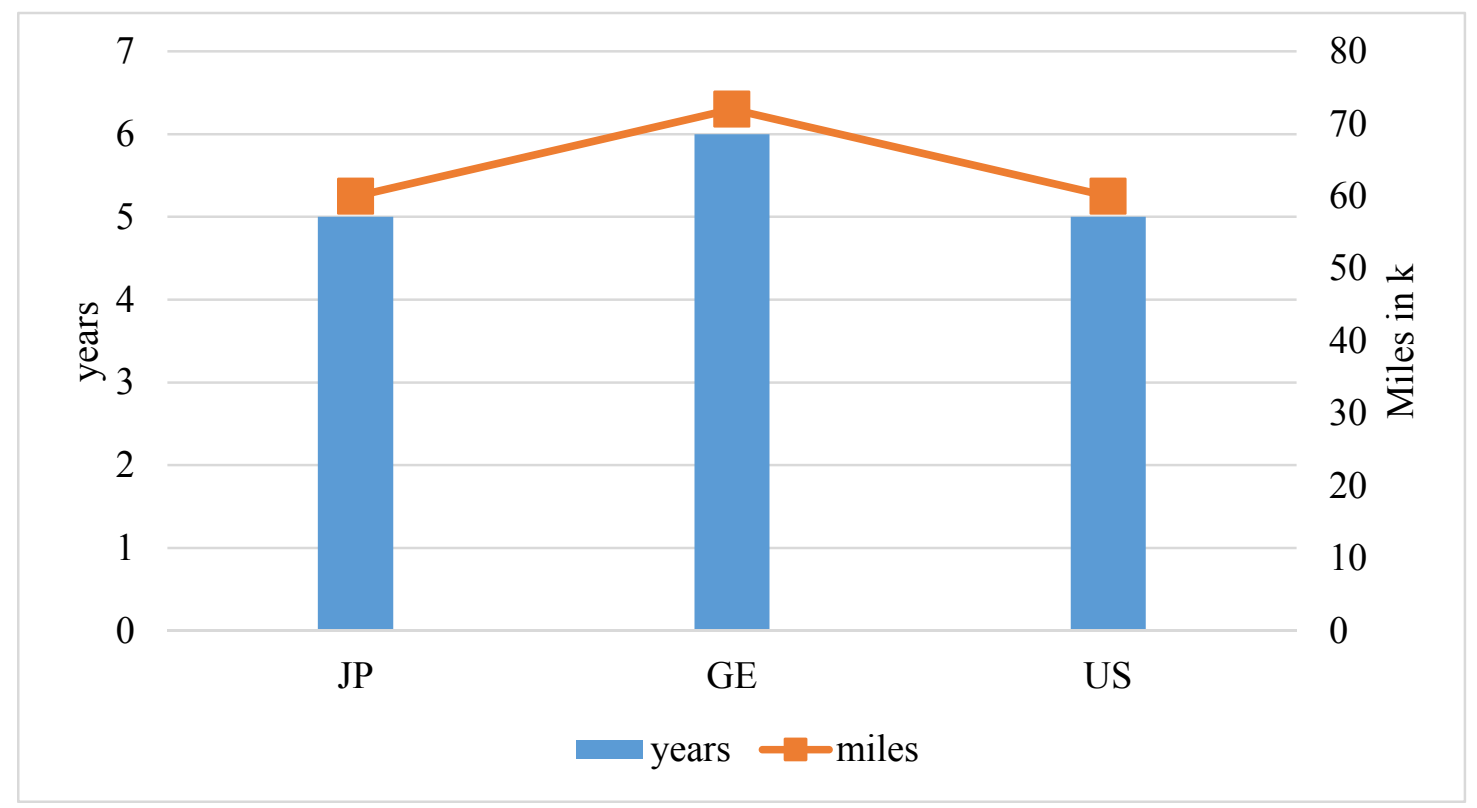

Figure 30: Powertrain and transmission coverage, standard

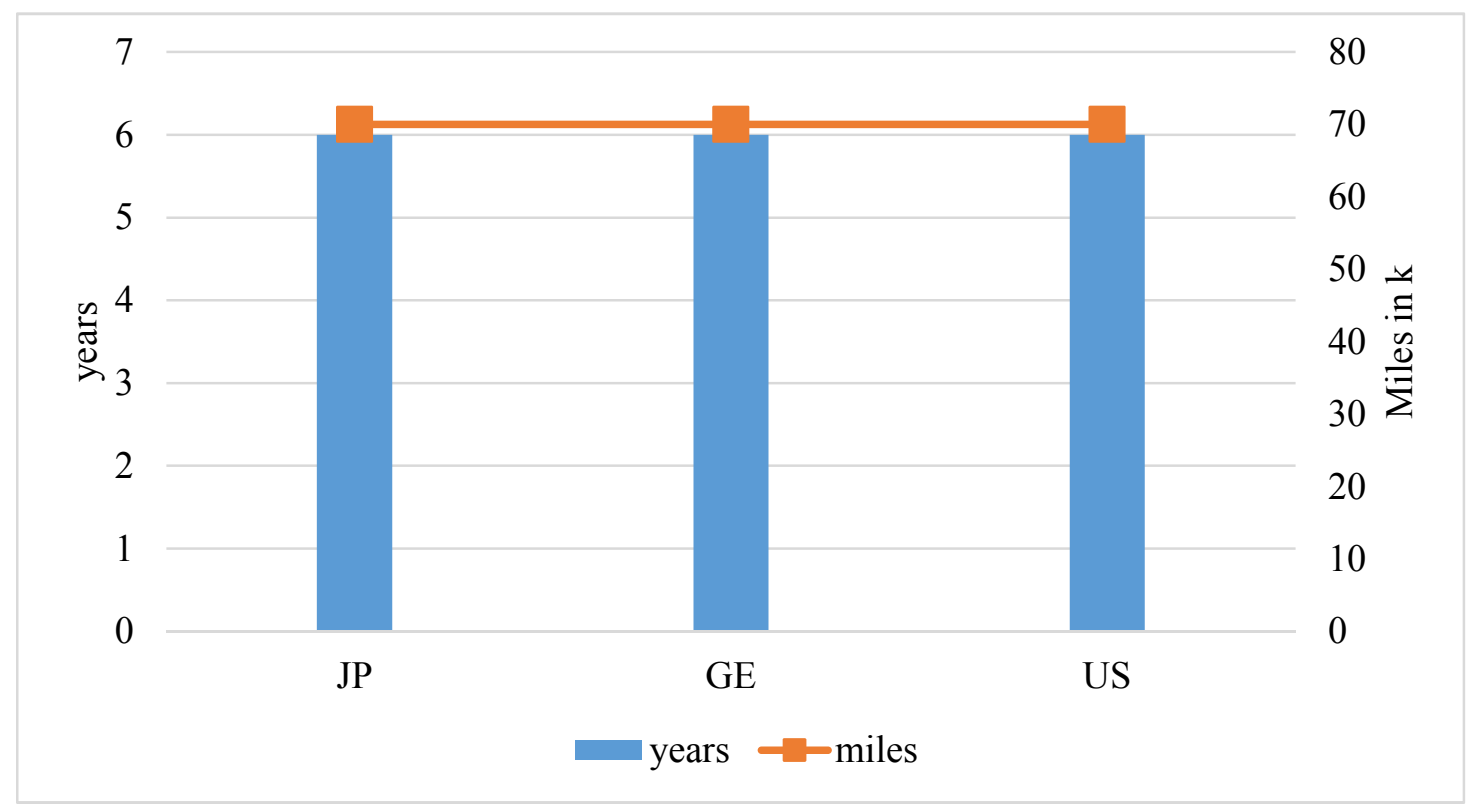

Figure 29: Powertrain and transmission coverage, luxury 


\subsection{Hypothesis 9}

\section{Japanese car dealerships are more customer-related than their US and GE competitors}

In order to investigate this hypothesis, open-ended questions 16 and 17 of the interview will be analyzed. Important key words will be identified, counted and grouped. Based on this analysis, focus areas of different car makers and their strategies for the future can be determined. As a first step, the top 8 most used words are listed which can be seen in Table 27. The left column shows the ranking, and the second column shows the top 8 most used words of the US makers. The number of points equals the number of times the word was used in notes taken during the interview. Then the results for the GE and JP makers are shown in the next columns.

As one can see, rank 1 and 2 are the same for JP and US makers. All US car dealerships used the word customer 92 times which gives an average of more than 11 times per interview, compared to 80 times or 10 times per interview of the JP car dealerships. This underlines that JP and US car dealerships have the customer as their number one priority. The term "dealer" is followed on the second rank, used 63 times or about 8 times per interview of the US car dealerships, compared to 77 or about 10 times per interview of the JP car dealerships. This shows that US and JP car dealerships put their car dealership on the second rank after their customers. The actual "brand" is named 40 times or 5 times per interview at JP car dealerships (rank 3) followed by the word sale (32 times, 4 times per interview). US car dealerships used the word "sale" a bit more often than the name of the brand they are selling (36 times, about 5 times per interview; 32 times, 4 times per interview). In fact, US car dealerships named this word 
more often than their JP or GE competitors. GE car dealerships are different though. After analyzing their interviews, it becomes clear that GE car dealerships focus more on their brand and the company of the products they are offering (57 times or 7 times per interview) than their US or JP competitors. Furthermore, GE car dealerships tend to work much closer together with their manufacturer, as proven in hypothesis 7 and 8 (They offer more extended dealer options coming from their car manufacturer and use more off-site facilities which are mainly at the car manufacturer). The second most used word by GE car dealerships is the word "customer" which is the same for the JP and US car makers, underlines the importance of their customers (49 times or 6 times per interview). The word dealer (36 times or about 5 timer per interview) and sale (23 times or 3 times per interview) follow in rank number 3 and 4.

Furthermore, it is interesting to compare the other top 8 most used words in the list. Another word that all the car dealerships use is "service". It is ranked $5^{\text {th }}$ for US and JP and $7^{\text {th }}$ for GE car dealerships. However, the term "service" is used less than "sales" which underlines the great importance of selling cars for a dealership and therefore beating their given sales goals by the end of the month. Moreover, GE car dealerships used the word "SUV" about 3 times in the interview which is more often than US or JP makers. GE car dealerships expect SUVs to be about 60 to $65 \%$ of their business in the near future. In addition to SUVs, US car dealerships named trucks as being their most important and profitable business. 
Table 27: Most important words and number of times it was mentioned in the interviews

\begin{tabular}{|c|l|l|l|l|l|l|}
\hline Ranking & US & points & GE & points & JP & points \\
\hline 1 & Customer & 92 & The "brand" & 57 & Customer & 80 \\
\hline 2 & Dealer & 63 & Customer & 49 & Dealer & 77 \\
\hline 3 & Sale & 36 & Dealer & 36 & The "brand" & 40 \\
\hline 4 & The "brand" & 34 & Sale & 23 & Sale & 32 \\
\hline 5 & Service & 25 & Incentive & 19 & Service & 31 \\
\hline 6 & Online & 16 & SUV & 17 & Online & 19 \\
\hline 7 & Manufacturer & 15 & Service & 15 & Manufacturer & 12 \\
\hline 8 & Truck+SUV & 14 & Manufacturer & 13 & Incentive & 11 \\
\hline
\end{tabular}

Table 27 shows the top 8 most used words by the different car dealerships. Now, each of these words is put into one of three different categories that will be defined in the next paragraph. This is done in order to determine which of these three categories is used the most by every country.

Table 28 describes every group. Group 1 contains all words out of Table 27 that describe customer-related activities that are done in order to please the customer and increase the customer satisfaction, e.g. the word "customer" or "service". Group 2 contains words that describe dealership-related activities in order to increase car sales and to grow, for example "dealership", "sale", "incentive" or "online". The third group includes maker-related activities to boost sales such as the name of "the brand", "SUV and trucks" or "manufacturer". 
Table 28: Description of the three groups

\begin{tabular}{|c|l|}
\hline Group & Description \\
\hline $\mathbf{1}$ & Customer-related activities in order to gain customers \\
\hline $\mathbf{2}$ & Dealership-related activities in order to boost \\
\hline $\mathbf{3}$ & Maker-related activities in order to boost sales \\
\hline
\end{tabular}

According to figure 31, US and JP makers tend to use the same distribution of their groups, as about $35 \%$ of their most used words are customer-related, about $44 \%$ are dealership-related and about 22\% maker-related. That shows that JP and US car dealerships strongly focus on their dealership and dealership activities to boost sales, followed by customer-related activities. US dealerships use the word "sale" more often than their JP and GE competitors which indicates that US car dealerships are more willing to push sales or focus on increasing their sales than the others. Maker-related activities only follow on the $3^{\text {rd }}$ rank. However, the picture looks different for the GE car dealerships. With almost $40 \%$, German car dealerships strongly focus on makerrelated activities followed by dealership activities (36\%) and customer-related activities (26\%). That's because GE car dealerships do not only sell a product but also sell the brand and the positive, highly-engineered product image that is connected to cars made in Germany. Furthermore, GE car dealerships work together very closely with the manufacturer in terms of customization and as a result of their build-to-order strategy and strongly focus on SUV as part of their future business as they use the word "SUV" more than their competitors. 


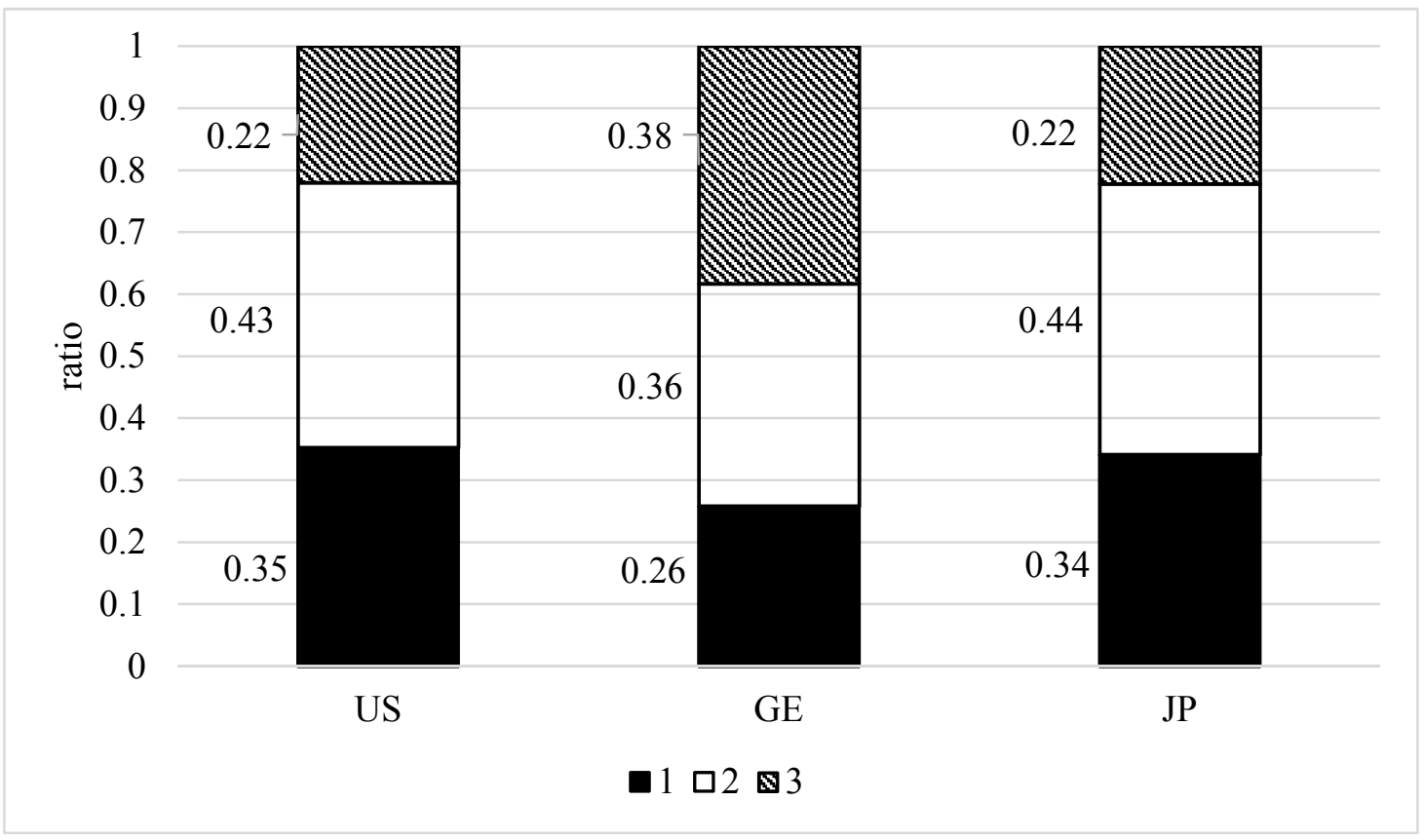

Figure 31: Grouping and their percentual distribution 


\subsection{Hypothesis 10}

\section{Japanese makers are leading in e-mobility}

In order to investigate this hypothesis, the answers to the open-ended question 16 will be analyzed regarding the words and terms used about future risks and challenges. Furthermore, question 17 aims to examine the makers' strategy about future powertrain and mobility concepts.

After analyzing the different interviews, the answers will be scaled from -1 to 1 where -1 means that the dealership is totally opposed to the use of EVs (electric vehicle) and PHEVs (plug-in hybrid electric vehicle) as part of their brand's future mobility, and where 1 is the most positive answer, and 0 means neutral. Only numbers that are rounded to one decimal place can be given such as $-0.8,-0.1,0.4,0.0 .0 .9$ etc. The allocation process for the points depends on how the different car dealerships include EVs and PHEVs in their future model policy and how convinced these dealerships are about e-mobility. For example, a dealership that already offers a great amount of EVs and PHEVs and that is very positive about e-mobility as part of future mobility, will get a score of 1.0. If a dealership is very positive about e-mobility but still needs 2 to 3 years before more EVs come on the market, the score given is 0.9 , and so on. The more dampened the enthusiasm about e-mobility and/or the longer the time until new models come on the market, the lower the score. A score between 0.0 and 0.5 is defined as the "dampened positive" area where car dealerships see e-mobility as part of their future strategy but also mention a few obstacles and/or still need a few more years before they are able to introduce new EVs and PHEVs to the market. Dealerships that offer more PHEVs than EVs get a lower score, as PHEVs still include an internal combustion 
engine compared to EVs. The area between 0.0 and -0.5 is defined as the "dampened negative" area where car dealerships see more obstacles and are more critical at this point of time. They might have one or two PHEVs but do not plan on introducing more to the market in the next couple of years as they do not expect the breakthrough of this technology in that time. The area between -0.5 and -1 is defined as the "negative" area where car dealerships explicitly mention the downturns of e-mobility and are skeptical about the technology and whether the obstacles can be solved in the next couple of years. Furthermore, these dealerships do not have PHEVS or EVs and do not plan on introducing them to the market in the next years. The more negative a dealership is, the more negative the score.

Based on these explanations, the answers from the interviews will be evaluated. For example, one GE luxury maker said that electric vehicles would be part of their strategy and they will be redesigned and completely developed. That accounts for both EVs and PHEVs. Furthermore, the brand described itself as a frontrunner in e-mobility but also mentions that government support should be increased. This answer is a very positive response regarding whether e-mobility is part of the company's strategic plan or not. The score for this answer is 0.9 on that scale. A US maker answered question 17 by saying that they are skeptical in terms of EV due to the price of batteries and asked the question whether one can really save money with that technology. Furthermore, they indicated that they would rather use diesel technology and increase fuel economy of gas engines instead of using electric vehicles. That is a pretty negative answer and that is why a score of -0.8 was given. After analyzing the 24 different interviews and assigning them a number between -1 and 1, Figure 32 can be built. The solid dot shows the average 
value. The US average value is -0.075 , the GE average value is 0.625 and the JP average value -0.05 .

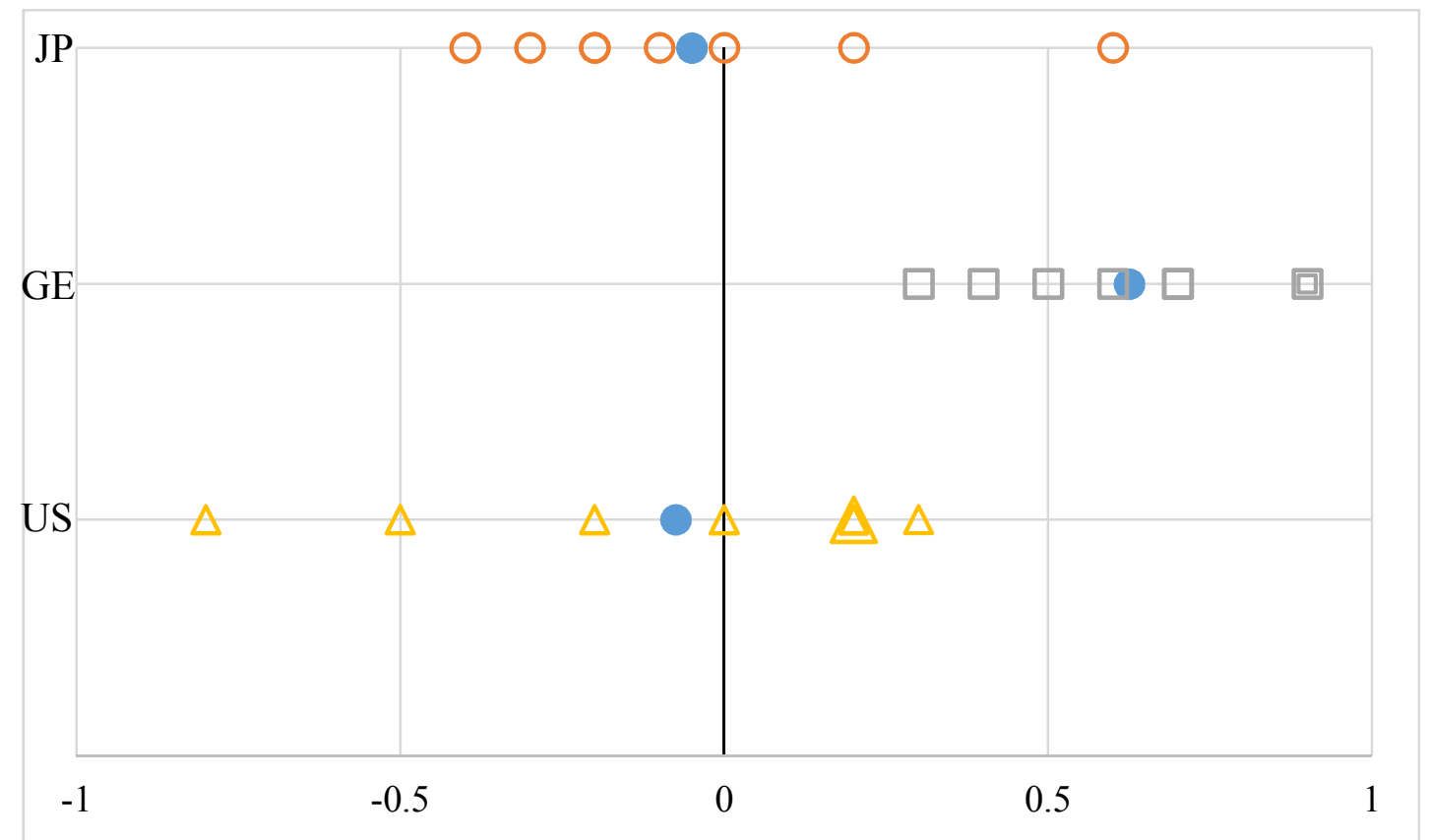

Figure 32: How convinced are car dealerships about e-mobility?

Surprisingly, JP and US dealerships seem to answer the question quite similar. Three US dealerships received a negative score, one a neutral and four a positive score, whereas five JP dealerships received a negative score, one a neutral and two a positive score. Two of the US makers answered very negatively about e-mobility as their future powertrain concept as they had a lot of doubts about the battery price, the range, the resell value and the very slow market. One dealership called electric vehicles "dead products" as they are "extremely unpopular". Another car dealer called electric vehicles as "crucial" in order to fulfil 2025 gas consumption goals and another mentioned that "they seem to be a little bit behind in that field". Generally speaking, US makers seem to be divided on the question of whether e-mobility should be a key concept of future mobility as the answer varies between great skepticism and moderate acceptance. 
JP dealerships seem to be slightly negative about e-mobility except for two dealerships. Only 5 of the 8 dealerships offered more than one PHEV or EV and 2 do not even offer EV or PHEV. For the most part, JP car dealerships usually offer PHEV instead of EV. Some dealerships focus on the improvement of their actual gas engines or develop new diesel engines for trucks and SUVs. One maker works on "fuel economy and tries to make the car lighter and 100\% recyclable". Another JP maker said that "PHEV and fully EV was not good for this market and we are waiting for higher gas prices to boost sales of PHEV”. One JP car dealership said that the infrastructure needed to be improved and fully EV was only for US makers in order to compensate for their high truck and SUVsales. To summarize, Japanese car dealerships do not seem to be more focused on EV or PHEV than their US competitors. A reason for that might be that JP makers have been offering EV and PHEV in particular for many years without seeing an actual breakthrough of that technology. Most car dealerships expect e-mobility to be a substantial part of their business in 10 or more years.

However, GE car makers seem to be different here. All eight interviews were scored positive with a minimum score of 0.3 and a maximum of 0.9 . Furthermore, the spread between the best and worse value is the lowest ( 0.6 vs. 1.0 at JP and 1.2 at US car dealerships) which indicates that all makers at least tend to see e-mobility as a positive trend. Although GE car makers have not been strong in the area of EV and PHEV, they seem to be extremely positive about a near breakthrough of e-mobility. More than half of the GE car dealerships expect that breakthrough "within the next four to five years" as "the cars manufacturers put all their effort in the development of EV". Furthermore, six out of the eight dealerships will put their focus in pure EV instead of 
PHEV which shows their commitment to that area. One car maker called this trend "the right thing to do for the environment". Another dealer describes his brand as a "frontrunner" in the field of e-mobility and another claims that his company "will be big in e-mobility". Although GE car makers have been weak in this field and a lot of their business was done by their JP competitors, they seem to be extremely willing to close that gap and even plan on becoming the leader in that new market. Therefore, GE car makers seem to be very positive, optimistic and consequent but also brave with their e-mobility strategy. One reason for that could be that GE car makers were forced by customers to reduce their activities in the development of diesel engines after Volkswagen's emission scandal went public, and increase their spending in e-mobility in order to restore their positive image.

Although some of the JP and US car makers have offered a couple of EV and PHEV for the past years, the market has not seen a breakthrough yet. GE car makers just recently started their e-mobility strategy but put a lot of effort and motivation in it. It was also found that their car dealerships are more positive and convinced about emobility as a crucial part of future mobility than their JP and US competitors. At that point of time, especially two JP makers seem to have a certain advantage in the field of e-mobility but that might be different in about five years as GE car dealerships are finally changing their strategy, their personnel's mindset and eventually their products.

After analyzing all ten hypotheses and sub-hypotheses, Table 29 shows how many of the sub-hypotheses are significant. For hypothesis $6,8,9$, and 10 , no subhypotheses were defined. 
Table 29: Number of sub-hypotheses that were found significant

\begin{tabular}{|c|c|c|}
\hline Hypothesis & $\begin{array}{l}\text { Number of significant } \\
\text { sub-hypotheses }\end{array}$ & $\begin{array}{l}\text { Total number of sub- } \\
\text { hypotheses }\end{array}$ \\
\hline 1 & 5 & 10 \\
\hline 2 & 2 & 10 \\
\hline 3 & 5 & 10 \\
\hline 4 & 7 & 9 \\
\hline 5 & 4 & 9 \\
\hline 6 & \multicolumn{2}{|c|}{$\mid$} \\
\hline 7 & 4 & 1 \\
\hline 8 & \multicolumn{2}{|c|}{} \\
\hline 9 & \multicolumn{2}{|c|}{} \\
\hline 10 & \multicolumn{2}{|c|}{} \\
\hline
\end{tabular}




\section{CHAPTER 5}

\section{CONCLUSION}

\subsection{Summary of Findings}

The goal of this thesis was to gain a deeper understanding of the different order fulfilment and after-sales strategies which are used in the US by various automobile manufacturers from Japan, Germany and the US. The main result of this study is that German, Japanese and American car makers and their dealerships cannot be compared with each other appropriately without distinguishing between standard and luxury makers. For example, the results show that there is no significant difference between the delivery time of Japanese and American or Japanese and German car dealerships in general but when standard and luxury makers are considered, the picture is different. Now, it can be shown that Japanese standard car dealerships have a lower delivery time than US standard car dealerships whereas Japanese luxury car dealerships have a higher delivery time than German luxury dealerships.

Another main result of this study is that German luxury car dealerships are stronger than their Japanese and American competitors. For example, German luxury car dealerships offer more models than their Japanese and American luxury competitors,

have a lower delivery time and offer more extended dealer options than Japanese and American luxury car dealerships. Furthermore, German luxury dealerships sell more vehicles per dealership than their Japanese rivals which shows that German luxury car dealerships work more efficiently. German luxury car dealerships also still offer more customization for their customers as they use the build-to-order strategy more than their 
Japanese and American luxury rivals. German luxury car makers have a wellpositioned, highly competitive luxury model range and not only sell a product but also sell the brand and the positive, highly-engineered product image that is connected to cars made in Germany.

Japanese standard car makers have been very successful in the US over the past decades but their German and American standard competitors were able to reduce the gap. For example, the average percentage of vehicles sold from the inventory at Japanese standard car dealerships is $89 \%$, whereas US and German standard car dealerships sell about $85 \%$ of their vehicles from the inventory. However, Japanese standard car dealerships still have a very strong position in the inexpensive sedan- and crossover-business as their average MSRP is much lower than the average US standard MSRP. US standard makers are strong in selling expensive SUVs and trucks. Furthermore, Japanese car dealerships still have the highest inventory turns (4.2), followed by the Germans (3.7) and the Americans (2.4). That indicates that Japanese car makers still have a much leaner and eventually faster dealership system than their German and US competitors.

In terms of electric mobility, it can be concluded that at this point of time, Japanese makers still have a slight advantage over their German and American rivals, because they offer more EV and PHEV models at this time. However, this is likely to change in the future as German car dealerships are changing their strategy, personnel's mindset and products. They are more positive and convinced that electric vehicles and hybrids are a crucial part of future mobility, when compared to their Japanese and American competitors. 


\subsection{Future Work}

For this research, 24 different car dealerships were interviewed whose answers were transcribed after the interview. However, only two participants agreed to be audiorecorded which had an impact on the quality of the data as the other 22 interviews were transcribed based on notes taken during the interview. In addition, future studies could include quantitative Likert style scales regarding brand image, e-Mobility outlook, or other topics of interest. Furthermore, the sample size of 24 is relatively small as only 8 interviews from German, Japanese and US car dealerships were conducted, and all were limited to the state of Rhode Island and very close surroundings. Because of the small sample size, the standard deviation of some results is relatively high which led to the choice of an $\alpha$-value of 0.1 . This leads to a $10 \%$ chance of a type I error where the null hypothesis would be rejected although it is correct.

In order to increase the accuracy of the study, future work should extend this study to further states in New England and the US as this will lead to a smaller standard deviation. This could allow the use of an $\alpha$-value of 0.05 . Furthermore, future work could include interviews with managers and experts at the companies' automotive planning and scheduling departments in addition to dealership interviews. Another very common method in the automotive industry is the use of the Delphi survey method. This means that the questions from this interview will be asked again to the participants but this time, they will be able to see the de-identified answers from the other dealerships. Based on this influence, they might correct or elaborate their previous answer. Consequently, this strategy encourages the participants to revise their earlier answers in light of the replies of other participants. Hence, the range of the different answers could 
be decreased and the answers could converge towards the "correct" answer (Wright, 1999).

Despite the named limitations of the study, the goal was achieved as the ten hypotheses and their sub-hypotheses that were tested gave a good overview of the differences between Japanese, German and American car dealership approaches in the US. Their model policy, average delivery time and dealer options were studied, as well as their after-sales activities, service and personnel strategy. This is one of the first studies that includes the dealership perspective about electro mobility and distinguishes between standard and premium makers of Japanese, German and American car dealerships in the US car market. It is a valuable base for future work in the field of comparing different car dealership approaches in the US. 


\begin{abstract}
APPENDIX A
$\underline{\text { Recruitment material: }}$

Dear Sir or Madam,

You are being asked to take part in a research study conducted by the University of Rhode Island (URI). The purpose of this research study is to gain a deeper understanding of the order fulfilment and after-sales strategies of dealerships that represent automobile manufacturers from around the world. The researchers will analyze similarities and differences between the approaches that various car makers use. If you agree to be in this study, you will have an interview with the researcher that will last approximately 60 minutes. The interview will be audio recorded if you allow take place at your dealership. You are eligible to participate if you are a manager at a dealership and you have to be older than 17. Questions will be asked about the order fulfilment strategy as well as specific questions regarding the after-sales business. The questions can be provided in advance, if needed. There are no known risks, benefits or compensation. If you have questions about the study, at any time feel free to contact Dr. Valerie Maier-Speredelozzi from the Mechanical, Industrial and Systems Engineering Department at 401-874-5187. She is the Principal Investigator and responsible for the research. Furthermore, this research has been approved by the University of Rhode Island Institutional Review Board.
\end{abstract}


Interview questions:

1. Do you agree to proceed with the interview and begin with audio recording?

2. How many different models does the company offer?

(In this case, a model is meant to be a separate car, including different options. However, if there is a hybrid or electric version of this specific vehicle, it counts as two different models. The amount of models is equal to the number given on the website. Commercial vehicles are not included.)

3. How many days does it take to get the car after placing an order with the auto maker if the customer cannot find the car on the lot?

(This question refers to the customer. Is there any difference in the time for the customer and the dealership? When the customer orders a car, is the order placed immediately?)

4. How much dealer inventory do you have? (How many cars are waiting to get sold on the lot?)

5. What percentage of all customer orders is sold from inventory?

6. What dealer options do you have?

7. Are the dealer options decided by the dealer or the auto maker?

8. Do you order option parts directly at the parts makers or at the auto maker?

9. Do you receive a sales quota from the auto maker?

(To determine whether the company sets a fixed target of cars that need to get sold)

10. Do you receive sales incentives from the auto maker?

11. What are the main challenges in the after-sales-service business?

(General overview of the challenges and problems that are faced today)

12. Is the average time that is needed to fix a customer service measured? (If a customer gets to the dealership to make an oil change, a brake check or a filter replacement, is the average time that is needed for the work measured?)

13. How are service personnel trained and who gets trained?

14. What kind of warranty models do you offer?

(If a customer buys a car at your dealership, which different types of warranties is he/she able to buy and what does the warranty include? Which one is the best-seller?)

15. How is the customer satisfaction rate measured?

(How do you determine that your customers are happy with the service you provided?)

16. What are the main challenges for the future and what does the dealership of tomorrow look like?

(Open question, also consider the trend towards BEV and HEV and their effect on a car repair, amount of spare parts etc.)

17. Are there already BEV (Battery Electric Vehicles) or HEV (Hybrid Electric Vehicles) in your show room or offered by this auto maker? 


\section{Low Risk Survey Consent Form for Research}

You are being asked to take part in a research study. The purpose of the research study is to gain a deeper understanding of the order fulfilment and after-sales strategies of dealerships in Rhode Island that represent automobile manufacturers from around the world. The researchers will analyze similarities and differences between the different concepts that various car makers use. Please read the following before agreeing to be in the study. If you agree to be in this study, you will have an interview with the researcher that will last approximately 60 minutes. Questions will be asked about the order fulfilment strategy as well as specific questions regarding the after-sales business. The questions can be provided in advance, if needed. There are no known risks, benefits or compensation.

Your responses will be confidential and you have to be older than 17 years and a manager at the dealership. The responses will be used in a master thesis. If you agree to be audio recorded, you can ask for the recording to stop at any time. The audio recording will not identify you by name and will be destroyed within 1 year of completing the study.

The decision to participate in this study is entirely up to you. You may refuse to take part in the study at any time without affecting your relationship with the investigators of this study or the University of Rhode Island (URI). Your decision will not result in any loss of benefits to which you are otherwise entitled. You have the right not to answer any single question, as well as to withdraw completely from the survey at any point during the process; additionally, you have the right to request that the researchers not use any of your responses.

You have the right to ask questions about this research study and to have those questions answered by me before, during or after the research. If you have questions about the study, at any time feel free to contact Dr. Valerie Maier-Speredelozzi from the Mechanical, Industrial and Systems Engineering Department at 401-874-5187.

Additionally, you may contact the URI Institutional Review Board (IRB) if you have questions regarding your rights as a research participant. Also contact the IRB if you have questions, complaints or concerns which you do not feel you can discuss with the investigator. The University of Rhode Island IRB may be reached by phone at (401) 874-4328 or by e-mail at researchintegrity@etal.uri.edu. You may also contact the URI Vice President for Research and Economic Development by phone at (401) 874-4576.

You may keep a copy of this document for your records. You may also contact the researcher to request a copy. By proceeding with the interview, you indicate that you have read and understood the above and volunteer to participate in this study and consent to be audio recorded. 


\begin{abstract}
APPENDIX B
Appendix B contains the notes of the 24 different interviews. At first, the 8 German interviews will be shown followed by the Japanese and the American. After taking the interviews, the number of models given during the interview was adjusted based on the definition of different car models made in the methodology section. The adjusted answer is written in squared brackets [\#]. Furthermore, in order to make the different car dealerships anonymous, their name is replaced by the country's abbreviation and a number.
\end{abstract}

GE1

1. Do you agree to proceed with the interview and begin with audio recording?

It is going to be hard to audio-record me because I get interrupted very quickly and very often. It might be easier for you to just put down some notes.

2. How many different models does the company offer?

At this moment, [GE1] is selling 11 [13] different models

3. How many days does it take to get the car after placing an order with the auto maker if the customer cannot find the car on the lot?

If the customer cannot find his car in the inventory, the car will get ordered and built in Germany. This process usually takes around 90 days but that's something that we don't do anymore. Only 2-3\% of the customers order their own specific car and are willing to wait that long. That's usually something for high-price products. Once the order gets placed, which happens the same day when the customer orders his car, the allocation process starts and tries to find a free spot that is available. This means, when the car can be produced and how long it is going to take to bring all the extras together. That process can take several days.

4. How much dealer inventory do you have? Right now there are 162 cars on the lot which is a high number compared to the average that is around 100 cars. The reason for that is that the business has been a bit slow this year and the production is still high. Furthermore, the winter is not the time when people think about buying a 50,000 or $60,000 \$$ car because of all the potholes, the salt or the sand on the streets. It is just not on their list. Usually, sales recover in march though.

5. What percentage of all customer orders is sold from inventory? 
About $75 \%$ of the time people choose to take a car from the dealerships inventory.

6. What dealer options do you have?

There are many different options and they all depend on the model. For some cars there are only 5 options but for others there are nearly 50 different options. Sometimes the whole variety of options makes it hard for customer to decide what they should take and what not. Therefore the automaker tries to offer not only single accessories but also more and more option-packages. However, all the operations are being done here at the dealership.

7. Are the dealer options decided by the dealer or the auto maker?

As we only sell [GE1] -products, all the dealer options are decided by [GE1]. They don't come from us.

8. Do you order option parts directly at the parts makers or at the auto maker? All the parts come from the OEM (Original Equipment Manufacturer) so therefore come from [GE1]. This is part of our contract that we are having with [GE1]. We are not allowed to get cars off the market.

9. Do you receive a sales quota from the auto maker?

We receive a yearly quote of the amount of cars that we have to sell. We get this information at the beginning of the year. They call that DSP which means dealer sales plan. They revise this plan as business is off. There are many factors that have an impact on our business. This can be the stock market, a national disaster or a war.

10. Do you receive sales incentives from the auto maker?

Yes, we do receive them from [GE1]. If we hit the target we get the money. So they usually break it down quarterly and will send us x-amount of money. If you don't hit it, they give an extra incentive if the business is slow. The incentive is different though and depends on the car. A 100,000 \$ [GE1] A8 gets another amount as a smaller hatchback. The A8 in this case would get between 4,000 and 6,000\$. Could also be only $500 \$$.

11. What are the main challenges in the after-sales-service business? Generally speaking, there are two main challenges for the after-sales-service business. The first problem is the availability of parts as all the parts come from Germany and sometimes take an unpredictable amount of time until the parts arrive at the dealership. Let's say there is a major uniform problem that causes a recall of let's say 300 people, a big problem is to get the parts needed. The second problem is the manpower. Not having enough people that can fix the cars in the amount of time it should be repaired.

12. Is the average time that is needed to fix a customer service measured?

Not specially measured but the numbers come from experience and the manufacturer knows how much they call for that job. The parts usually come from Germany and go to New Jersey or Massachusetts.

\section{How are service personnel trained and who gets trained?}


[GE1] sends them out. They go to Massachusetts or New Jersey and they stay there for 2 to 3 days and get trained on the new models.

\section{What kind of warranty models do you offer?}

Every customer gets the [GE1] warranty that they put on their cars which is 4 years and 50,000 miles. However, the warranty can be extended in terms of coverage, time, the make, the model etc. Actually, there is an infinite number of different warranty models that customer can choose from. The warranty can come from [GE1] but also from other insurance companies.

\section{How is the customer satisfaction rate measured?}

This is what J.D. Power does. They send an email to every customer that bought a car or did a service at the dealership and they will ask the customer to answer different questions about the service at the company and the dealership in general.

16. What are the main challenges for the future and what does the dealership of tomorrow look like?

The main challenges are going to be the trend towards SUV and HEV. HEV have been a challenge for [GE1] so far but with the new Q8 there is one new upcoming model. The Q8 is going to be a SUV as the company tries to shift its model lineup to $60-65 \%$ SUV and 30-35\% sedans. Customers want all kind of SUV. Small, midsize and large SUV. This is because families are carrying around more and more different stuff and materials and they need more and more room. Furthermore, the dealership of the future should offer the family all kind of options they need. This store has been renovated two years ago in order to make the customer feel more comfortable with a bar, restrooms and a lounge. All these changes come from [GE1] and are all brand related. That's why every [GE1] dealerships looks quite similar.

\section{Are there already BEV (Battery Electric Vehicles) or HEV (Hybrid Electric} Vehicles) in your show room or offered by this auto maker?

The company had an [GE1] Q5 hybrid which was not even a plug-in hybrid. But they stopped production and will come with a brand-new Q5 HEV which is going to be a plug-in hybrid too.

\section{GE2}

1. Do you agree to proceed with the interview and begin with audio recording? I prefer when you just take notes because I don't want to be audio-recorded.

2. How many different models does the company offer? 
Right now [GE2] offers six different SUVs and six different sedans plus two different electric vehicles, so in total we are offering 14 [15] different models.

3. How many days does it take to get the car after placing an order with the auto maker if the customer cannot find the car on the lot?

What we would do first is, we would try to locate the vehicle in the inventory or we would just build our own car. If the car comes from South Carolina, where usually our SUV models are build, it would take between 4 to 6 weeks. If we would order one of our sedans which are built in Germany, it would take 6 to 9 weeks. We do a lot of ordering cars at the manufacturer, so I would say it's about $25 \%$.

4. How much dealer inventory do you have?

Right now, I have 87 new cars in our store which is about average for our size of store. We are a small to medium size store. Our main business is from April to December.

5. What percentage of all customer orders is sold from inventory?

The majority tries to find it from our inventory, so I think $75 \%$ can find their car based on our and other dealers inventory. And 25\% would place an order at the maker. We have about $10 \%$ of our customers that would always order a car at the manufacturer.

6. What dealer options do you have?

We can actually do a lot of car cosmetics and accessories at the dealership such as exhaust pipes, wheels, spoilers, navigation systems or we can also add performance packages. Usually we would add all these things right at the port when a car comes from the factory. Here at the dealership, we usually don't do a lot of things. We might just add a tow hitch or small things like that. But usually we offer different trim levels with different accessories. However, even our baseline models are equipped with rear cameras and leather, something every customer has to have today.

7. Are the dealer options decided by the dealer or the auto maker? All the options are controlled by [GE2].

8. Do you order option parts directly at the parts makers or at the auto maker? We order our parts at [GE2] only. This has to do with the high quality standard the company is offering and also the validity of our cars warranties.

9. Do you receive a sales quota from the auto maker?

Yes we receive a month to month sales quota which I would consider is realistic. It is based on our market share and the market performance.

10. Do you receive sales incentives from the auto maker?

Yes we do get them. There are special rebates and special incentives such as a 1500 dollar loyalty incentive, we have to give to the customer in order to reduce the MSRP.

11. What are the main challenges in the after-sales-service business? 
When customers bought a car, you want to make sure that they would stay at your facility and use it. So what we do is we give discount coupons to encourage them to get parts accessories. We want them to get to the [GE2] dealership. We also offer them discounts on a performance upgrade that id backed by the manufacturer's warranty. We usually have a high loyalty rate as we have people that bought their third, fourth or fifth car at the dealership. About $50 \%$ of our customers finance and the other $50 \%$ lease their car.

12. Is the average time that is needed to fix a customer service measured?

There are guidelines from [GE2] that say how long an oil change or a transmission job would usually take and that is the time the customer pays.

13. How are service personnel trained and who gets trained?

[GE2] is very good at training as they provide monthly training for their employees. They would send people and also want people to go through the car and understand the product. They do in-house and out-house training.

14. What kind of warranty models do you offer?

Every new car comes with a 3 year $36 \mathrm{k}$ miles maintenance warranty which covers scheduled maintenance such as tires, windshield, brakes and wiper blades. There is also the 4 yrs 50k miles bumper to bumper repair warranty and if it is required the warranty can be extended. The three year warranty does not cover brakes and wipers.

\section{How is the customer satisfaction rate measured?}

This is very important for us. Everyone that bought a new or preowned vehicle will get an email survey and the customers have to answer that. If the result is less than good, we failed and we will have to report the result and try to figure out how we can improve that. It is about 10 questions. And by the end of each month, we compare our monthly performance to the other stores by CSI. By the end of the year we are also compared to the other dealership in the region and the best receive special incentives for their sales.

16. What are the main challenges for the future and what does the dealership of tomorrow look like?

The thing is that today, everybody, even the low-budget vehicles have backup cameras, navigation and things like that. The thing is about having the best technology in terms of passenger safety such as blind sport, pedestrian warning etc. and the best quality and customer service in the market. And of course, the new styling of our new vehicles.

17. Are there already BEV (Battery Electric Vehicles) or HEV (Hybrid Electric Vehicles) in your show room or offered by this auto maker?

Today, [GE2] has a very good selection of PHEV such as the X5, 3er and 5er sedans and the $\mathrm{i} 3$ as a fully EV and the $\mathrm{i} 8$ as a performance EV. 
1. Do you agree to proceed with the interview and begin with audio recording?

It is better when you just take notes because I don't know if I get interrupted or not during the interview.

2. How many different models does the company offer?

At this moment, [GE3] offers sedans and SUV. For the sedans, the company offers 2, 3, 4, 5, 6 and 7 series plus the convertible Z4. For the SUVs, [GE3] offers the X1, $\mathrm{X} 2, \mathrm{X} 3, \mathrm{X} 4, \mathrm{X} 5$ and the X6 which gives 13 different models. Furthermore, the company offers the electric vehicle $\mathrm{i} 3$ and the hybrid i8. So in total, [GE3] offers 15 models. Most of the models use a 4 cylinder engine, followed by a 6 and some 8 and 12 cylinder engines. There are also a couple of diesel engines, especially for the 3 and 5 series and the X5 and the upcoming X7 such as several PHEV. The positive thing about [GE3] is that we use the same engines in different models meaning that the 2, 3, 4 series have the same 4 cylinders and the 5, 6 and 7 series use the same 6 cylinder engine. In some models we offer the $601 \mathrm{hp}$ twin turbo W12 cylinder engine.

3. How many days does it take to get the car after placing an order with the auto maker if the customer cannot find the car on the lot?

Sometimes, it is very difficult to meet the customers guideline. Therefore, if a car cannot be found in the lot, we basically do three different things. The first thing is that we order the car in Germany what we do for the majority of our sedans. The whole process takes between 6 to 8 weeks where 1-2 weeks are allocation and other processes and the actual production and shipping to New Jersey takes 6 weeks. The second option is ordering the SUVs in Spartanburg, South Carolina. Here, the whole process takes between 3 to 4 weeks. The third but very rare option is the individual ordering process. Here, a customer can choose its own leather that is usually not available for the car but they will customize it for you. This implies a significant higher amount of money. It takes between 3 to 6 months and costs between 2,000 and 7,000 \$. But this is very rare and only happens once or twice a year. 10 to $20 \%$ of the customers customize their own car (optn 1 or 2) and another 10 to 20 percent find the cat on another dealer's lot. To find the car we use a very sophisticated system. In total, I have to say that we can find a decent amount of factory ordered cars which makes sense as customers want to build their own 40,50, 60 or 100k $\$$ car.

4. How much dealer inventory do you have?

Right now, I have 176 new cars and 98 pre-owned cars.

5. What percentage of all customer orders is sold from inventory? 
It's about $60 \%$. That's because buying a car is always something emotional. People see the car and fall in love with it. Also, [GE3] has one of the highest brand loyality which is about $90 \%$.

6. What dealer options do you have?

Very minimal. If you order a car, it comes with all tec options from the factory. Because [GE3] does not want the quality to drop and therefore installs all the options with the high [GE3] standard in the factory. So there is little customization at the dealership. However, what we do is offer a high amount of car cosmetics such as wheels, spoilers, carbon fiber optics and also work with Dinan, the tuning company of [GE3]. You can increase the hp and that does not change the actual warranty [GE3] gives you and they just do it in the dealership.

7. Are the dealer options decided by the dealer or the auto maker?

All the options are controlled by the manufacturer and they have to get authorization from [GE3] always. [GE3] is like Apple where the company wants to ensure the high quality standard.

8. Do you order option parts directly at the parts makers or at the auto maker? The parts are ordered at [GE3] and [GE3] sends them directly to the dealership.

9. Do you receive a sales quota from the auto maker?

Yes we do receive sales quota from the auto maker. We get a new vehicle quota and a pre-owned quota. However, we do not only receive a quota from [GE3] but also from the dealership holding Penske automobile. But this is only a quota for the total vehicle sales. However, the difference between the two different quotas is less than 5 percent. In comparison to other companies, our sales goals are realistic as we are grouped by different markets. We are in the market $\mathrm{E}$ and therefore we are not compared to cities like NYC, LA or MIA which are in group F. Every group has similar demographic characteristics. Furthermore, the last 5 to 7 years are considered when the new sales quotas are determined.

10. Do you receive sales incentives from the auto maker?

Yes we do get them. Whenever a car comes in. However, factory-ordered incentives might be gone by the time the car comes. I can only give the incentives today. The incentives are decided on a monthly basis and we get them every first of the new month. The incentives per car depend on several factors: How do you get your car? Buy? Lease? Loyalty? And that depend on the submodel, whatever they want to push. The incentive can be between 0 to 6000 \$.

11. What are the main challenges in the after-sales-service business?

12. Is the average time that is needed to fix a customer service measured?

13. How are service personnel trained and who gets trained?

14. What kind of warranty models do you offer?

Every new car comes with a 3 year $36 \mathrm{k}$ miles maintenance warranty which covers scheduled maintenance such as tires, windshield, brakes and swiper blades. There is 
also the 4 yrs 50k miles bumper to bumper repair warranty and if it is required the warranty can be extended. The company only offers [GE3] products but there is also a non [GE3] tire warranty. [GE3] insurances are usually a bit more expensive but also more convenient because it is faster to book them. An extra warranty can cost up to $8000 \$$ and can include extras in power-train, suspensions, and electronics and also extended in length and time

\section{How is the customer satisfaction rate measured?}

This is very important for [GE3]. After a customer bought a car, he or she gets a survey containing 4 questions and they can value how their experience was (1-10) and if they would recommend the business. Plus they can make comments twice. In our new model, the system distinguishes in promoter who achieve 9-10 points, passive (7-8 points) or detractors who chose less than 8 points. The overall score is determined by subtracting the promoter minus the detractor. Because it is so short, it is worth it spending the time and everything works via email. Also [GE3] sees the result and they have to act when a customer is a detractor and they have to proof that to [GE3].

16. What are the main challenges for the future and what does the dealership of tomorrow look like?

Customers are really smart. With the use of the internet they don't want to negotiate anymore and they know the prices. More and more people don't go to the dealership anymore but do home shopping and contact 5-6 different dealership. So the customer do their research and therefore online recommendation is very important. Also, by 2025, the overall fleet has to achieve an average consumption of $54.5 \mathrm{mpg}$. In 2017 [GE3] was at $40 \mathrm{mpg}$ based on the sold models. The supply and demand of big engine cars is therefore controlled by [GE3]. Lets say, if they send me 3 series cars, they will send my 12320,18330 and 4340 in order to push four cylinder cars. It's always a trade-off of profit and fuel economy because you make more money with 6 cylinder cars.

17. Are there already BEV (Battery Electric Vehicles) or HEV (Hybrid Electric Vehicles) in your show room or offered by this auto maker?

Yes [GE3] offers more and more plug-in-hybrids that are able to drive 15 to 20 miles fully electronically and the i 3 is able to drive 120 miles fully electronically. In the future, every single model will be available as a PHEV. The problem here is, where do you put the battery as you cannot just put the battery somewhere in the car. The cars get redesigned. However, [GE3] is a frontrunner in EV. Also the state and the government should support the sale of PHEV and EV. 
1. Do you agree to proceed with the interview and begin with audio recording?

I don't want to be audio-recorded.

2. How many different models does the company offer?

We are offering nine [10] different models plus one electric vehicle which gives a total number of ten vehicles.

3. How many days does it take to get the car after placing an order with the auto maker if the customer cannot find the car on the lot?

If customers are very serious about their order, we would just try to do a dealer swap and get a deposit from the customer. We usually do not order at the manufacturer because our customers are not willing to wait that long.

4. How much dealer inventory do you have?

Right now, we have about 250 new and preowned vehicles in stock which is about average.

5. What percentage of all customer orders is sold from inventory?

I would say about $70 \%$. Because of the internet these days, customers know what they want and they know if we have it in stock or not and they would just come to us if we have it or they would go to the place which has the car.

6. What dealer options do you have?

We can do wheels and tires and other stuff but we usually don't do that. What we don't do is swapping leather. We recommend our customers getting as higher trim that includes leather.

7. Are the dealer options decided by the dealer or the auto maker?

All the options are controlled by the manufacturer.

8. Do you order option parts directly at the parts makers or at the auto maker? If a car is in a lease, we would use OEM parts but if there is someone coming that bought a car or another maker, our parts center also uses third party companies.

9. Do you receive a sales quota from the auto maker? Yes we receive a month to month sales quota which I would consider is realistic.

10. Do you receive sales incentives from the auto maker? Yes we do get them and we should always give that to the customer.

11. What are the main challenges in the after-sales-service business?

10 years ago people would still negotiate the price but today we already give them the lowest price.

12. Is the average time that is needed to fix a customer service measured?

Yes it is based on a catalogue the manufacturer provides us.

13. How are service personnel trained and who gets trained?

They do instore and out-store training every year. 


\section{What kind of warranty models do you offer?}

For our new cars we offer a 6 year 72k miles bumper to bumper warranty and 4 $\mathrm{yr} / 50 \mathrm{k}$ miles for Audi.

15. How is the customer satisfaction rate measured?

Customers can leave a google review, they can visit our website and also use the dealerrater which is a very powerful instrument today.

16. What are the main challenges for the future and what does the dealership of tomorrow look like?

Right now, we are facing a very strong shift towards small and midsize SUVs and these vehicles are very hot right now. Also, we expect a shift towards more BEV and PHEV in the next years as soon as the infrastructure is getting better.

17. Are there already BEV (Battery Electric Vehicles) or HEV (Hybrid Electric Vehicles) in your show room or offered by this auto maker?

We offer the egolf which will have up to 125 miles range by the end of this year and many more models are planned within the next 5 years.

\section{GE5}

1. Do you agree to proceed with the interview and begin with audio recording?

I don't want to be audio-recorded.

2. How many different models does the company offer?

We are offering 13 [10] different models plus one electric vehicle which gives a total number of 14 vehicles.

3. How many days does it take to get the car after placing an order with the auto maker if the customer cannot find the car on the lot?

If customers cannot find their car on the lot, we would locate the car and swap it. We can also order the car at one of our factories and then it really depends on the models. Depending on the models it can take 4 to 6 months, so usually try to find the car.

4. How much dealer inventory do you have?

Right now, we have 178 new and 72 preowned vehicles in stock which is about average as we start in our main season.

5. What percentage of all customer orders is sold from inventory? I would say about $85 \%$ of our customers find the car here.

6. What dealer options do you have?

We cannot change the options, we only do accessories. If someone wants to have leather for example, they would just get a different trim level, as we offer three of them.

7. Are the dealer options decided by the dealer or the auto maker? 
The accessories are decided by the dealership but [GE5] decides the different trim levels. All these levels are decided by an allocation system.

8. Do you order option parts directly at the parts makers or at the auto maker? We order all the parts directly at the OEM.

9. Do you receive a sales quota from the auto maker? Yes we receive it but it is called an objective. So we don't have to hit that goal but it could be good for our reputation in the company and it could also impact the allocation process for the next months.

10. Do you receive sales incentives from the auto maker?

The company defines different levels and every level is connected with a certain cash incentive. The higher the level, the higher the cash incentive. There is either dealer cash that directly goes to the dealership and the dealership can do whatever it wants and there are rebates that the company gives to its customers. Right now, we are giving $500 \$$ off for the all-new Atlas.

11. What are the main challenges in the after-sales-service business? A challenge is that customers know the real price before they come in the dealership. So it is hard for us to find the best price for this specific situation. This is especially a problem when people trade-in their car.

12. Is the average time that is needed to fix a customer service measured? I cannot answer you this question.

13. How are service personnel trained and who gets trained?

They would do in-store and also out-store training. Next month I will go to a facility in order to learn about the all-new Jetta.

14. What kind of warranty models do you offer?

For our new cars we offer a 6 year $72 \mathrm{k}$ miles bumper to bumper warranty and usually customers would only get this kind of insurance because that everything they need.

15. How is the customer satisfaction rate measured?

The company sends out surveys after each purchase or service. Furthermore, the company works with J.D. power which compares us with other brands. In terms of the dealership, I don't know if we are ranked and compared to the other dealerships in the region. This is more a question for a manager.

16. What are the main challenges for the future and what does the dealership of tomorrow look like?

I think in the future, everything is going to be automated and there will be a set price and you go to a place and pick up the product. I think this is how it is going to be in about 10 years. Also a main challenge is the SUV trend. Today we are selling more SUVs than cars and this trend is still going to intensify.

17. Are there already BEV (Battery Electric Vehicles) or HEV (Hybrid Electric Vehicles) in your show room or offered by this auto maker? 
We offer the egolf which will have up to 125 miles range by the end of this year and many more models are planned within the next 5 years. I think that [GE5]is going to be strong in EV because that's where they put all their concentration on.

GE6

1. Do you agree to proceed with the interview and begin with audio recording? I prefer when you just take notes because I don't want to be audio-recorded.

2. How many different models does the company offer?

We are offering about 15 [19] different models with different submodels and trim levels.

3. How many days does it take to get the car after placing an order with the auto maker if the customer cannot find the car on the lot?

If the car exists we would try to do a dealer trade because that would be the fastest. If the car does not exist or the dealer does not want to give it up, we would place and order at the manufacturer and wait for the next allocation round where we would get the vehicle. It usually takes between 2 to 3 months and if the car is produced in the US such as our SUV and 6 to 8 weeks if it comes from Germany.

4. How much dealer inventory do you have?

Right now, we have about 150 new and 60 pre-owned vehicles which is pretty much about average.

5. What percentage of all customer orders is sold from inventory?

I would say about $50 \%$. That is much lower than the other companies because our customers are so specific and even after we try to do dealer swaps, still $10 \%$ of the customers would like to order their car and are willing to wait.

6. What dealer options do you have?

We can do mat flabs, running boards or roof rags. This is more the accessory parts but we would not physically replace parts at the vehicle because [GE6] would do that at their factory in order to keep their high standard. But we can add performance to the car if the customer wants to. We would do that with the car maker together such as Brabus.

7. Are the dealer options decided by the dealer or the auto maker?

All the options are controlled by the manufacturer and we would get the cars based on what they project for the region.

8. Do you order option parts directly at the parts makers or at the auto maker? We use [GE6] parts only. This has to do with the high quality standard the company is offering and also the validity of our cars warranties.

9. Do you receive a sales quota from the auto maker? 
Yes we receive a month to month sales quota which I would consider is realistic. It is based on our market share and the market performance.

\section{Do you receive sales incentives from the auto maker?}

Yes we do get them and we should always give that to the customer. So, if a car costs 80,000 dollars and we get a rebate of 1,000 dollar, we have to give that discount directly to the customer, so a new car will cost 79,000 dollars instead.

11. What are the main challenges in the after-sales-service business?

All the prices are just a couple of clicks away and therefore we have very educated customers. Furthermore, in order to be special, we have to provide them with special services such as free pick-ups \& deliveries.

12. Is the average time that is needed to fix a customer service measured?

The manufacturer has quotes for a brake job, telling the mechanic how long he should need in order to fulfil the job. He only gets paid or the time and the customer will only pay that time.

13. How are service personnel trained and who gets trained?

For our new models, a [GE6] rap comes in and does all the training with the people. Sometimes we would also take a look at our competitors and do a comparison to learn something about the others. Our main competitor is BMW and Audi and in some parts Lexus.

14. What kind of warranty models do you offer?

For our new cars we offer a 4 year 50k miles engine and transmission warranty. We usually do leasing, it's about $60 \%$ and $40 \%$ does cash or financing. Leasing is very good for us because we can keep the customer and at the end of the time we get very good, certified pre-owned vehicles.

\section{How is the customer satisfaction rate measured?}

[GE6] will send out surveys and they measure different KPIs and CSI. At the end they will compare all the data with other dealerships and the management will get different incentives, based on the comparison.

16. What are the main challenges for the future and what does the dealership of tomorrow look like?

Right now, we are facing a very strong shift towards small and midsize SUVs and these vehicles are very hot right now. As a dealer I would say that the buyer is being more educated with the amount of different websites that it can use. In the past, the sales department was the most profitable part of the business, however today it is the service part that has become very important.

17. Are there already BEV (Battery Electric Vehicles) or HEV (Hybrid Electric Vehicles) in your show room or offered by this auto maker?

[GE6] does offer PHEV and an EV which is GLC e and basically only sold in California. However, in 2019 they will start offering that here and they have more vehicle in their pipe. So far, the BEV and PHEV have not been successful but in the 
future they will. In about 3 to 4 years, every model will be equipped with a mild hybrid system that can assist in fuel economy.

GE7

1. Do you agree to proceed with the interview and begin with audio recording?

VIt is better when you just take notes because I don't know if I get interrupted or not during the interview.

2. How many different models does the company offer?

At this moment [GE7] is offering 8 [10] different models.

3. How many days does it take to get the car after placing an order with the auto maker if the customer cannot find the car on the lot?

That really depends where the car is made. [GE7] builds cars in Mexico, the US and Germany. If cars come from Germany, they can take 6 to 10 weeks. If you want to customize you own Atlas for example which is our new mid-size SUV, it can take up to 18 to 30 weeks because there is such a high demand. And it also depends on the order cycle. But this something we usually only do if there is no cat at the dealer or we cannot find the car on another lot. But usually for the popular cars like the Jetta, it is search and find on the lot, we do not need to order the cars.

4. How much dealer inventory do you have?

Right now, I have 220 new cars and 70 pre-owned cars which is about average.

5. What percentage of all customer orders is sold from inventory?

It's about $90 \%$. People usually take a look at the inventory and we get new cars with different trims daily. We offer the trims S, SE and SEL.

6. What dealer options do you have?

We can do a couple of things. We have done roof top, tow hitches, rear locks, heated seats, leather. So a car arrives and when the customer wants something different, we usually do that for him in our service place.

7. Are the dealer options decided by the dealer or the auto maker?

Usually, when the dealer is smart, he will decide what options he wants to offer so the options are decided by the dealer.

8. Do you order option parts directly at the parts makers or at the auto maker? We get the parts from [GE7] but more and more people do the after sales on their own as they can get more and more parts on their own from a third-party parts dealer.

9. Do you receive a sales quota from the auto maker?

Yes, we get a sales quota from the automaker.

10. Do you receive sales incentives from the auto maker? 
Yes, if you sell the quota you will get x-amount of money. If the sales person sells a car, he will also get a certain amount of money. For example, on a 2017 Passat you will now get $4500 \$$ whereas a 2018 Passat gives you $2500 \$$. This is because they want to get rid of the 2017 model. For the new Atlas they started giving between 1500 and 2500 dollars.

11. What are the main challenges in the after-sales-service business?

So far, we do not face any challenges in the after-sales service as we are having a great after sales service department

12. Is the average time that is needed to fix a customer service measured?

It is and because based on that experience we can determine how much time does it take to do an oil change or how much time does it take to change the brakes. That's what we usually do. When a customer comes in to make an oil change, we ask him to change his brakes etc. This is something we do on our experience. We want to be sure that we do not calculate $1.5 \mathrm{~h}$ and then need $2.5 \mathrm{~h}$.

13. How are service personnel trained and who gets trained?

They go to special training facilities and become a certified [GE7] service personnel. Only when they are certified, they are allowed to work at a dealership.

14. What kind of warranty models do you offer?

Every new car comes with a 6 year $72 \mathrm{k}$ miles bumper to bumper warranty and older models from 2017 only get the 3 year $36 \mathrm{k}$ miles warranty.

15. How is the customer satisfaction rate measured?

There is a survey that is send to the customer that comes from the dealership and [GE7].

16. What are the main challenges for the future and what does the dealership of tomorrow look like?

The internet is one of the main challenges. For example, customers check the value of their car but very often, the value is wrong because it is only an average price and does not consider the condition of the car. This is a problem when customers want to trade-in their car.

17. Are there already BEV (Battery Electric Vehicles) or HEV (Hybrid Electric Vehicles) in your show room or offered by this auto maker?

We have the eGolf that can drive up to 100 miles fully electrical and by the end of this year if will go up to 200 miles. By 2019 and 2020, there are going to be more $\mathrm{EV}$ and PHEV. It is the right thing to do for the environment. 
1. Do you agree to proceed with the interview and begin with audio recording?

It is better when you just take notes because I don't know if I get interrupted or not during the interview.

2. How many different models does the company offer?

At this moment [GE8] is offering 9 [10] different models.

3. How many days does it take to get the car after placing an order with the auto maker if the customer cannot find the car on the lot?

Usually, we would try to locate the car within other dealerships and then just swap the car. There is also the possibility of placing an order at the automaker. The time it takes to get the car to the dealership really depends on the model. For our US and Mexican-made cars, it takes about 6 weeks, for the German-made cars up to 10 weeks. That really depends where the car is made.

4. How much dealer inventory do you have?

Right now, I have about 150 vehicle which is about average. The business this year has been pretty decent and steady.

5. What percentage of all customer orders is sold from inventory?

I would say it's about $95 \%$.

6. What dealer options do you have?

We don't do a lot of accessories and customizing. If customers want leather seats for example, they would just order a higher trim level. Sometimes we do add leather to lower trims but that is pretty rare.

7. Are the dealer options decided by the dealer or the auto maker?

All the options are decided by the OEM

8. Do you order option parts directly at the parts makers or at the auto maker? Only at the OEM.

9. Do you receive a sales quota from the auto maker?

Yes, we get a quota which we call a goal. I would consider that goal being realistic.

10. Do you receive sales incentives from the auto maker?

Yes, in the past we did not give too much incentives but right now, we are giving more and more incentives. What we do is, we give all the incentives to the customers.

11. What are the main challenges in the after-sales-service business?

The main challenge are the after-sales-facilities such as pepboys or autozone who seem to be cheaper on the first view but they are not. So we have to be very competitive and offer a very good price. Because in the end, the others are more expensive than you might think.

12. Is the average time that is needed to fix a customer service measured?

There is something we call labor time guide. That means that a job always costs the same whether mechanic $\mathrm{A}, \mathrm{B}$ or $\mathrm{C}$ did the job and he or she needed longer than 
predicted in the book. The customer always pays the price in the book. This book comes from the manufacturer.

\section{How are service personnel trained and who gets trained?}

[GE8] will send someone here that shows the technology about a new car or product. Furthermore, they go for a training. That might be in Massachusetts or New Jersey. All these tests are required throughout the year. The majority of these tests are webbased but some of them are also in person.

\section{What kind of warranty models do you offer?}

For our 2018 models, we changed to a 6 year 72k miles bumper to bumper warranty and older models from 2017 only get the 3 year 36k miles warranty. That is another sales incentive as it shows the confidence in our products and the quality of our products.

\section{How is the customer satisfaction rate measured?}

That is measured by different surveys whenever a customer had a sales and service at our dealership. So the survey is pretty detailed, containing 16 to 17 questions with several sections and they can be voted 1 thru 10. Although it's a pretty long survey, customers will answer. And then we are ranked with all the dealerships in New England. We do not get any special money for being the first, but of course if gives you a privilege in getting the best cars etc.

16. What are the main challenges for the future and what does the dealership of tomorrow look like?

In the future, everything depends on the expression of a brand and a car, the quality and the durability. What we will also see is a large increase in BEV and that will have an impact on our maintenance models. Today, our cars have an average maintenance interval of $10 \mathrm{k}$ miles. It used to be 3 to $5 \mathrm{k}$ miles. But BEV have barely maintenance and it might happen that we don't see them until they return their car after 2 years. Compared to a lot of other makers in the market, I don't think that the breakthrough of BEV takes that long. Within the next 4 to 5 years, we will see a couple of new models that will have a much higher range than recent models. However, New England has the problem of the infrastructure. We have to bring in more charging stations. The state was supporting sales and infrastructure but they cut the program in the middle of 2017. Other states in New England still have a program like this.

17. Are there already BEV (Battery Electric Vehicles) or HEV (Hybrid Electric Vehicles) in your show room or offered by this auto maker?

We have the eGolf that can drive up to 100 miles fully electrical and by the end of this year if will go up to 200 miles. By 2019 and 2020, there are going to be more $\mathrm{EV}$ and PHEV. I think that [GE8] is going to be big in BEV. 
1. Do you agree to proceed with the interview and begin with audio recording?

No, please do not audio-record me.

2. How many different models does the company offer?

[JP1] offers 15 different models, mostly sedans, a couple of SUVs and Cross-overs and a mini-van and two different trucks.

3. How many days does it take to get the car after placing an order with the auto maker if the customer cannot find the car on the lot?

If a customer cannot find his car on the lot we usually swop with another dealership that takes us 1 to 2 days. If we have to order the car at the factory, it takes us 6 to 8 weeks to get the car.

4. How much dealer inventory do you have?

We have 125 new cars and 450 used cars. So this dealership sells more used cars than new cars. That's because of its location and the social factors around the dealership.

5. What percentage of all customer orders is sold from inventory? I would say about $98 \%$ of our customers find their car here on the lot.

6. What dealer options do you have?

We have a lot different accessories we offer but what we don't do is adding leather seats because that effects the cars warranty. So what we do is, we add a DVD or a Navigation system but that's not common. Most of the customers take the car how it comes. We do also offer special accessories and do the work at an outside vendor.

7. Are the dealer options decided by the dealer or the auto maker?

They are decided by the dealership.

8. Do you order option parts directly at the parts makers or at the auto maker? Service and parts are ordered by the [JP1] parts distribution center and if they need a part very quickly, they also order it at AutoZone.

9. Do you receive a sales quota from the auto maker?

Yes we get a quota for the dealerships and also for the sales people. But they are very different sometimes and depend on the dealership.

10. Do you receive sales incentives from the auto maker?

They did it but they don't do that anymore because they don't want to hurt the resell value and obviously there is not a big need to do that because the market share is going in the right direction for us.

11. What are the main challenges in the after-sales-service business?

Our main challenge is actually our customer. Because of the internet we have to be very transparent and tell them the right price. It is not possible for us to lie to the customer and therefore we are not making as much money as we used to do. Also, 
customers are not patient anymore. They show up and they want to get the purchase done in under 30 minutes. But this is actually impossible to do. The car is the $2^{\text {nd }}$ biggest purchase in the life so you need to take your time and find the best deal and the best offer for you.

12. Is the average time that is needed to fix a customer service measured?

Yes it is. When a customer calls us, we give him a rough idea how long it is going to take and what he has to expect. We do that because we also want to schedule our service as best as possible and to have as many customers as possible.

\section{How are service personnel trained and who gets trained?}

We have a so-called virtual academy. So we do everything online. The course and the tests, everything is going to be in the dealership. It used to be outside but they don't do that anymore.

\section{What kind of warranty models do you offer?}

For our new cars we have the 3 years and 36k miles bumper to bumper, warranty and 5 years $60 \mathrm{k}$ miles powertrain warranty. Our trucks come with a 7 years $100 \mathrm{k}$ miles warranty, so it also depends on the model. There is also the possibility to extend the warranty when you buy the car. We usually work with the third party company and customers prefer to take the service of the third-party company because they can do and offer what they want.

\section{How is the customer satisfaction rate measured?}

Usually our customers use dealerrater, so they can do everything online. That is usually for our used cars. For our new cars, [JP1] sends out a survey after a customer bought the car. This is just something to evaluate the brand and the dealerships gets evaluated by dealerrate. For us it is very important that the review of the dealership is good because you want to get customers back for service etc.

16. What are the main challenges for the future and what does the dealership of tomorrow look like?

People will less and less come to the dealership and get information in an interview or discussion with the sales people. They just want to come to set an appointment for the test drive and they select their car online. What I think is that in 10 years from now, we will have a so-called product presenter and you will only pick up your car at the place where they keep all brands at one place.

17. Are there already BEV (Battery Electric Vehicles) or HEV (Hybrid Electric Vehicles) in your show room or offered by this auto maker?

We have the [JP1] that can drive 130 miles fully electric and people usually lease this car because they always want to have the best standard of technique. And as EV are improving very quickly, they will change their cars more often. However, I don't think that this is going to be something for the near future. Maybe in California but not here. A lot of people still buy combustion engines so in the near future (5-8 
years) we are still working on better gas engines and diesel engines. But in 10 to 20 years it will probably be electric.

JP2

1. Do you agree to proceed with the interview and begin with audio recording? I prefer that you take notes.

2. How many different models does the company offer? At this moment [JP2] is offering 8 [7] different models.

3. How many days does it take to get the car after placing an order with the auto maker if the customer cannot find the car on the lot?

It usually takes 4 to 6 weeks but we would typically swap the car with another dealer. So someone who has the car in red gets ours in white.

4. How much dealer inventory do you have?

Right now, I have 170 cars on the lot

5. What percentage of all customer orders is sold from inventory?

It's about $85-90 \%$. The best way to get the best deal is to finance a car that is on the lot because then you can get all the important incentives.

6. What dealer options do you have?

Not so many actually. What we usually do is we equip the car with mats, roofs, rugs, we upgrade the navigation system or we install a SD-card slot. If we want to add something very special, like a special color to the car, we job-out but we take care of it.

7. Are the dealer options decided by the dealer or the auto maker?

Usually it is decided by the automaker but there are a couple of things that we do. For example we do the VIN edging for our windows that is actually not required by [JP2]. This an anti-theft method.

8. Do you order option parts directly at the parts makers or at the auto maker?

We receive most of the accessories from the OEM. What also happens is that customers can add leather or heated seats without having to order the premium trim. [JP2] makes it possible that they can order the mid or low trim and add what they want and need. Also [JP2] is a brand with a very high loyalty rate.

9. Do you receive a sales quota from the auto maker?

Yes, we get a sales quota from the automaker which is on a monthly basis.

10. Do you receive sales incentives from the auto maker?

Yes, we get the incentives to derive sales to the business. They change monthly or even daily or for a special week-end such as Presidents day. Typically you can find all the incentives on the website. Right now, we offer not so much incentives for the 
2018 models but more for the 2017 models. Also, [JP2] does not something the others do. Other car dealers they want to make the car as cheap as possible and therefore add incentives you may not be eligible for. We call that [JP2] compliance. Therefore, the cars sometimes do not look as cheap as the others but only because the others are not as cheap as they look like. We want to make the price more transparent.

\section{What are the main challenges in the after-sales-service business?}

The huge amount of information that is out there is a problem. The instant information that is out there is not always good but because it can be wrong sometimes. This leads to the trend that more and more car dealers are making less and less money with a car compared to that what they used to do. So in the future, you need to make sure that more and more customers come to your dealership, ask for a car and you have to sell the service and the right parts. The problem is that we are not making our money by selling the cars anymore but by selling the service and the parts.

12. Is the average time that is needed to fix a customer service measured?

Absolutely, it is about the potential to decrease the amount of time and the length of stay. Because we actually want them to come, get their car fixed and then leave as quickly as possible so we have the capacity for the next customer.

\section{How are service personnel trained and who gets trained?}

People that work here already have some certain training and when they start working for [JP2], they have to complete another x-amount of courses online.

\section{What kind of warranty models do you offer?}

Generally speaking, we offer hundreds of warranties. The standard warranty comes with 3 years $36 \mathrm{k}$ miles bumper to bumper warranty and a 5 years $60 \mathrm{k}$ miles powertrain warranty. This includes basically the mechanical components. Also our pre-owned cars get a 7 years $100 \mathrm{k}$ miles warranty so that customers can be confident that a pre-owned car is reliable. All these warranties come from [JP2]. For accessories and other supplementary warranties such as tire protection or a gap insurance, there are outside warranty companies, a gap insurance is an insurance that pays the difference between the amount the insurance is willing to pay and the actual cost the driver had.

\section{How is the customer satisfaction rate measured?}

We measure that with a so-called CSI. The customer gets an anonymous questionnaire from [JP2] and gets asked about service and sales. If the results are summed up it gives a score and therefore a ranking of the dealerships.

16. What are the main challenges for the future and what does the dealership of tomorrow look like?

Less and less customers come to the dealership or schedule an appointment. And when they schedule an appointment, they might not come. It seems as if customers 
are not committed to an appointment. Another challenge is the huge amount of information that is out there. Every deal can be verified and therefore people are not coming into the dealership anymore. However, the dealership offers you the possibility of being focused and concentrated. You can have a more open conversation and around $80 \%$ of the potential customers get in the dealership and leave with something else. Instead of a SUV, they want a compact or 2 rows instead of 3 rows. Also, a big problem is people do not trust car dealerships and car dealers. They think they are dishonest and want to cheat. So one of the biggest issues for the future is to overcome the people's anxiety.

17. Are there already BEV (Battery Electric Vehicles) or HEV (Hybrid Electric Vehicles) in your show room or offered by this auto maker?

[JP2] has worked on the fuel economy of the vehicles instead of developing EV and PHEVs. The cars have become lighter and 100\% recyclable.

JP3

1. Do you agree to proceed with the interview and begin with audio recording? I prefer that you take notes.

2. How many different models does the company offer?

At this moment [JP3] is offering 7 [14] different models. We also offer pre-owned vehicles from different brands.

3. How many days does it take to get the car after placing an order with the auto maker if the customer cannot find the car on the lot?

We would usually call local dealerships in Connecticut and Massachusetts and ask them if we could swap the cars. We usually don't order cars at the manufacturer because it just takes too long. [JP3] is a pretty easy company. They order 7 different models with 4 to 5 different trims and colors.

4. How much dealer inventory do you have?

We have about 200 cars in total, new and pre-owned but we usually sell much more new cars.

5. What percentage of all customer orders is sold from inventory?

It's definitely a high amount of customers. I would say around $80 \%$ or even more $[90 \%]$.

6. What dealer options do you have?

We offer a lot of options. Usually we would just send the cars out. If customers want leather, a spoiler or a moon roof, we just bring the car to a third party company in Massachusetts where they do the job for us. That's just easier for us because they 
have trained people and enough space where they could do the job. But usually the customers take the car how it comes.

7. Are the dealer options decided by the dealer or the auto maker?

There are some options and accessories that are [JP3] specific but for the aftermarket they have no control so we usually choose options that have a lower price.

8. Do you order option parts directly at the parts makers or at the auto maker? We try to get as many parts as possible from third party companies. Of course, [JP3] does not want to see that but they have little control over that business.

9. Do you receive a sales quota from the auto maker?

We receive a sales quote on a monthly basis. This is something that is for the whole dealership and also for the sales people. I would consider these sales goals as realistic but they also vary depending on the actual economic situation etc.

10. Do you receive sales incentives from the auto maker?

We usually provide special rebates to graduated college students or active militaries.

What they do is they give $\mathrm{x}$-amount of dealer cash and you would get the money back-end when you sold x-amounts of cars. But they don't give as much as they did. There are actually two models we don't put any incentives on because the customer will even buy the car without incentives because they are so perfect cars and have a high resell value.

11. What are the main challenges in the after-sales-service business?

I would really say it's the communication. You have experienced and unexperienced sales people and you need to be aware that customers want to get their job done quicker than soon. Furthermore, you need to show back and follow up on your customers because otherwise they will go somewhere else.

12. Is the average time that is needed to fix a customer service measured?

Yes, it is measured by the manufacturer. They provide us with the estimated time that a job should usually do.

13. How are service personnel trained and who gets trained?

The manufacturer offers online tests that everyone needs to take. Sometimes they offer offside classes but today they try to do more and more course at the dealership.

14. What kind of warranty models do you offer?

Basic insurance is 3 years and 36k miles bumper to bumper and 5 years $60 \mathrm{k}$ miles powertrain insurance.

15. How is the customer satisfaction rate measured?

The manufacturer sends surveys to their customers after someone went into sales or service. And based on these surveys they sales and service people get their bonus. We always make a comparison to other dealerships and based on that result, [JP3] provides special incentives for the dealerships with a high customer satisfaction rate.

16. What are the main challenges for the future and what does the dealership of tomorrow look like? 
It's definitely going to change. People do not want to negotiate anymore and they know the best price for the car or the service. I think in the future we will more have something like product consultants like at best buy who know the product very well but there are not going to be any sort of negotiations. The internet has already changed a lot of things. Today there is nothing that I can tell you, you don't find online.

17. Are there already BEV (Battery Electric Vehicles) or HEV (Hybrid Electric Vehicles) in your show room or offered by this auto maker?

Yes we have both, PHEV and fully electric vehicles. But so far these kind of cars have not been good for this market. To give you a feeling for that I can tell you that I still have a couple of 2013 and 2014 hybrid electric vehicles in my stock that I cannot sell. In the future it will probably go better, especially when gas gets more expensive, it will also be a questions of gas mileage.

JP4

1. Do you agree to proceed with the interview and begin with audio recording?

Yes, you can audio-record me.

2. How many different models does the company offer?

[JP4] offers six [7] different models.

3. How many days does it take to get the car after placing an order with the auto maker if the customer cannot find the car on the lot?

We can locate cars from other dealers and swap it first. It would usually take three months if you order that from scratch and they will come from Japan and Mexico. Haven't had this experience yet though. Production is main stream and not so many packages are offered so therefore customers would just take the car from the lot or swap it.

4. How much dealer inventory do you have?

About 120, just new cars. That is on the high side because we are getting in the spring time. We are ramping that up as we are getting a new model and winter is usually slow.

5. What percentage of all customer orders is sold from inventory?

I would say about $80 \%$. We usually lease new cars, it's about $75 \%$. That's what the customer and we prefer, mainly because of lower payments and it's more affordable.

6. What dealer options do you have?

These cars are luxury cars and they are already very nice equipped. Toyota and [JP4] don't come with too many options and therefore you can easily upgrade ceilings or a moon roof. We don't do that because the cars already have running boards, grills, 
all weather mats. We would do that at our service area. Plus we have different packages.

7. Are the dealer options decided by the dealer or the auto maker?

It's up to us really. The dealers build the cars how they want it. They have an allocation system and we can take the cars how they come we can take them or decline and wait for the scratch. Except for the all-new models, they just build new cars and send them out. The first models don't really have much to say. Later, you start customizing how you need them.

8. Do you order option parts directly at the parts makers or at the auto maker? Both, we with our cars would try to use [JP4] genuine parts and aftermarket parts because they are cheaper.

9. Do you receive a sales quota from the auto maker?

Yes they have targets, objectives on the monthly basis. And they are based on historic data and they are realistic. Yes, they call it margins money. You get money based on the volume you do. They have different tiers. It is based on you historic data and the formulate objectives and if you hit certain amount of percentage you get $x$-amount of money.

10. Do you receive sales incentives from the auto maker?

[JP4] uses dealer cash vs. direct rebates. Dealership would lower the transaction price. We would not give a lot of incentives to the customer like rebates, its more dealer cash that we get. A lot of manufacturer on the luxury side are like that because they want to sell the price and not the product. The luxury brands have to be careful how to sell the car. Because of the competitiveness we would just give the dealer cash to the customer.

\section{What are the main challenges in the after-sales-service business?}

Well the main challenge right now is a lot of pressure on the profit margins because of the competitiveness of dealers and also because the influx of product. There are a lot of products. You don't want to lose too much money. You look at its entity. New sales department should not lose too much money. The other challenge is retention. You want to make sure that you keep the customers and make sure that they come to our service center rather than going to other independent centers. A lot of customers do that that. But how can we increase that percentage?

\section{Is the average time that is needed to fix a customer service measured?}

It is measured. They know exactly what they are doing. Not as important today because we give loans. So they would usually drop off the car in the morning and take it back in the evening. But the manufacturer has guidelines and also others publish such data. They would get a complementary vehicle during the day while we fix the car.

13. How are service personnel trained and who gets trained? 
The OEM sends field people to dealerships. There are modules where they test sales people. Also we do our own training such as walk around. First one comes from [JP4], second from us and third is the walk arounds. On occasion they would travel to some other places in order to take different tests.

14. What kind of warranty models do you offer?

It's a standard bumper to bumper warranty. Its 4 years and $60 \mathrm{k}$ miles and customers can purchase an extension that comes from a third party company.

15. How is the customer satisfaction rate measured?

It is measured by [JP4]. They send questionnaires once the car is reports sold. It's a pretty detailed interview. The trend is of making the questionnaire shorter. And we have been complaining about that a lot because customers would not answer these long questionnaires. Some of the questions were not important or were confusing. We prefer to have a handful of questions.

16. What are the main challenges for the future and what does the dealership of tomorrow look like?

The Internet and virtual reality are playing a bigger and bigger role. Online transaction might come. People still do their research online and then talk to a sales person. No clear idea about car sharing or self-driving. What about the younger generation using Uber and Lift and the people that live in urban areas. What about online purchase? This are the main challenges of the future. What about sales in the future when people more and more share cars?

17. Are there already BEV (Battery Electric Vehicles) or HEV (Hybrid Electric Vehicles) in your show room or offered by this auto maker?

We do not offer EV or hybrid electric vehicles at this point.

JP5

1. Do you agree to proceed with the interview and begin with audio recording?

Yes okay, you can audio-record me.

2. How many different models does the company offer?

Right now, the company offers 12 [10] different models and if you put the five [6] hybrids on top of that you get 17 [16] different models. That's about the same what Mercedes-Benz has but more than Audi or BMW has.

3. How many days does it take to get the car after placing an order with the auto maker if the customer cannot find the car on the lot?

So there are two different steps. The first one is, there is dealer swaps and therefore we are looking into other dealerships inventory from Maine to Virginia and see if we can get the car at one of the 70 dealers or what. We can pick it up with the truck. 
If it wasn't available that way we order it. It's between 8 to 12 weeks. Some are made in Canada, Japan, Turkey and also the US. Depending on the model. If it comes from Japan, it takes longer because it's for 30 days on a vessel. If we swap the car, we can instantly get the car, it is just a matter of getting the driver. Most customers don't want to wait for their car, we live in a world of instant gratification. But there are also the very rare eccentric people that are willing to wait for more than one year.

4. How much dealer inventory do you have?

Right now, we have 110 new cars on the lot and about 80 used cars on the lot at any given time. Presold is just about 5\%. This is about an average number. But not to much presold though.

5. What percentage of all customer orders is sold from inventory?

It's probably $80 \%$ of the customers and the other $20 \%$ will probably do the dealer swap. Ordering is very rare, it is not even discussed. [JP5] makes its pretty easy for the customers to buy a car as they only have a limited amount of different packages.

6. What dealer options do you have?

It can actually get pretty expensive for the customer because you cannot change anything without adding it to the MSRP, so you cannot exchange the wheels and keep the price. So we can do many things like wheels, moldings, trailer hitches but it just adds to the price they have to pay. We do have the port options meaning that we can add some accessories at the port, when it hits the US.

7. Are the dealer options decided by the dealer or the auto maker?

In this brand, the dealerships does. [JP5] is very free in saying the dealership has the control. They don't force us doing anything. But they want us to put some accessories on the cars like the tail fin on the trunk and you can add that afterwards.

8. Do you order option parts directly at the parts makers or at the auto maker?

Never the parts maker. So [JP5] is the mediator between the dealership and the parts maker. So we would put our order in and every night there is an 18-wheeler that will show up at the dealership. They say [JP5] on the box and that's where we get our parts from. We usually get that from Massachusetts or sometimes from California and very rarely from Japan.

9. Do you receive a sales quota from the auto maker?

They look at market share. So in Rhode Island, there are that many cars sold, you [JP5] should have that certain amount of cars sold. There is no money attached to it. It is just suggested, that's where we should operate. What they do is, they take a look at the end of the year. They had good customer satisfaction etc. and if you are good, you get a reward and if you don't hit that you don't get the reward. But there is no cash, I wish there was because I was good last year. People usually buy a Mercedes in order to show their success. In Rhode Island BMW is the first, Mercedes the second, [JP5] the third and Audi the fourth. 


\section{Do you receive sales incentives from the auto maker?}

Sometimes they might do that but usually they try to gear that towards the sales person or sales manager. So they might give an extra $200 \$$ reward to the people because they want to move the car out of the port but that is not too often. [JP5] is a clean brand, they don't give a lot of incentives. They give a lot incentives to the car though. They would just give the money to customer and not to the dealership. Lots of incentives to the customers, all the time. [direct rebates $>$ dealer cash]

11. What are the main challenges in the after-sales-service business?

We are not in the car business, we are in the people business. Meeting the expectations of the guests. And that changes with age. Generation $Y$ that is your age has already done all the research, tell me the truth. Don't want to be glutted with emails and surveys. The more technological we become the more personal we want to become. Know their name, hold the door for them, carry their stuff to their car, bring their car to their office and don't make them come to your place. Just think one step ahead of them. Start with a coffee or diet coke. Make me feel important is the new thinking.

12. Is the average time that is needed to fix a customer service measured?

We do measure it. They know how long all the jobs are usually going to take. We measure that by how we book our work. We know that every car needs about two hours by average and a couple of hundred dollars.

\section{How are service personnel trained and who gets trained?}

Manufacturer usually does that. They stop at the dealership, they have training, webinars, and sale materials and then the sale and service managers have to follow that path and make sure that their employees continue learning. Spearheaded by the service manager.

\section{What kind of warranty models do you offer?}

When they buy a new car its 4 years and $50 \mathrm{k}$ miles with bumper to bumper on the highline brands. And then there is a powertrain warranty that will extend that to $70 \mathrm{k}$ miles on particular things like an engine or the transmission. The customer has the choice to get an extended warranty.

\section{How is the customer satisfaction rate measured?}

Third party measures that. Medalia oversees a lot of other car makers and they would send out a survey after purchasing and servicing a car. Every customer, every times. Now it's just emails and they will ask them a couple of questions and they score 0 to 10 and when they score 9 or 10 its good, if its 7 or 8 , the survey can extend. But they usually just want to know if they were happy with that service, if you would recommend the dealership to a friend and if you would come back. If someone says no, that's a red flag. It can then end up being 20 questions. We get all the returns in at real time. Sales is honeymoon and Service is divorce court. In sales usually a 10, 
service is a little bit more a challenge. Maybe someone did not answer my phone call.

16. What are the main challenges for the future and what does the dealership of tomorrow look like?

The dealership of the future will more look like best buy or Apple. And the days of the sales person are just gone and the car business is behind the times. The customers wants to come in with no pressure and wants to talk to product person like at Best Buy and spend as much time as I need, let me learn the car and then they want to talk about a price, talk to a manager and want to leave. But that's a lot of risk. Because you are relying on the customer. Sales people are selling cars. But that day is coming. 15 dollar an hour job maybe in future and stay for 2 years and then they leave. But we are not there yet. Electrical grid is not robust enough right now and we know that this is fragile. How do we charge all the cars? We still need to spend trillions of dollars and power that by solar and then we can get BEV. Companies want to do that and I prefer hybrids to BEV. Technology is not there yet. We also have to face the café-laws.

17. Are there already BEV (Battery Electric Vehicles) or HEV (Hybrid Electric Vehicles) in your show room or offered by this auto maker?

We are bringing a new hybrid cross-over by the end of this year. So far we have 5 different hybrids right now.

JP6

1. Do you agree to proceed with the interview and begin with audio recording? No, please do not audio-record me.

2. How many different models does the company offer?

[JP6] in the US offers 15 [14] different models, mostly sedans, a couple of SUVs and Cross-overs and a mini-van and a truck.

3. How many days does it take to get the car after placing an order with the auto maker if the customer cannot find the car on the lot?

[JP6] is company that works with the allocation system meaning that they offer you these cars and you have to take them. You cannot place an order at the dealership but what we do is we use our dealer network to get the car to our dealership if the car is not on the lot. We look if someone else has it.

4. How much dealer inventory do you have?

We have a 110 new cars and 60 cars are incoming in the next days. So for a store of this size it's really good.

5. What percentage of all customer orders is sold from inventory? 
I would say about $90 \%$ of our customers find their car here on the lot. So you have to keep in mind that [JP6] is a Tier 2 brand like Toyota, Nissan and Volkswagen. Daimler, BMW are Tier 1. They will offer you many different accessories that you can choose of, but we do not do that here.

6. What dealer options do you have?

We have a lot different accessories we offer from moldings and exhaust tips but usually customers just take their car how it comes to the dealership. They would just spend about $200 \$$ on extras.

7. Are the dealer options decided by the dealer or the auto maker?

All the parts and the accessories are decided by [JP6].

8. Do you order option parts directly at the parts makers or at the auto maker? Everything comes from the OEM.

9. Do you receive a sales quota from the auto maker?

Yes, we receive them. And they are pretty hard to hit. But if we don't hit them, nothing happens to us. The thing is, they use the sales in order to determine how many cars we get for the next month. So if we sell more cars than we usually do, they will give us more cars the upcoming month.

10. Do you receive sales incentives from the auto maker?

Some brands base their business on incentives. So lets say there is a Chevrolet Silverado that has a price sticker of $40,000 \$$ on it and you get $10,000 \$$ incentives, people ask where does this $10,000 \$$ come from. Also the question is: "What is the actual resell value for that car? Is it 40,000 or $30,000 \$$ ?". So giving huge discounts actually just hurts the customer and the dealership. [JP6] is not like Chevrolet or BMW, they don't have to give this rebates and they do that because that only hurts the resell value. So what we do is, that we show the actual price of the car which is lower at the beginning but there is also not much fighting for rebates.

\section{What are the main challenges in the after-sales-service business?}

Warranties are getting longer and the dealership is suffering from that trend. Usually, we get money by selling oil, change the tires etc. Since the cars use synthetic oil today, better tires and better cars in general, customers don't have to come in that often anymore. In the past, they made their oil change every 3,000 miles now they do it every 7,500 miles or the brakes last 40,000 miles instead of 20,000 miles. That turns service down. Also, people can easily buy parts online and they will use YouTube videos and fix the cars by their own instead of going to the dealership.

12. Is the average time that is needed to fix a customer service measured?

Yes it is. You should always make an appointment and while you make it, we try to find out what has to be done with the car. Based on that first analysis we can determine whether the customer should wait until his job is done or we should provide him a rental car. 


\section{How are service personnel trained and who gets trained?}

The factory has certain requirements and every years training. That can be done online and also offside in extern facilities, the factories or during test drives. And they have to be [JP6] -certified.

14. What kind of warranty models do you offer?

For our new cars we have the 3 years and 36k miles bumper to bumper, warranty and 5 years $60 \mathrm{k}$ miles engine and transmission warranty. There is also the possibility to extend the warranty when you buy the car. We usually work with the third party company and customers prefer to take the service of the third-party company.

\section{How is the customer satisfaction rate measured?}

So every time you purchase a car or get your car serviced, they will send out an email and ask 15 questions about the service in general, the cleanness, the car itself etc. and usually about $20 \%$ of the customers answer the survey.

16. What are the main challenges for the future and what does the dealership of tomorrow look like?

I my opinion, instead of going to a Chevrolet, a Buick and a GMC dealership, we will just go to a GM dealership. Or instead of a Lincoln, Mercury or Ford place, we will go to a Ford place. So we will see the elimination of dealerships and also the elimination of sales people. And more and more people will just click and pick which means they will just choose their car online and pick it up and these places.

17. Are there already BEV (Battery Electric Vehicles) or HEV (Hybrid Electric Vehicles) in your show room or offered by this auto maker?

It really depends on the oil prices. If the price goes up, people prefer 4 cylinder vehicles. That's what really helped us 2007 and 2008. But when the price drops, people prefer big 8 cylinder engines. But, generally speaking, the EV is something people will probably go to it. That's because we have to fulfill a certain fuel economy in their fleet and we can only do that by selling EV to compensate 8 cylinder engines. But that's only something for the American makers.

JP7

1. Do you agree to proceed with the interview and begin with audio recording? No I don't want to be audio-recorded.

2. How many different models does the company offer?

Right now, the company offers 7 [9] different models including two PHEVs. 
3. How many days does it take to get the car after placing an order with the auto maker if the customer cannot find the car on the lot?

If the customer only wants that car, we try to swap the car. At first we try to sell from our inventory. It is possible to buy the car from the manufacturer but it takes between 8 to 12 weeks to build the car. They have so many cars in advance and therefore it takes very long to do the allocation for the specific customer order.

4. How much dealer inventory do you have?

Right now, we have 175 cars which is a bit higher than usual because we want to be prepared for the spring and summer where car sales are usually higher.

5. What percentage of all customer orders is sold from inventory?

I would say it's about $99 \%$.

6. What dealer options do you have?

Usually our cars come well equipped and therefore, we only change roof rails for the SUVs or remote starter for SUVs and sedans. But most of the customers keep their car how it comes.

7. Are the dealer options decided by the dealer or the auto maker?

All the options and accessories come from [JP7], because we are very particular about warranty and product quality on our products. We don't use other after-market products because they don't look good and when something goes wrong with it, the warranty does not cover it.

8. Do you order option parts directly at the parts makers or at the auto maker? All the accessories and parts come from the OEM.

9. Do you receive a sales quota from the auto maker?

We receive a quota for the dealership.

10. Do you receive sales incentives from the auto maker?

We get dealer cash and use that to discount our vehicles for the customer but also we don't want to devaluate the brand. Chevy does so the question is what is the real value of the car when they give you 10k off for a Silverado?

11. What are the main challenges in the after-sales-service business?

Cannot fix issues with a car and $99.9 \%$ of the customers do their research first and know what they want and see the price online.

12. Is the average time that is needed to fix a customer service measured?

$\mathrm{X}$

13. How are service personnel trained and who gets trained?

Online testing, we go through the car and do self-drives and also the sales person needs to be convinced to do that voluntarily.

14. What kind of warranty models do you offer?

New $4 \mathrm{yr} / 50 \mathrm{k}$ limited and $6 \mathrm{yr} / 70 \mathrm{k}$ powertrain and used cars go through [JP7] checks and we sell aftermarket warranties, we work with [JP7] and Allstate aftermarket warranties. 


\section{How is the customer satisfaction rate measured?}

10 to 15 questions in a survey and also if they would recommend the dealership

16. What are the main challenges for the future and what does the dealership of tomorrow look like?

It's not going to change, people still want to touch and feel and drive and I don't think there will be an online purchase because of that

17. Are there already BEV (Battery Electric Vehicles) or HEV (Hybrid Electric Vehicles) in your show room or offered by this auto maker?

We have one hybrid but I have not heard anything about further future models.

JP8

1. Do you agree to proceed with the interview and begin with audio recording? I prefer that you take notes.

2. How many different models does the company offer? At this moment [JP8] is offering 22 [24] different models.

3. How many days does it take to get the car after placing an order with the auto maker if the customer cannot find the car on the lot?

If you build your own car and get it sent, it takes around 6 weeks. Our cars come from Japan and Alabama, Usually we have something like that every three months. If we cannot find the appropriate car in the lot, we would just look in the inventory or swap the cars with another dealer. We just get build-to-order calls for special cars like the Tundra. Let's say someone wants to have this pick-up truck as a two-wheel drive in this area. Normally, people buy 4WD here.

4. How much dealer inventory do you have?

Right now, I have 500 new cars on the lot and around 100 used cars.

5. What percentage of all customer orders is sold from inventory? I would say it's about $85 \%$.

6. What dealer options do you have?

We offer a lot accessories such as rims, sunroofs etc. and that comes from our parts department. Usually, we do all these accessories at trucks and 10 years ago, we did a lot installation at our cars. But today, the cars are more and more equipped with that what customers want and need such as leather and media players. So I would say, that $95 \%$ of the customers keep their car how it is.

7. Are the dealer options decided by the dealer or the auto maker?

So all these options come from the OEM but the dealership can make some wishes about that what went well over the last years. [JP8] is a company that is based on the allocation system. That means that we get our parts and cars by the beginning of the month and we can choose of a pool of cars and parts. 
8. Do you order option parts directly at the parts makers or at the auto maker? So we usually keep all the important parts in the stock but if we need parts, we just order at the headquarters in Massachusetts and have the same or the next day.

9. Do you receive a sales quota from the auto maker?

We receive a sales quote on a monthly basis. We call it objective and it is our goal to hit it. I would consider it being realistic because it is based on the actual market share in a region. So what happens is that they divide up the markets into different smaller markets and we should try to keep or increase our market share.

10. Do you receive sales incentives from the auto maker?

Yes, we do. Every month or quarter they have a sales contest where they offer different bonuses, trips or awards. We call it spits and sometimes the sales people get more money for selling a Camry. The same accounts for service. So they get bonuses when they sell a certain amount of oil filters for example. Usually they would not give a big incentive on 2018 cars right now because the model year just has started. But they would offer more incentives on a 2017 car.

11. What are the main challenges in the after-sales-service business?

As we want to grow, we have to consider customers that do not live close to the dealership but we want to make it attractive for the customer to come to our dealership. Also, tracking our customers can be hard sometimes. Usually, they should come in and check their car every 6 months, have an oil change, check brakes etc. But when they have not been in the store for a while, we just contact them and ask what is going on, why they haven't been to the dealership and you try to woo them with coupons and special offer. We want to make sure they stay at our dealership and do not go to another place because when they stay with you they will buy their next car at our dealership. Furthermore, cars are getting better so customers do not really see a difference between our cars or our competitors and therefore, the loyalty rate is decreasing as people tend to switch their cars more often so you need to offer an outstanding service to the customer in order to be different to our competitors.

12. Is the average time that is needed to fix a customer service measured?

We don't want our customers to wait and therefore we need to provide them a relative expectation of their waiting time. Because when the time is exceeding a certain period, we might drive them home, rend them a car or let them wait until the job is made. We provide them with complimentary services such as manicure or stress less couches and drinks.

\section{How are service personnel trained and who gets trained?}

Our personnel is trained at our headquarters in Mansfield. So the trainer goes over the new stuff and tests our employees. That has to be done by a certain time period.

14. What kind of warranty models do you offer? 
Basic insurance is 3 years and $36 \mathrm{k}$ miles bumper to bumper, we call it comprehensive warranty and 5 years $60 \mathrm{k}$ miles powertrain insurance. When customers purchase a car, they can extend their warranty and add extra maintenance plans and get service reduced later. This could be [JP8] or a third party company. Usually customers will buy the product from the third party because they have so much more extras to offer and are freer.

\section{How is the customer satisfaction rate measured?}

After the sales, [JP8] sends a survey to the customer asking about the dealership experience and trying to find out whether the dealer and the sales person has done a good or not good job. Also JD Power contacts the owner after having their car for 3 or 5 years and asks about their experience. In my opinion [JP8] is so good because they never break down and run for ever. That's at least something the customers think. So we are saying that $90 \%$ of the 1990 Camrys are still on the road.

16. What are the main challenges for the future and what does the dealership of tomorrow look like?

I think that companies like carvana.com are one of our main concerns for the future. Because that would mean that customers don't have to go to the dealership anymore but they can just buy everything online. People will not be waiting to come in especially as cars are more and more having the same level. So the car is actually not that important anymore. The challenge is to keep the people form thinking that buying over the internet is better than going to the dealership although they might spent more time and do not receive their instant gratification.

17. Are there already BEV (Battery Electric Vehicles) or HEV (Hybrid Electric Vehicles) in your show room or offered by this auto maker?

Yes, we have the RAV4 as an EV and [JP8] is also working on hydrogen vehicles. [JP8] has always been at the forefront at HV with the Prius and they kept evolving that car over the years. We are also working on alternate fuel and also the technology is Japanese and they are pretty smart in terms of technology such as the plug in Prius in order to hit the 2025 gas mileage goal.

US1

1. Do you agree to proceed with the interview and begin with audio recording? I prefer that you take notes.

2. How many different models does the company offer? At this moment [US1] is offering 23 different models.

3. How many days does it take to get the car after placing an order with the auto maker if the customer cannot find the car on the lot? 
Usually it takes 6 to 8 week but only $1-2 \%$ of our customers do that. Mostly, when customers know what they want such as F150 or Mustang customers. So it's usually more for special cars and trucks.

4. How much dealer inventory do you have?

Right now, I have 500 new cars on the lot and around 120 used cars.

5. What percentage of all customer orders is sold from inventory?

I would say it's about $80 \%$.

6. What dealer options do you have?

It is all about the accessory. Quite often we customize cars with DVD-players or leather seats, covers, bed liners etc. I would say that more than $50 \%$ of our truck customers customize their trucks but less than $15 \%$ their regular cars. There we usually put a remote start in. 3

7. Are the dealer options decided by the dealer or the auto maker?

It's usually more a decision from the dealer

8. Do you order option parts directly at the parts makers or at the auto maker? At the OEM.

9. Do you receive a sales quota from the auto maker?

Yes, we receive them. But they are pretty realistic as they are based on previous sales. Also they are based on the actual economics situation and of course you always try to make them higher.

10. Do you receive sales incentives from the auto maker?

Yes rebate, and we usually spend $95 \%$ of the amount of money that we can give and use for incentives on the customer. The other $5 \%$ go to dealer cash when they hit their sales goals and cash for the dealer person.

11. What are the main challenges in the after-sales-service business?

After-service equipment malfunctioning and also trends where dealers are not needed anymore. In future, you will be able to start your car from the phone and the manufacturer will just install the electronics and sell the app so no more service at a dealership is needed.

12. Is the average time that is needed to fix a customer service measured? Yes it is. When someone calls you, they schedule your appointment in their calendar. That is important, especially when we have so much business like we do have right now.

13. How are service personnel trained and who gets trained?

Sales and service people have to be [US1] -certified. Once a month, people from extern are coming and we meet them in the conference room in order to keep their status as [US1] -certified.

14. What kind of warranty models do you offer? 
For our pre-owned cars, we have the standard lemon laws for cars, that's 30 to 90 days. For our new cars we have the 3 years and 36k miles bumper to bumper, warranty and 5 years $60 \mathrm{k}$ miles engine and transmission insurance.

15. How is the customer satisfaction rate measured?

Sales sends out a survey from the manufacturer about the service at the dealership. Also, customers give us online reviews.

16. What are the main challenges for the future and what does the dealership of tomorrow look like?

Being like tesla in the car business. Run the dealership without sales person. However, I think that the approval process in parts and finance a car cannot be automated and therefore, you always need a sales person.

17. Are there already BEV (Battery Electric Vehicles) or HEV (Hybrid Electric Vehicles) in your show room or offered by this auto maker?

We offer both EV and PHEV but so far, they are very unpopular. Between 2005 and 2009 , there was a certain demand for these cars but right now I would consider these cars as dead products. They have a low resell value and the only reason I think they build it is because of the 2025 gas consumption goals.

US2

1. Do you agree to proceed with the interview and begin with audio recording?

No, please do not audio-record me.

2. How many different models does the company offer?

So we are a franchise company selling three different car companies. We sell [US2], they offer 2 different models, we sell [US2]with 5 different models and [US2] with 5 different models.

3. How many days does it take to get the car after placing an order with the auto maker if the customer cannot find the car on the lot?

If someone wants to have a car that he or she orders at the maker, it usually takes 6 to 8 weeks until they bring the car here. That usually happens with [US2]. But if a customer cannot find his car on the lot, we would rather do a so-called dealer swap. We do that in more than $50 \%$ of the cases.

4. How much dealer inventory do you have?

Right now, we have about 300 different new cars all over the three companies. We have been growing well over the last couple of months.

5. What percentage of all customer orders is sold from inventory? I would say it's about $75 \%$.

6. What dealer options do you have? 
We have a special guy in the service area that has been doing his job for more than 35 years. He is specialized in up fitting all the [US2] [US2]because that is where we do most of our options and accessory business with. So for the [US2]we have so many different options such as tires, suspensions, air ride suspensions, LEDs, etc. and we all do that in house with our parts and service.

7. Are the dealer options decided by the dealer or the auto maker?

All the parts are ordered at the manufacturer. We have hundreds of different accessories especially for the Wrangler. All the other models usually do not get customized.

8. Do you order option parts directly at the parts makers or at the auto maker? Everything comes from the OEM.

9. Do you receive a sales quota from the auto maker?

Yes, we receive them. And of course you want to hit them. It is called GVP and says that you get $\mathrm{X}$-amount of money back when you sold this amount of cars. Our strategy is to sell on small margins a lot of cars and get back the money from the quota. So in terms of the sales person, $50 \%$ of their salary is bonus-based and comes from their customer satisfaction rate and sold volume.

10. Do you receive sales incentives from the auto maker?

Yes, what we give is a so-called loyalty incentive and also if you come from another maker, we give a certain amount of money. Furthermore, active military and farmers get special discounts. And we all it VIN-sensitive, so all the discounts are based on an actual model with a certain trim.

11. What are the main challenges in the after-sales-service business?

So more and more of our business is done online and therefore, we have to be aware of our google reviews. Because if someone wants to buy a car, they will usually check out the online reviews of the dealership. So you want to make sure, that we have at least a four out of five star rating.

12. Is the average time that is needed to fix a customer service measured?

Yes it is. When someone comes in with a car, we send a master certified technician who checks the car and estimates the amount of work and the implied time for a job. That takes about 10 minutes. Based on that diagnostic, we can decide if we provide a rental car or let the customer wait until the job is done.

\section{How are service personnel trained and who gets trained?}

There are in house and out of house training sessions. Once in a month, a [US2] representative come sin and tests us on the products and procedures. We also have to pass certain tests in order to stay certified. That is for both, service and sales personnel.

14. What kind of warranty models do you offer?

For our new cars we have the 3 years and 36k miles bumper to bumper, warranty and 5 years $60 \mathrm{k}$ miles engine and transmission warranty. We also cover our new 
cars with a 3 years $/ 36 \mathrm{k}$ miles roadside assistance comparable to the AAA. There is also the possibility to extend the warranty when you buy the car. We usually work with the third party company that backs up $95 \%$ of our warranties.

15. How is the customer satisfaction rate measured?

Our companies and particularly [US2] have a high customer loyalty. So I have customers that have bought over 10 cars at the dealership. The cars are user-friendly and therefore have a high resell value. That is especially the advantage of [US2]. But for [US2] and [US2] it's pretty much the same.

16. What are the main challenges for the future and what does the dealership of tomorrow look like?

I think that in future we are going to have a limited amount of sales people and the necessity of dealerships is going to decrease.

17. Are there already BEV (Battery Electric Vehicles) or HEV (Hybrid Electric Vehicles) in your show room or offered by this auto maker?

We offer a hybrid version of the [US2] but we are pretty skeptical in terms of electric vehicles. The question you have to ask is do you really safe money with that? What about the price of the batteries? Out companies and especially [US2] are using the Diesel to increase the fuel economy or just continue improving the actual gas engines.

\section{US3}

1. Do you agree to proceed with the interview and begin with audio recording?

I prefer that you rather just take notes instead of audio-recording me.

2. How many different models does the company offer?

At this moment [US3] is offering 6 different models but by the end of this year it is going to be 9 models as we are developing two all-new SUVs and a sedan. For a very long time, we only offered big or midsize-SUVs but we are changing that now.

3. How many days does it take to get the car after placing an order with the auto maker if the customer cannot find the car on the lot?

So there are actually two different options here. The first option is to try to locate the at car at one of our dealerships. To do so, we go as far as 300 miles (Pennsylvania). The second option is to build it at the manufacturer but this takes between 6 to 8 weeks and most of the customers do not want to wait that long. Usually only 4 to $5 \%$ of the customers would do that. The other thing is that we want to sell this month as we can only guarantee certain incentives for this month. So if a customer gets his car next month, we don't know what the actual price is going to be.

4. How much dealer inventory do you have? 
Right now, I have about $12.5 \mathrm{M}$ \$ in inventory which is about 270 cars. This contains both new and pre-owned vehicles but we sell much more new. The actual price of a [US3] is about 60,000 $\$$ which is even more than the actual purchase price for all these German premium brands such as BMW and Audi. This is good but also bad. On the one hand it allows us to earn a lot of money with one car but on the other hand we just have a specific amount of customers that want to buy this car. I car is only good if you can sell it because that's what creates revenue and profit. For [US3] as a brand, I can say that we do not compete with other specific brands but our models are compared to other models from our competitors. For example, we compare the Escalade to the Land Rover but we do not compare our sedans to the ones from the German premium makers.

5. What percentage of all customer orders is sold from inventory?

It's about 95 to $98 \%$. That's good but it also shows us that we are overproducing as we can serve all our customers from our lot. You need to know that the company is now in a change. There is someone coming from Audi, who is right now creating a new strategy for the brand and he takes all the positive stuff that he learned at did at Audi to the brand. After 5 years of decline we see some stagnation this year and expected to brand to grow by next year when the new models arrive.

6. What dealer options do you have?

What we usually do is we offer more packages. So the customer can choose between three different trims at a car. So there is the standard, the premium and the premium superior and that usually has all the options you can take automatically. So what we can do is, we can change the color, the wheels or the grills and we order all the parts through the manufacturer and do it here at the service area. But this is usually something for less than $5 \%$ of the customers.

7. Are the dealer options decided by the dealer or the auto maker?

So they let us do what we want because we are an independent dealer. But usually you try to sell what the manufacturer gives to you. So we are seeing that the influence of the manufacturer is kind of increasing which can also be a good thing because the manufacturer takes care that the quality and the processes follow his standard. The thing is that they sometimes try to force us doing something we just cannot do because we are making less margins. We are making less margins and can be short of money sometimes. But for our dealership that does not happen because we are part of a bigger group (Herb Chambers) so money is not the question. And that allows us to renovate the store like [US3] wants us to do.

8. Do you order option parts directly at the parts makers or at the auto maker? I would say that I order about $98 \%$ of our parts and accessories at the manufacturer.

9. Do you receive a sales quota from the auto maker?

Yes, we get a sales quota from the automaker. Usually on a monthly and quarterly basis. The formula they used to do did not make much sense because GM would 
always try to push sales and increase the numbers even though when the overall market goes down. But it is still different from manufacturer to manufacturer but what I can see is that [US3] is going more and more separate and that is also good for us.

10. Do you receive sales incentives from the auto maker?

It always depends on the strategy a company is following. GM usually gives large discounts but for the new ones they barely gives incentives because they don't need to. Over the time, you give more and more incentives. So we get our money once we submitted the car and we are getting the money than.

11. What are the main challenges in the after-sales-service business?

The majority of the after-sales business is done at the F\&I department which is also the most profitable. They even send an extern company that checks and rates our F\&I department. What we also do is we sell warranties and we do that all over our companies we offer at Herbs. We also sell a lot of other brands' preowned cars and sell them a warranty. That's how we try to get them.

12. Is the average time that is needed to fix a customer service measured?

Yes, the maintenance time is measured and we have data from the manufacturer. We need that in order to determine whether we should provide a complementary vehicle or if we can let the customer wait. But of course you don't him to wait an hour for a simple oil change. Also our leasing rate is very high. We have about $70 \%$ leasing which is high. That makes sense because for a car that costs $60,000 \$$ in average it is just more comfortable to pay by rend. Usually cheaper cars such as Japanese cars are not leased, they would rather finance the car. Concerning our loyalty: I want to say it's great but also we had a dramatic decrease in cars that we sell every month. In 2013 it was 550 a month and now that's significantly lower.

\section{How are service personnel trained and who gets trained?}

They get training from [US3]. If a new model comes out they come in advance and do training on the car. They do that every year. It's in store but also out store. The sales people they go out and ride and drive the car. .

14. What kind of warranty models do you offer?

We offer a 4 years $50 \mathrm{k}$ miles bumper to bumper warranty and a 6 years $70 \mathrm{k}$ miles drivetrain warranty. This includes basically the mechanical components. For our pre-owned vehicles, we give them 6 years and $100 \mathrm{k}$ miles.

\section{How is the customer satisfaction rate measured?}

This is actually something that is done by the manufacturer. They put us into groups and compare us with other dealerships in that group. Our group contains dealerships in New Jersey, Connecticut and Rhode Island. Every customer gets a survey after a service or a purchase and they rate us. And of course no one wants to be average. Based on the customer satisfaction rate, we bonus our sales consultant and sales 
advisor. It's just something you have to do because you cannot pay someone $100 \%$ of this salary without giving him a reason to work for customer satisfaction.

16. What are the main challenges for the future and what does the dealership of tomorrow look like?

The main challenge is going to be the millennials. Meaning your generation. We need to approach customers differently and every customer independently. I think the way how people grew up affects their behavior. Everybody wants to share everything that he is doing. Now, all our cars have an Apple set up and everything is about the driver, about you. So we need to talk about things away from the brand. The customer is changing. The internet already has playing a big role, that's normal today.

17. Are there already BEV (Battery Electric Vehicles) or HEV (Hybrid Electric Vehicles) in your show room or offered by this auto maker?

I think, we have been behind a bit in that field. We had a Plug-In but this car failed, not because it was bad but just because it was too expensive. Now we have another but I haven't ordered anyone and no one asked me about that car. I think this is more something for the next 10 to 15 years. I think by that time, $50 \%$ of the cars are going to be electric.

US4

1. Do you agree to proceed with the interview and begin with audio recording? I prefer that you take notes.

2. How many different models does the company offer?

In this franchise we offer four different brands. We have [US4] with 5 models, [US4] with 2, [US4] with 3 and [US4], but besides the [US4], they usually just sell commercial vehicles.

3. How many days does it take to get the car after placing an order with the auto maker if the customer cannot find the car on the lot?

We usually just do swaps with other dealerships and try to avoid manufacturer orders. They take 4 to 8 weeks and we just do that if a customer wants something very particular.

4. How much dealer inventory do you have?

Right now, I have 250 vehicles on the lot. The most of them are [US4] and [US4].

5. What percentage of all customer orders is sold from inventory?

I would say it's about $90 \%$.

6. What dealer options do you have? 
We do a lot of customization, especially with the [US4]. Customers want to put rise suspensions, life kits, heavy duty accessories. With the regular cars we add remote starter or things like that. But Jeep in particular has a huge variety of accessories.

7. Are the dealer options decided by the dealer or the auto maker?

We base all the options and accessories on the wishes of our customers. The OEM usually does not tell us what we have to order or what we should not.

8. Do you order option parts directly at the parts makers or at the auto maker? All the accessories come from the OEM, the maintenance parts too but when cars get older we try to get cheaper after-market parts. We procure some of these parts at third-party companies such as AutoZone if the car has been on the road for a while. Of course, the manufacturer does not like that but we are independent and want to offer the best service for our customers.

9. Do you receive a sales quota from the auto maker?

We receive a target number, a so-called MSR (minimum sales responsibility). This number depends on our geography, the competition and our area. Let's take [US4] as an example. The company knows their market share in this specific area and based in the actual market and the market share, they derive the MSR. Because you want to have a certain market share in the area.

\section{Do you receive sales incentives from the auto maker?}

This is actually a point of contention. Because we as a dealership are part of a VGP, a so-called volume growth program. It gives us a number ne need to hit every month and if we do so, we get back a certain amount of money. The higher you hit that VGP, the more money you get. On the one hand it forces us to stock cars on the lot on the other hand it leads to the behavior of short deals. Especially smaller dealers tend get rid of their cars by the end of the month because they are dependent on these payments. Last month, for example, we received $40,000 \$$ for beating our VGP. For some of the cars though, we don't receive any incentives because they are very hot models and get sold without incentives such as the [US4].

11. What are the main challenges in the after-sales-service business?

First of all, we don't push service. When our customers buy a car we usually provide them with a so-called service contract. That covers 5 years and 70,000 miles with $100 \$$ deductible. But it's not for maintenance parts

\section{Is the average time that is needed to fix a customer service measured?}

As many other dealerships, we work as a flat-rate shop. That means that the whole industry follows a book that is standardized and it tells the dealership how long this job is going to take. This the amount of hours the customer has to pay and the mechanic gets paid. If he is faster, he makes plus because he works less but receives more money. If he is slower, he loses money. The customer will always pay the 2 hours.

\section{How are service personnel trained and who gets trained?}


The manufacturer trains them, they come in and they have to do online tests. We are one out of three first dealerships in Rhode Island and therefore all our worker need to be certified. So let's say if the company gives a certain amount of incentive to the [US4], you are only qualified for that incentive when you are a certified worker. So that is an extra incentive for the employees.

14. What kind of warranty models do you offer?

Basic insurance is 3 years and 36k miles for basically the whole car and 5 years $60 \mathrm{k}$ miles for the drivetrain and transmission. For pre-owned cars we offer the 90 days warranty and offer a service contract for the customers. Especially for the pre-owned cars we work together with third party companies. But that really depends on the car. Let's say we sell a pre-owned Honda, the [US4] insurance might not be the right product for him so we tell him that and sell him a third party product. Actually, we have a lot of different brands for our pre-owned vehicles as we see that as a chance to gain more customers.

\section{How is the customer satisfaction rate measured?}

It is measured by the manufacturer. We encourage our customers to respond to surveys or give us a review on google or yelp. The manufacturer sends out 10 questions and the results will be shown in an intern system at the manufacturer. The questionnaire asks about the overall customer quality and there is also an employee survey. It determines the service and sales performance.

16. What are the main challenges for the future and what does the dealership of tomorrow look like?

It is always changing. I have been in that business for several decades now and there were always significant changes. The last big change was caused by the internet. It changed the ordering process and service. Customers can do their research on the internet and they get all their information. When the internet came, people start doing their research online, they printed everything out and came to the dealership. Well, you can fight or embrace the internet. We embrace it because it is actually better because customers have an idea what they want and what they are looking for. 25 years ago people came in and said they want to have a car and now they know this and that, they know the pricing etc. and you cannot fight it. But we have one advantage. If you take a shoe store: people go there, try to find their show and their size and then they would go home and order the shoe online. That is something that would not happen to a dealership. That's because we are franchised and that helps us a lot. People always want to drive the car, smell and touch the product, and that is not going to change. So that's a leg-up we have here.

17. Are there already BEV (Battery Electric Vehicles) or HEV (Hybrid Electric Vehicles) in your show room or offered by this auto maker?

Yes, we have the Pacifica hybrid. But I have them on my lot for a long time. So people do not appreciate the short range and the expensive price. Americans like 
performance. However, in about 10 years I would guess that there will be about $25 \%$ hybrid electric vehicles. Electric vehicles are here to stay. But as long as the energy is cheap and available, the internal combustion engine will be the dominant power unit of a vehicle.

\section{US5}

1. Do you agree to proceed with the interview and begin with audio recording?

Yes, you can audio-record me.

2. How many different models does the company offer?

So we are a franchise company selling two different car companies. We sell [US5] and [US5]. [US5] has six different models, two of them are sedans and [US5] offers 8 models, all of them are crossovers and Trucks. So in total we offer 14 different models.

3. How many days does it take to get the car after placing an order with the auto maker if the customer cannot find the car on the lot?

If we order the car directly from [US5] it would take 10 to 12 weeks and sometimes 8 weeks. But this is very rare. Only $5 \%$ of our customers do that, usually if customers want to have a specific truck with that type of engine, 2 wheel drive or a double cab. For $10 \%$ of our customers, we try to locate the car at one of our other dealerships and do a so-called dealer swap.

4. How much dealer inventory do you have?

Right now, we have about 300 different new cars all over the two companies. We have been growing well over the last couple of months and as the main season arrives we have about 300 cars on transit, meaning they are on the railway to the dealership.

5. What percentage of all customer orders is sold from inventory? Based on the numbers I gave you, I would say it's about $85 \%$.

6. What dealer options do you have?

We don't do options here. For leather, heated seats or sun roofs for example we would send out our cars at let the job be done at special service centers that are thirdparty companies. In-store we do a lot of accessories. I would say about $50 \%$ of our trucks get extra accessories on top of the MSRP.

7. Are the dealer options decided by the dealer or the auto maker?

What happens is that [US5] will tell us what is available and based on past numbers and projections, they will send us the models equipped with the options they intend to get sold the most in the area. If we need special accessories that [US5] does not offer, we will order that at third party companies such as autozone etc.

8. Do you order option parts directly at the parts makers or at the auto maker? 
The source is our parts department and they would always order [US5] parts, especially when a car is under lease because otherwise it will not be covered by the warranty. However, if a car is not a [US5] product, which happens sometimes or the customers explicitly wishes to get a cheaper after-market product, we would also go to other brands. About $25 \%$ of our customers do other parts because of the price.

9. Do you receive a sales quota from the auto maker?

Yes, we receive them. It is on a monthly basis and different for [US5] and [US5]. They have not been realistic but now they are modified and we are also able to beat the goals. For example, last year the market in the region was up about 4 to $5 \%$ but our target was to increase the sales by about $40 \%$ which, of course, was impossible. [US5] is a bit upscale compared to Toyota.

10. Do you receive sales incentives from the auto maker?

Yes we do and it directly goes to the customer. [US5] incentives are very detailed so when a customer comes in an takes a look at the price sticker of our cars, they will always the MSRP and under it, it will show our discounts. And we are very aggressive with that as we try to offer the best deal. [US5] will give a rebate on the car plus bonus X, Y and Z. For example, they might give 900 dollars on a new car, but give 2750 dollars if you come with another vehicle that is not [US5] brand. When the customer comes in, we already have the lowest price for him and there is barely any negotiation. I think the stigma where you wanted to pull out as much money as possible from the customer is over. In 2000 we had 22 [US5] dealerships in Rhode Island, in 2018 there are only 8 left. So you really need every trade and make volume. So you need to sell the car and try to reach the objective in order to get some dealer cash back that you gave as a rebate to the customer earlier the month. I would say about $75 \%$ of our customers still want to negotiate the price.

\section{What are the main challenges in the after-sales-service business?}

I think trading in a car Is difficult. Customers usually do an online research on what their car is worth. Its shows them X-amount of dollars but when they come in and ask us to evaluate the car, we give them Y-amount of dollars. So this is a challenge, as our value is usually lower than the value the customers found online. Furthermore, another challenge is the technology in the cars. Today, the transmission or the engine is not our main problem anymore like it used to be 20 years ago. Our new problems are all programming issues like "my phone does wont pair with my car". Generally speaking I think that reprogramming makes cars better and makes them go faster not like some of the smartphones sometimes. Furthermore, you want to make sure that your service is the best.

12. Is the average time that is needed to fix a customer service measured?

Absolutely. When a car is under warranty, the time that is needed for a service is measured and is defined in a book. The customer will only pay this amount of money and also the mechanics is paid that much. So if a job is supposed to take 2 hours, the 
customer pays $2 \mathrm{~h}$ and the mechanics get the money for 2 hours. With better training and well equipped mechanics, you try to be faster so the mechanics can do more jobs and therefore get more money.

\section{How are service personnel trained and who gets trained?}

Every employee is trained by us in the store and also by [US5] online. They provide training, especially for the mechanics as they are most important. Also, our mechanics need to get trained in the field of programming, as we cannot accept when customers buy a 80,000 dollar [US5] truck and they have to come in after 70 miles because of a software error in the transmission.

\section{What kind of warranty models do you offer?}

For our new cars we have the 3 years and 36k miles bumper to bumper, warranty and 4 years $50 \mathrm{k}$ miles engine and transmission warranty.

\section{How is the customer satisfaction rate measured?}

So there are two different ways of measuring the satisfaction rate. We as a dealership hand our small cards, asking 5 questions and customers will just answer them right away, using a pen. It turns out that customers still like it that way and we get a return rate of over $75 \%$ which is very good. Furthermore, the company will send out a survey for each customer are sales and service. They will send an email asking 2 questions: How was the experience at the dealership and would you recommend the dealership to another person? The first question is to be rated 1 through 5 and the second 1 through 10. At the end of the year they will take a look at the other dealership in the region and the Zone and we are usually in the top $10 \%$.

16. What are the main challenges for the future and what does the dealership of tomorrow look like?

I think for the future what we need is transparency. We need to show the customer what the price is and we should not waste their time by negotiation or searching for the actual price. We should just have it. Customers still want to negotiate so we can give them an extra hundred dollar off but not much more. Also I think that people will always want to talk to a sales person. So the question is how we can satisfy the customer's wishes and needs. These are the real questions.

Also $90 \%$ of our customers shop online and find their exact car and then they come to us. So I think the dealership has still a place to do business. In future, our cars will be self-driving, will be electric driven. Furthermore, I think that for Apple and Google it will be hard to build cars as it requires so much in terms of production facilities or distribution. So they will rather specialize on selling the software.

\section{Are there already BEV (Battery Electric Vehicles) or HEV (Hybrid Electric} Vehicles) in your show room or offered by this auto maker?

EV are coming but right now, [US5] is only offering them at Chevrolet. [US5] has promised to bring $25 \mathrm{EV}$ until 2025. Most of that is driven by China because of their policy. However, I think that by 2030 , there will still be the internal combustion 
engine but it will be coexistence. It really depends on the gas price. The thing about EV though is, how can these vehicles be fixed and maintained? What happens in the case of an accident? How should first responders rescue the passengers?

US6

1. Do you agree to proceed with the interview and begin with audio recording? I prefer that you take notes.

2. How many different models does the company offer?

At this moment [US6] is offering 19 different models, with commercial vehicles 26 models.

3. How many days does it take to get the car after placing an order with the auto maker if the customer cannot find the car on the lot?

It usually takes 6 to 8 weeks but we would typically swap the car with another dealer. Actually we only order 5 to 6 times a year. This is only something for special vehicles such as heavy duty or corvette.

4. How much dealer inventory do you have?

Right now, I have 97 cars on the lot. This is a bit more than average because after Christmas it is a tough time as customers have already spent all their money and new models are coming to the dealerships.

5. What percentage of all customer orders is sold from inventory? It's about 80 to $90 \%$ and we usually swap less than 10 times a year

6. What dealer options do you have?

Most accessories on trucks such as steps, covers or all-weather floor mats. If we don't have them in stock, we have to order them.

7. Are the dealer options decided by the dealer or the auto maker?

Actually it's both. So the whole nation is broken up in different regions with different leases, options and even prices. But we can also decide what to do because we know our customers the best. A lot of our customers return their car or come from another company and we give special incentives. Furthermore, we have to consider that our customers lease more and therefore return their cars more often.

8. Do you order option parts directly at the parts makers or at the auto maker? We stick with the products from General Motors, our mother.

9. Do you receive a sales quota from the auto maker?

We are kind of getting a volume-based quota and the objective is to hit the goal and get dealership bonus. Sales people get a separate bonus which accounts for $1 / 4$ to $1 / 3$ of the salary. So we follow the strategy that we want to reduce the price of our cars 
and consequently hit the sales goal and get the money back by the end of the month. And the sales goal is derived from the performance the last year.

\section{Do you receive sales incentives from the auto maker?}

Yes, for example special financing deals or leasing deals as we want our customers to lease a car. Also we want to make sure that we can keep a certain amount of market share. For example, right now we offer 2,500 \$ for a Japanese car that you trade-in and 1,500 $\$$ for a German car, if you change to us. Furthermore, we are offering 8,200 \$ on incentives for the Silverado as the new model is starting soon. Furthermore, the Silverado has always been number one in NE although the F150 is top seller in the US.

\section{What are the main challenges in the after-sales-service business?}

Free services. Right now, as [US6], we offer our customers free first and second maintenance. We do a free oil change and tire rotation. The problem is that people get used to it and are not willing to start paying money or are angry if something brakes down because they did not maintain their vehicle properly.

12. Is the average time that is needed to fix a customer service measured?

Yes it is because we want to schedule our appointments properly. SO we get the data from GM but we as a dealership measure these numbers in order to be able to schedule our appointments. Because today it is very important to have good online reviews as customers check the online ratings before they think about coming. SO if we talk about an oil filter, we might need 30 minutes or if we are busy it might take 90 minutes. So usually we schedule 90 minutes and try to be faster. So you want to tell them more and make them happy.

\section{How are service personnel trained and who gets trained?}

We have to do several online tests and courses in order to obtain all the product information we need to get. Every month a person from GM comes and teaches us about the models.

\section{What kind of warranty models do you offer?}

Basic insurance is 3 years and 36k miles bumper to bumper and 5 years $60 \mathrm{k}$ miles powertrain insurance. For the EV and Hybrids, they offer 8 more years or 100,000 miles on certain electronic components.

\section{How is the customer satisfaction rate measured?}

[US6] sends a survey after a service and sales action containing a bunch of questions. Then the dealerships are ranked and the best get a bonus. The questionnaire contains 10 questions and they will not only rate the brand or the dealership but also the sales and service personnel. Also, you want to make sure that your online reputation is very good. 30 years ago, the average customer went to 4 different dealerships, today it's 1.2 dealerships which means that they already know what they want when they go in the dealership and that you usually only get one change to convince the customer. 
16. What are the main challenges for the future and what does the dealership of tomorrow look like?

One thing I am concerned about is a lease bubble. Today, our business is $60 \%$ leasebusiness and people will return their car when their contract is over. This leads to a flood of used cars that we as a dealership can sometimes only sell with use incentives and offers. It is very hard to predict the resell value of these used cars as there is such a huge offer.

17. Are there already BEV (Battery Electric Vehicles) or HEV (Hybrid Electric Vehicles) in your show room or offered by this auto maker?

Tesla really made it cool to have an EV. However, I am not really worried about it because [US6] is already offering Bold EV which is either number one or number two in the national sales. In order to beat the federal restrictions for fuel consumption, we have to equip our sedans with a so-called start-stop system which turns of the engine when the car stops at a red traffic light. That allows us to sell pick-ups and trucks. The good thing about [US6] is that I have a car for everyone, compared to Toyota. UI can offer a car for the father, the mother and the children.

\section{US7}

1. Do you agree to proceed with the interview and begin with audio recording?

No, I don't want to be audio recorded.

2. How many different models does the company offer?

At this moment [US7] is offering 22 models.

3. How many days does it take to get the car after placing an order with the auto maker if the customer cannot find the car on the lot?

It can take 8 to 12 weeks. The amount of people that order brand new is very low. What we usually do is locate another dealer and try to get car from them. This can happen in 1-2 days.

4. How much dealer inventory do you have?

Right now, I have 800 cars on the lot which is on the upper bound of the average. But this makes sense because I am selling 200 [US7] a month and especially for Trucks, the F150 and the Explorer there is a huge demand.

5. What percentage of all customer orders is sold from inventory? It's about $95 \%$

6. What dealer options do you have?

We have a lot of different options. We can add leather, roof tops, seats, paintings, we can increase the hp. This can cost up to 4,000 \$ and especially the F150 is a car that we customize a lot. For example, we have our own Tasca edition.

7. Are the dealer options decided by the dealer or the auto maker? 
It is actually a decision made by the dealership following the idea "what you did you will do". Because the demand for options varies between different regions and therefore it makes sense to let dealerships offer what customers in their region want. For example, in New England customers buy a lot 4WD because of the snow compared to Florida.

8. Do you order option parts directly at the parts makers or at the auto maker? We order the parts at the maker.

9. Do you receive a sales quota from the auto maker?

Yes, we get a sales quota from the automaker. It is called sales acceptancy and is given on a monthly basis.

10. Do you receive sales incentives from the auto maker? Yes we do.

11. What are the main challenges in the after-sales-service business?

The gas price is one of the main challenges because we do a lot of our business with trucks. Furthermore, I believe that the internet helps and creates a more educated consumer. At one point in the future, the internet can make the dealership redundant because cars are delivered by let's say Amazon.

12. Is the average time that is needed to fix a customer service measured? I cannot answer this question. You have to ask to a professional sales person.

13. How are service personnel trained and who gets trained?

They have to pass several tests online in order to be a professional sales or service personnel. Also, they have to go to the headquarter in Detroit to get special training. They also have to go to the Tasca University where they get all the skills to become a certified employee. We pay them a one month salary and give them the chance to work for us 3 to 5 months where we monitor them and if it's successful, we hire him.

14. What kind of warranty models do you offer?

We offer a 3 years $36 \mathrm{k}$ miles bumper to bumper warranty and a 5 years $60 \mathrm{k}$ miles drivetrain warranty. That's for the mechanical components.

15. How is the customer satisfaction rate measured?

There is a CSI sheet that the company sends to their customers and they fill out the survey. Then, the results go to [US7]. Our goal Is to get a 95\% score which is very hard.

16. What are the main challenges for the future and what does the dealership of tomorrow look like?

One of the challenges is always to have the right product the customer wants to have. This is especially very difficult for smaller dealerships as they always have to swap their cars with other, bigger dealers. You always want to make sure that you have the right cars in your lot that you can sell by the end of the month. Tasca is also a company that prefers leasing offers as this increases to chance to get the customer 
back after the contract ends. If the customer only finances his car, you never know if he or she returns. Right now, we get back 6 to 7 out of 10 people as they come back every 2 to 3 years.

17. Are there already BEV (Battery Electric Vehicles) or HEV (Hybrid Electric Vehicles) in your show room or offered by this auto maker?

The company already offers 3 different Hybrids and 2 different EV and its number is likely to increase.

\section{US8}

1. Do you agree to proceed with the interview and begin with audio recording? No, I don't want to be audio recorded.

2. How many different models does the company offer? At this moment [US8] is offering 6 models.

3. How many days does it take to get the car after placing an order with the auto maker if the customer cannot find the car on the lot?

It can take 12 to 14 weeks. People usually do that when they buy a new Navigator because the cars they order cost about $90,000 \$$ and they are not willing to accept every kind of car. They order the car they want to have.

4. How much dealer inventory do you have?

Right now, I have 100 cars on the lot

5. What percentage of all customer orders is sold from inventory?

It's about $95 \%$

6. What dealer options do you have?

Not so many actually. Usually the cars come fully equipped. We can add a moon roof, change the color etc. We do not change seat covers because a [US8] has leather always.

7. Are the dealer options decided by the dealer or the auto maker?

The dealership follows the guideline from [US8] and we follow them. We build how [US8] wants us to build the car.

8. Do you order option parts directly at the parts makers or at the auto maker? We order the parts at the maker.

9. Do you receive a sales quota from the auto maker?

Yes, we get a sales quota from the automaker. If we beat them, we actually get nothing special. However, the makers tries to make it more attractive to achieve a long-term growth. For example, right now there is a two month sales goal and when you hit it, you will get 75,000 dollars. Right now, I have not beaten this goal but there are still a couple of days to go in this month. Sometimes, the money they offer is just $4,000 \$$. 


\section{Do you receive sales incentives from the auto maker?}

Yes we do, and the incentive is between 0 to 5000 \$, it depends on the model. But what I do is, I tag the price with the incentive. So when the price is 50,000 dollars and I get 5,000 dollars off, I will tag 45,000 dollars.

11. What are the main challenges in the after-sales-service business?

It is the contact to the customer. Our problem as a luxury brand is not the money. We have money but our problem is the contact to the customer and the time. So we need to take time. Therefore, we use the CRM-system which is a customer relationship management system. All the data about a customer is filled in the system and creates automatic messages. For example, if a customer has its birthday, we send him an email saying "Happy birthday". The thing about [US8] is that 90\% of our customers come back and this is also because of our leasing philosophy. We always want to make our customers turn in the old car and get a new one

12. Is the average time that is needed to fix a customer service measured? I cannot answer this question. You have to ask to a professional sales person.

\section{How are service personnel trained and who gets trained?}

They have to pass several tests online in order to be a professional sales or service personnel. Also, they have to go to the headquarter in Detroit to get special training. So they have to pass a bunch of tests.

14. What kind of warranty models do you offer?

We offer a 4 years 50k miles bumper to bumper warranty and a 6 years $70 \mathrm{k}$ miles drivetrain warranty. This includes basically the mechanical components.

\section{How is the customer satisfaction rate measured?}

So there are two different surveys. The first comes from the dealer and the second comes from the manufacturer. For us, the one from the manufacturer is more important as it also compares the dealership with other dealerships and where the dealership still has to improve. The customer gives a feedback between 100, 75, 50, -50 and -100 .

16. What are the main challenges for the future and what does the dealership of tomorrow look like?

One of the main challenges is going to be plug-in hybrid. I believe this is going to be concept of the next decades. Also the way how customers are going to buy their cars. They are going to order more and more online, they will click and pay online and negotiate per email. This is something the brand [US8] is going to shift to. Only the pick-up of the car will be at the dealership.

17. Are there already BEV (Battery Electric Vehicles) or HEV (Hybrid Electric Vehicles) in your show room or offered by this auto maker?

No, the company does not really offer PHEVs or EVs and it is probably going to take a little while until the first PHEVs are coming in. 


\section{BIBLIOGRAPHY}

Acura. (2018, May 08.). Acura Web page. Retrieved from https://www.acura.com/innovation

Audi USA. (2018, May 12.). Audi USA homepage. Retrieved from https://www.audiusa.com/about

Automotive News. (2018, May 27.). Retrieved from http://www.autonews.com/article/20150112/RETAIL07/150119934/vw-plansto-add-100-u.s.-dealerships-by-2018

Automotive News. (2018). Automotive News Data Center Data Tables and Lists. Automotive News.

AutoNews. (2018, May 27.). Retrieved from http://www.autonews.com/article/20131216/RETAIL07/312169974/mazdau.s.-dealer-network-faces-shake-up

AutoTeamAmerica. (2014). 2025 Dealership Vision: What Lies Ahead! AutoTeamAmerica, vol. 2.

AutoTrader. (2018, May 27). Retrieved from https://www.autotrader.com/carreviews/first-time-ford-tops-chevy-number-us-dealers-79318

Bekker, H. (2018, January 17). Car Sales Statistics Best selling cars. Retrieved from 2017 (January to December) International: Car Sales Worldwide: https://www.best-selling-cars.com/international/2017-january-decemberinternational-car-sales-worldwide/

BMW USA. (2018, May 12.). Retrieved from https://www.bmwusa.com/

Bodisch, G. R. (2009). Economic Effects Of State Bans On Direct Manufacturer Sales To Car Buyers. The United States Department of Justice, vol. 9, no.1.

Buehler, B. (2018). Average Transaction Price for car makers in the US. Irvine: Kelly Blue Book.

Buick USA. (2018, May 12.). Retrieved from http://www.buick.com/

Cadillac. (2018, May 12.). Retrieved from http://media.cadillac.com/media/us/en/cadillac/news.detail.html/content/Pages/ news/us/en/2018/jan/0105-cadillac-sales.html

Carney, D. (2018, May 13). Retrieved from www.nbcnews.com/id/32678823/ns/business-autos/t/volkswagen-targetsmainstream-america/\#.Wve-Z0xFyP8

Carsalesbase.com. (2018, May 12). Retrieved from carsalesbase.com/us-car-salesdata/mazda/

Carter, B. R. (2015). An Introduction to Automobile Dealerships. Chicago: The Appraisal Journal, vol. 83, pp.193-200. 
Cash. (2018, February 19). Trotz Dieselskandal erneut größter Autobauer der Welt. Retrieved from https://www.cash.ch/news/top-news/trotz-diesel-skandalvolkswagen-erneut-groesster-autobauer-der-welt-1 136515 (02/19/2018)

Chappell, L. (2002). BMW moves beyond just-in-time production. Detroit: Automotive News, vol. 76, p.2N.

Cremer, A. (2018, April 11). German carmakers eye further U.S. market share gains in 2018: VDA. Retrieved from https://www.reuters.com/article/us-autoshowdetroit-germany/german-carmakers-eye-further-u-s-market-share-gains-in2018-vda-idUSKBN1F41MA

DeBord, M. (2018, May 27). Retrieved from http://www.businessinsider.com/fordceo-says-business-changing-dealer-network-2017-1

Dombrowski, U. \& Engel, C. (2014). Impact of Electric Mobility on the After Sales Service in the Automotive Industry. Braunschweig: Elsevier, vol.16, pp.152157.

FCA. (2018, June 3). Retrieved from https://www.fcagroup.com/enUS/brands/Pages/Dodge_SRT.aspx?sct=overview

Ford. (2018, May 12). Retrieved from http://corporate.ford.com/company.html?gnav=footer-aboutford

General Motors. (2018, June 03.). Retrieved from About General Motors: https://www.gm.com/company/about-gm.html

GMC. (2018, May 12.). Retrieved from http://www.gmc.com/

Hasbro Inc. (2018, April 21.). Retrieved from https://www.wizards.com/d20modern/d20mdice/dice.htm

Hitomi, K. (1992). Present trends and issues in Japanese manufacturing and management . Kyoto: Technovation, vol.12, pp.177-189.

Hitomi, K. (2005). Historical trends and the present state of the US industry and manufacturing. Kyoto: Elsevier, vol. 25, pp.673-681.

Holweg, M., \& Pil, F. (2004). The second Century: Reconnecting customers and value chain through Build-to-Order Moving beyond Mass and Lean in the Auto Indutry. Cambridge, MA: MIT Press.

Honda USA. (2018, May 27.). Retrieved from https://hondainamerica.com/investmentmap/\#!national\%7C\%2Cdealerships\%7Cemployment

Infiniti. (2018, May 12). Retrieved from https://www.infinitiusa.com/

International Organization of Motor Vehicle Manufacturers. (2018). Retrieved January 14., 2018, from http://www.oica.net/category/production-statistics/2016statistics/ 
Investopedia. (2018, April 11). Retrieved from Investopedia:

https://www.investopedia.com/terms/m/masscustomization.asp

Jeep. (2018, May 12). Retrieved from https://www.jeep.com/jeep-life.html

John Lippert, C. T. (2018, May 27.). Retrieved from

https://www.bloomberg.com/news/articles/2016-04-04/lexus-presses-on-withhaggle-free-pricing-as-dealers-push-back

Knoema. (2018, April 15). https://knoema.de/floslle/top-vehicle-manufacturers-in-theus-market-1961-2016 . Retrieved from https://knoema.de/floslle/top-vehiclemanufacturers-in-the-us-market-1961-2016

Lexus. (2018, May 12). Retrieved from www.lexus.com/about

Malorny, C. (2018, April 11). TU Braunschweig IFU After Sales Service. Retrieved from https://www.tu-braunschweig.de/ifu/forschung/ppslogistik/index.html

McKinsey \& Company . (2016). Automotive revolution - perspective towards 2030 . Detroit: Advanced Industries .

MediaCollege.com. (2018, April 20.). Home.Journalism.Interviews. Retrieved from https://www.mediacollege.com/journalism/interviews/open-endedquestions.html

Mercedes-Benz. (2018, May 12). Retrieved from https://www.mbusa.com/mercedes/index

Meyr, H. (2004). Supply chain planning in the German automotive industry. OR Spectrum, vol.26, pp.447-470.

Mouawad, J. (2007). Rising Demand for Oil Provokes New Energy Crisis. New York: The New York Times.

Muffatto, M. (1999). Evolution of production paradigms: the Toyota and Volvo cases. Padua: Integrated Manufacturing Systems, vol.10, issue 1, pp.15-25.

Nissan USA. (2018, May 27). Retrieved from https://www.nissanusa.com/about/corporate-information.html

Omar Sabbagha, M. N. (2015). Impact of Quality Management Systems and Aftersales Key Performance Indicators on Automotive Industry: A Literature Review. University Kebansaan Malaysia: Elsevier, vol.224, pp.68-75.

Parry, G. \& Roehrich, J. (2013). Automotive Enterprise Transformation: Build to Order as a sustainable and innovative strategy for the automotive industry? Journal of Enterprise Transformation, vol.3, issue 1, pp.33-52.

Perezgonzalez, J. (2018, June 25). Significance level - disambiguation. Retrieved from http://wikiofscience.wikidot.com/stats:significance-level

Pine, B. (1993). Mass customization. Boston: Harvard Business School Press, vol.10, issue 4, pp.360-361. 
PR Newswire Association LLC. (2017). Automotive Aftermarket Industry to hit $\$ 680$ Billion by 2024: Global Market Insights Inc. New York: PR Newswire Association LLC.

RAM. (2018, May 13). Retrieved from https://www.ramtrucks.com/

Reuters. (2018, April 11). NY Times. Retrieved from GM to Drop Monthly U.S. Vehicle Sale Reports: https://www.nytimes.com/reuters/2018/04/03/business/03reuters-usa-autosgm.html

Rosevear, J. (2018, May 27). Retrieved from https://www.fool.com/investing/2016/10/16/why-most-cadillac-dealers-turneddown-general-moto.aspx

Salvadora, F., Forzab, C. \& Rungtusanathama, M. (2008). Modularity, product variety, production volume, and component sourcing: theorizing beyond generic prescriptions. Journal of operations management: Elsevier, vol.20, issue 5 , pp.549-575.

Schneider, M. C. (2016). Volkswagen: Eine deutsche Geschichte. Berlin: Berlin Verlag.

Schonberger, R. (2007). Japanese production management: an evolution-with mixed success. Journal of Oper. Manag, vol.25, issue 2, pp.403-419.

Shahnoush Shahrouzi Fard, S. M. (2015). Performance measurement of the after-sales service network: Evidence from the automotive industry. Firouzkoh: Management Science Letters, vol.5, issue 10, pp. 927-932.

Spearman, M., \& Hopp, W. (2001). Factory physics. New York: McGraw-Hill Higher Education.

Staeblein, T., \& Aoki, K. (2014). Planning and scheduling in the automotive industry: A comparison of industrial practice at German and Japanese makers. München, Tokyo: Elsevier, Int. J. Production Economics, vol.162, p.258-272.

Statista. (2018, April 11). Retrieved from World Wide Car Sales from 1990 to 2018: https://www.statista.com/statistics/200002/international-car-sales-since-1990/

Takeishi A., F. T. (2001). Modularisation in the auto industry: interlinked multiple hierachies of product, production and supplier systems. Tokyo: Int. J. Automot. Technol. Manag, volume 1, issue 2.

Tomino, T. P. (2009). Market flexible customizing system of Japanese vehicle manufacutures: An analysis of Toyota, Nissan and Mitsubishi. International Journal of Production Economics, volume 118, issue 2, pp.375-386.

Townsend, J., \& Calantone, R. (2014). Evolution and Transformazion of Innovation in the Global Automotive Industry. Rochester: Journal of Production innovation Management, volume 31, issue 1, pp.4-7. 
Toyota USA. (2018, June 3). Retrieved from https:/www.toyota.com/usa/ourstory/index.html

Undercoffler, J. H. (2018, May 27). Toyota to move jobs and marketing headquarters from Torrance to Texas. Retrieved from http://www.latimes.com/business/autos/la-fi-toyota-texas-20140428story.html\#axzz309GEy6o2

United States General Accounting Office. (1993). Developing and Using Questionnaires. GAO.

University of Portsmouth. (2018, April 20.). Advantages and Disadvantages of Different Types of Interview Structure.

Vellequette, L. (2018, May 27). Retrieved from www.autonews.com/article/20170127/RETAIL06/301279881/fca-adding-asmany-as-400-u.s.-dealerships-sources-say

Vinit Parida, D. R. (2014). A Survey Study of the Transitioning towards High-Value Industrial Product-Services. Vassa: Elsevier, vol. 16, pp.176-180.

Volkswagen AG. (1993). Annual report 1993. Wolfsburg: Volkswagen AG.

Volling, T. \& Spengler, T. (2011). Modeling and simulation of order-driven planning policies in build-to-order automobile production. International Journal of Production Economics, vol. 131, issue 1, pp.183-193.

Wall Street Journal. (2018, April 11). The wall street journal, Market Data center, car sales. Retrieved from www.wsj.com/mdc/public/page/2_3022-autosales.html

West, E. (2015, October 16). Retrieved from 5 Car Quality Myths, Busted: http://www.jdpower.com/cars/articles/automotion-blog/5-car-quality-mythsbusted

Wieczorek, D. E. (2012). International Franchise and Distribution. DLA Piper.

Wilson, C. (2013). Interview Techniques for UX Practitioners: A User-Centered Design Method. Morgen Kaufmann.

Womack, J., Jones, D., \& Roos, D. (1990). The Machine that changed the world. New York: Rawson Associates.

Wright, R. A. (1999). The Delphi technique as a forecasting tool: issues and analysis. International Journal of Forecasting, vol.15, issue 4, pp.353-375.

Wyman, O. (2017, April 15). Studie zum Automobilvertrieb der Zukunft Systemprofit

2035. Retrieved from www.oliverwyman.de/content/dam/oliverwyman/europe/germany/de/insights/publications/2015/sep/OliverWyman_Grafiken_S

ystemprofit\%202035-Vertrieb_neu_erfinden_final_08092015.pdf 